\title{
Review Article \\ Stem Cells as Potential Targets of Polyphenols in Multiple Sclerosis and Alzheimer's Disease
}

\author{
Ankit Tandon, ${ }^{1}$ Sangh Jyoti Singh, ${ }^{1,2}$ and Rajnish Kumar Chaturvedi $\mathbb{D}^{1,2}$ \\ ${ }^{1}$ Developmental Toxicology Laboratory, Systems Toxicology and Health Risk Assessment Group, CSIR-Indian Institute of \\ Toxicology Research (CSIR-IITR), Vishvigyan Bhavan, 31, Mahatma Gandhi Marg, Lucknow, Uttar Pradesh 226001, India \\ ${ }^{2}$ Academy of Scientific and Innovative Research (AcSIR), CSIR-IITR Lucknow Campus, Lucknow, India \\ Correspondence should be addressed to Rajnish Kumar Chaturvedi; itrcrajnish@gmail.com
}

Received 9 May 2018; Accepted 19 June 2018; Published 12 July 2018

Academic Editor: Xudong Huang

Copyright (C) 2018 Ankit Tandon et al. This is an open access article distributed under the Creative Commons Attribution License, which permits unrestricted use, distribution, and reproduction in any medium, provided the original work is properly cited.

\begin{abstract}
Alzheimer's disease (AD) and multiple sclerosis are major neurodegenerative diseases, which are characterized by the accumulation of abnormal pathogenic proteins due to oxidative stress, mitochondrial dysfunction, impaired autophagy, and pathogens, leading to neurodegeneration and behavioral deficits. Herein, we reviewed the utility of plant polyphenols in regulating proliferation and differentiation of stem cells for inducing brain self-repair in $\mathrm{AD}$ and multiple sclerosis. Firstly, we discussed the genetic, physiological, and environmental factors involved in the pathophysiology of both the disorders. Next, we reviewed various stem cell therapies available and how they have proved useful in animal models of $\mathrm{AD}$ and multiple sclerosis. Lastly, we discussed how polyphenols utilize the potential of stem cells, either complementing their therapeutic effects or stimulating endogenous and exogenous neurogenesis, against these diseases. We suggest that polyphenols could be a potential candidate for stem cell therapy against neurodegenerative disorders.
\end{abstract}

\section{Introduction}

Neurodegeneration refers to the progressive loss of neurons in the Central and Peripheral Nervous System (CNS and PNS). Genetic and environmental factors both play a vital role in the progression of neurodegenerative diseases including Parkinson's disease, Alzheimer's disease (AD), and multiple sclerosis (MS) [1]. Hallmarks of these diseases are impairment of Ubiquitin Proteasome Pathway and accumulation of pathogenic proteins in the discrete brain regions due to oxidative and nitrosative stress, mitochondrial dysfunction, and impaired autophagy [2]. Currently, no cure exists for these diseases, and available drugs provide only symptomatic relief. Thus further understanding of the pathophysiology of these diseases is essential for controlling the menace caused by these diseases. In this review, we will focus on two major neurodegenerative diseases, namely, $\mathrm{AD}$ and $\mathrm{MS}$.

Neural stem cells (NSCs) are the cells of the brain that have the remarkable ability to develop into many different types of cells including neurons, astrocytes, and oligodendrocytes [3]. These cells are unspecialized cells that possess the property of self-renewal [3]. The main advantage of NSCs is that under certain physiological conditions these cells can be programmed to differentiate into neurons [4]. The NSCs hold a vast potential in the field of regenerative medicine in these debilitating diseases. Studies are being carried out frequently to tap this potential of NSCs against neurodegenerative disorders, with promising results [5].

Polyphenols comprise a set of naturally derived, synthetically synthesized, and semisynthetic organic chemicals characterized by the presence of multiple phenol structural units. They are mainly secondary metabolites of plants that are involved in defense and mostly present in fruits, vegetables, and cereals. They have immense benefits for health primarily due to their anti-oxidant properties. Many studies have highlighted their potential against a wide range of diseases [6]. In this review, we discuss the understanding of pathophysiology of AD and MS. Further we discuss how stem cells have proved their efficacy against these two diseases and finally how polyphenols can target stem cells for inducing brain self-repair or neurogenesis process (generation of new neurons) in $\mathrm{AD}$ and $\mathrm{MS}$. 
1.1. Alzheimer's Disease (AD). AD is the most prevalent type of dementia characterized by the progressive decline in cognitive abilities of an individual [7]. Individuals aged 65 years or older are susceptible to this disease [8]. In the present scenario, AD accounts for nearly $50 \%-70 \%$ of the total dementia of which the higher age group accounts for the larger proportion [9]. According to 2012 WHO report on "Dementia: A Public Health Priority" approximately 35 million people are presently affected with dementia, and the frequency is expected to double by 2030 and triple by 2050 [10]. The association of the pathophysiology of $\mathrm{AD}$ is with the death of neurons originating in the hippocampus region of the brain, which gradually affects the entire brain [11]. The primary cause of AD is the abnormal accumulation of a short peptide amyloid beta $(\mathrm{A} \beta) . \mathrm{A} \beta$ originates by the proteolytic cleavage of transmembrane protein, amyloid precursor protein (APP). Genetic, environmental, and physiological factors are involved in the progression of the disease [12] (Tables 1-3).

1.2. Multiple Sclerosis (MS). MS is primarily a neurodegenerative disease as it involves the progressive degeneration of the grey and white matter resulting in atrophy of the brain and spinal cord [13]. A 2015 study on the global prevalence of MS reported 2.3 million people affected by the disease [14]. MS is characterized by the presence of lesions or plaques predominantly in the white matter region of the brain and spinal cord [15]. It involves the loss of myelin sheath forming cells, termed oligodendrocytes, which helps in faster conduction of the nerve impulses (electrical signals) along neuronal axon [16]. While the cause of the disease remains elusive, it is primarily thought to be an autoimmune disorder [17]. MS is classified into relapsing-remitting MS and primary progressive MS, with the former being the more commonn.

Genetic, physiological, and environmental factors are involved in the progression of MS (Table 4). Presently there is no cure for MS, and treatments are available depending on the specific symptoms. As of 2012, monoclonal antibodies such as alemtuzumab, daclizumab, rituximab, ocrelizumab, and ofatumumab have shown positive results in clinical trials [18], of which FDA approved ocrelizumab for relapsing and primary MS in 2017. Estriol, a female sex hormone, has shown potential against relapsing-remitting MS in phase II trials [19].

\section{Polyphenols Utilizing Stem Cells against Neurodegeneration}

Stem cells are undifferentiated, unspecialized cells characteristic of multicellular organisms that possess the potential of plasticity, that is, to develop many different cells of the body. Due to their ability to form new specialized cells, they are being studied thoroughly for their uniqueness in the area of translational medicine. Studies are being carried out worldwide to tap their potential in the field of neurodegeneration. Stem cell therapy against neurodegenerative diseases such as Alzheimer's, Parkinson, MS, amyotrophic lateral sclerosis, and Huntington disease is a promising area of research. Below we review the important role played by stem cells in $\mathrm{AD}$ and MS and how polyphenols can target the potential of stem cells in these disorders (Figures 1 and 2).
2.1. Targeting NSCs in AD. NSCs are the cells that give rise to neurons and other cells of the neuronal circuitry of the CNS by a process known as neurogenesis [3]. They are localized in the adult brain in two specific regions, namely, the hippocampal dentate gyrus (DG) and sub-ventricular zone of the ventricles (SVZ). The process of generation of new neurons from endogenous NSCs in the brain of $A D$ patients and $\mathrm{AD}$ transgenic mice is found to be reduced. Therefore, NSCs could be targeted for enhancement of brain self-repair in AD. Several studies have implicated the role of NSCs in mitigation of AD pathology in mice. In hAPP transgenic mice expressing mutated human APP751, cerebrolysin treated NSCs were grafted, which led to increased levels of BDNF and furin and protection for neighbouring cells [20]. Genetically modified NSCs expressing A $\beta$-degrading enzyme neprilysin in 3xTg-AD and Thyl-APP transgenic AD mice models exhibited significant reduction in $A \beta$ pathology and increase in synaptic density [21]. 192 IgG-saporin derived AD rats transplanted with embryonic rat NSCs induced by NGFPEG-PLGA-nanoparticles facilitated differentiation of NSCs resulting in increased cholinergic neurons in basal forebrain regions, hippocampal synaptic formation, and generation of AChE-positive nerve fibers [22]. The APPsw-expressing (NSE/APPsw) transgenic AD mice transplanted with human NSCs exhibited improved spatial memory and increased neurotrophins (BDNF, NTF3, NTF4, NGF, VEGF, FGF2, and GDNF) levels, which resulted in decreased tau phosphorylation and $\mathrm{A} \beta$ production via Akt/GSK3 $\beta$ signaling [23]. NSC transplantation in the hippocampal region of APP/PS1 Tg AD mice demonstrated improved synaptophysin and growth-associated protein-43 (GAP-43) expression resulting in increased synapse density and integral mitochondrial structure [24]. Research has revealed that $\mathrm{A} \beta$ possesses proliferative effects on NSCs. In double-transgenic mouse model of AD co-expressing mutants of amyloid precursor protein (APPswe) and presenilin 1 (PSEN1dE9), an increase in expression of NSCs and neurogenesis marker genes was reported [25]. Inhibition of Akt hyperactivation and oleic acid-producing enzyme, stearoyl-CoA desaturase, rescued NSC proliferation impairments in AD brain [26]. Injection of NSCs in (APP/PS1) Tg AD mouse improved expression of N-methyl-d-aspartate (NMDA) 2B unit, synaptophysin, protein kinase $\mathrm{C} \zeta$ subtypes (PKC $\zeta$ ), tyrosine receptor kinase $\mathrm{B}(\mathrm{TrkB})$, and BDNF proteins related to cognitive function [27]. Improvement in number of doublecortin (DCX) positive neurons in the dentate gyrus region in human NSCtransplanted Tg2576 AD mice was observed [28]. Stem cell factor (SCF) and its receptor c-kit, involved in the migration of NSCs to sites of brain injury, are expressed on NSCs [29]. Epigenetic factors also play a crucial role in regulating stem cell proliferation and differentiation [30]. HDAC inhibitors regulate histone acetylation in APP/PS1 transgenic mice increasing the generation of new neurons [31]. Similarly morphogens such as mitogen-activated kinase 1/extracellular signal-regulated kinase 2 and orphan nuclear receptor TLX support adult NSC proliferation through epigenetic mechanisms $[32,33]$. These studies suggested that NSCs can be stimulated for proliferation and neuronal differentiation to mitigate cognitive dysfunctions in $\mathrm{AD}$. 
TABLE 1: Genetic factors involved in AD.

\begin{tabular}{|c|c|c|c|}
\hline S. No. & $\begin{array}{c}\text { Genetic } \\
\text { Factors/Mutations }\end{array}$ & Effect in AD & References \\
\hline 1. & $\begin{array}{l}\text { R47H (Variant of } \\
\text { TREM2) }\end{array}$ & It compromises microglial mediated clearance of aggregation-prone proteins in $\mathrm{AD}$ & [113] \\
\hline 2. & KIAA1462 & $\begin{array}{l}\text { It increases the risk of coronary artery disease, resulting in compromised blood flow to the } \\
\text { brain, and increases oxidative stress and inflammation }\end{array}$ & [114] \\
\hline 3. & APOE $\varepsilon 4$ & $\begin{array}{l}\text { ApoE regulates lipid homeostasis. } \varepsilon 4 \text { allele increases the risk of } \mathrm{AD} \text { by initiating and } \\
\text { accelerating } \mathrm{A} \beta \text { accumulation, aggregation, and deposition in the brain }\end{array}$ & [12] \\
\hline 4. & $\mathrm{P} 21$ & $\begin{array}{c}\text { P21 (cyclin-dependent kinase inhibitor) levels significantly decreased in peripheral blood } \\
\text { lymphocytes of AD patients }\end{array}$ & [115] \\
\hline 5. & SORL1 & $\begin{array}{c}\text { SORL1 gene encodes a protein LR11 responsible for cargo transport, chaperone-like activity, } \\
\text { signaling, and intracellular sorting. Down-regulation or dysfunction of LR11 has been shown to } \\
\text { lead to amyloidogenesis. }\end{array}$ & [116] \\
\hline 6. & PSEN1 & $\begin{array}{l}\text { Presenilin-1 functions as the catalytic subunit of } \gamma \text {-secretase that cleaves APP. PSEN1 mutations } \\
\text { initiate disease pathogenesis by increasing production of A } \beta 42 .\end{array}$ & [117] \\
\hline 7. & PSEN2 & $\begin{array}{l}\text { Presenilin-2 is the main component of the } \gamma \text {-secretase complex along with PSEN1. PSEN2 } \\
\text { mutation alters the } \gamma \text {-secretase activity and increases A } \beta 42 / 40 \text { ratio. }\end{array}$ & {$[118,119]$} \\
\hline 8. & CLU & $\begin{array}{l}\text { The clusterin gene acts as an extracellular chaperone involved in lipid transport, complement } \\
\text { regulation, apoptosis, endocrine secretion, and membrane protection. Elevated levels of CLU } \\
\text { have been reported in the frontal cortex and hippocampus in AD. }\end{array}$ & {$[120-122]$} \\
\hline 9. & ABCA1 & $\begin{array}{l}\text { ABCA1 mediates cholesterol homeostasis, generation of phospholipids and immune system. } \\
\text { The accumulation of } \mathrm{A} \beta \text { is shown in the brain of ABCA7-deficient mice. }\end{array}$ & {$[123,124]$} \\
\hline 10. & CR1 & $\begin{array}{l}\text { Complement Receptor-1 functions as a complement regulatory protein and helps in regulating } \\
\text { the immune system. CR1 alteration is associated with increased cerebrospinal fluid (CSF) A } \beta 42 \\
\text { and vascular amyloid deposition. }\end{array}$ & {$[125,126]$} \\
\hline 11. & CD33 & $\begin{array}{l}\text { CD33 mediates cell-cell interaction, inhibits immune cell functions and regulates cell growth } \\
\text { and survival via promotion of apoptosis. CD33 contributes to the pathogenesis of AD by } \\
\text { impairing microglia-mediated clearance of } \mathrm{A} \beta\end{array}$ & {$[127,128]$} \\
\hline 12. & MS4A & $\begin{array}{l}\text { MS4A regulates immunity and calcium influx. MS4A mediates AD pathogenesis via A } \beta \\
\text { generation, tau phosphorylation, and apoptosis by altering calcium homeostasis. }\end{array}$ & {$[129,130]$} \\
\hline 13. & BIN1 & $\begin{array}{l}\text { Bridging Integrator-1 regulates the immune response, synaptic vesicle endocytosis, apoptosis, } \\
\text { intracellular APP trafficking and clathrin-mediated endocytosis. BIN1 knockdown suppresses } \\
\text { tau-mediated neurotoxicity. }\end{array}$ & [131-133] \\
\hline 14. & CD2AP & $\begin{array}{l}\text { CD2AP mediates regulation of the cytoskeletal structure, cell adhesion, receptor-mediated } \\
\text { endocytosis, cytokinesis, apoptosis and intracellular trafficking. Suppression of CD2AP } \\
\text { expression altered } \mathrm{A} \beta \text { levels and decreased A } \beta 42 / \mathrm{A} \beta 40 \text { ratio. }\end{array}$ & {$[134,135]$} \\
\hline 15. & PICALM & $\begin{array}{l}\text { PICALM regulates intracellular trafficking and clathrin-mediated endocytosis. Knockdown of } \\
\text { PICALM regulated APP internalization and decreased A } \beta \text { production, thus acting as a major } \\
\text { regulator of brain A } \beta \text { production, APP internalization, and amyloid plaque load. }\end{array}$ & {$[136,137]$} \\
\hline 16. & EPHA1 & $\begin{array}{l}\text { EPHA1 mediates synapse formation, chronic inflammation, and immune function. Association } \\
\text { of EPHA1 variants with AD progression is well known. }\end{array}$ & {$[138,139]$} \\
\hline 17. & INPP5D & INPP5D is a chief mediator of cytokine signaling and relates to increased late-onset AD. & [140] \\
\hline 18. & PTK2B & $\begin{array}{l}\text { PTK2B is involved in activation of MAP kinase signaling pathway and calcium-induced } \\
\text { regulation of ion channels. Fyn kinase inhibition of PTK2B improved the learning and } \\
\text { memory impairment in AD mice. }\end{array}$ & {$[141,142]$} \\
\hline 19. & SLC24A4/RIN3 & $\begin{array}{l}\text { SLC24A4/RIN3 is involved in neural development, lipid metabolism, and endocytic pathway. } \\
\text { Association of SLC24A4 with methylation and brain DNA methylation is responsible for AD } \\
\text { pathology. }\end{array}$ & [143-147] \\
\hline 20. & ADAM10 & $\begin{array}{l}\text { In Tg2576 AD mice, ADAM10 mutations were shown to increase plaque load and } \mathrm{A} \beta \text { levels } \\
\text { and decrease hippocampal neurogenesis. }\end{array}$ & [148] \\
\hline 21. & PLD3 & $\begin{array}{l}\text { Phospholipase D3 is highly expressed in the brain and is involved in epigenetic modifications, } \\
\text { signal transduction, cell differentiation and neurotransmission. PLD3 is associated with APP } \\
\text { processing and its over expression has been seen in AD patients. Accumulation of PLD3 on } \\
\text { neuritic plaques in AD brains suggested its involvement in AD pathology. }\end{array}$ & [149-151] \\
\hline 22. & UNC5C & $\begin{array}{c}\begin{array}{c}\text { Neurons with UNC5C disease variant overexpression are more prone to } \mathrm{A} \beta \text {-mediated cell } \\
\text { death. }\end{array} \\
\end{array}$ & {$[152]$} \\
\hline
\end{tabular}


TABLE 2: Environmental factors involved in AD.

\begin{tabular}{|c|c|c|c|}
\hline S. No. & $\begin{array}{l}\text { Environmental } \\
\text { Factors }\end{array}$ & Effect in $\mathrm{AD}$ & References \\
\hline \multicolumn{4}{|c|}{ Toxic Metals } \\
\hline 1. & Aluminium & $\begin{array}{l}\text { It mediates } \mathrm{AD} \text { neuropathy through oxidative stress, inflammation, neurofibrillary } \\
\text { degeneration and cross-linking of } \mathrm{A} \beta \text { oligomerization. }\end{array}$ & {$[153,154]$} \\
\hline 2. & Copper & $\begin{array}{l}\text { It induces } \mathrm{A} \beta \text { plaques, oxidative stress, and neuroinflammation. Decreased Cu levels relate to } \\
\text { reduced expression of cytochrome } c \text {, ceruloplasmin and superoxide dismutase in AD brain. }\end{array}$ & [155-158] \\
\hline 3. & Iron & $\begin{array}{l}\text { Increased iron levels are associated with decreased tissue integrity in the hippocampus region } \\
\text { of } \mathrm{AD} \text { patients. Iron is involved in the formation of aggregates of } \mathrm{A} \beta-42 \text { leading to the } \\
\text { formation of amyloid fibrils. }\end{array}$ & {$[159,160]$} \\
\hline 4. & Lead & Lead exposure increases APP expression, $\mathrm{A} \beta$ production, and hippocampal gliosis. & {$[161,162]$} \\
\hline 5. & Cadmium & $\begin{array}{l}\text { High cadmium levels have been shown in the hippocampus and cerebral cortex in AD patients. } \\
\text { Cadmium leads to self-aggregation of the tau peptide R3 through neural and astrocyte cell } \\
\text { toxicity, thereby causing AD. }\end{array}$ & {$[163,164]$} \\
\hline 6. & Mercury & $\begin{array}{c}\text { Mercury causes increased A } \beta \text { levels, tau protein hyperphosphorylation, reduced binding of } \\
\text { GTP to } \beta \text {-tubulin, microtubule degeneration and compromised membrane structural integrity } \\
\text { of neurites and neuron growth cones. }\end{array}$ & {$[165,166]$} \\
\hline 7. & Arsenic & $\begin{array}{l}\text { Arsenic exposure leads to tau hyperphosphorylation, increase in amyloid beta levels, increased } \\
\text { generation of free radicals and increase in the inflammatory process. }\end{array}$ & [167] \\
\hline 8. & Selenium & $\begin{array}{l}\text { High selenium concentration is associated with reduced cholinergic signaling, increased } \\
\text { oxidative stress and degeneration of cholinergic neurons. }\end{array}$ & [168] \\
\hline \multicolumn{4}{|c|}{ Insecticides and Pesticides } \\
\hline 1. & $\begin{array}{l}\text { Organochlorines } \\
\text { Hexachlorocyclohex- } \\
\text { ane }(\mathrm{HCH}) \text { and } \\
\text { Aldrin }\end{array}$ & $\begin{array}{l}\mathrm{HCH} \text { and Aldrin are two extremely persistent pesticides which undergo bioaccumulation. } \\
\text { Increased blood levels of } \beta \text {-HCH have been associated with significant increase in AD risk, } \\
\text { oxidative stress, and neurotoxicity. }\end{array}$ & [169] \\
\hline 2. & Organophosphates & $\begin{array}{l}\text { Parathion causes morphological changes, affects non-cholinesterase targets like motor } \\
\text { proteins, axonal transport, and the neuronal cytoskeleton. }\end{array}$ & {$[170]$} \\
\hline 3. & Carbamates & $\begin{array}{l}\text { Carbofuran induces toxicity in neuronal nicotinic acetylcholinesterase receptors and reduces } \\
\text { hippocampal neurogenesis, thereby leading to memory deficits. }\end{array}$ & {$[171-173]$} \\
\hline 4. & Bipyridyl & $\begin{array}{l}\text { Paraquat induces mitochondrial dysfunction in cerebral cortex, thereby promoting } \\
\text { impairment of cognitive function with elevated levels of } A \beta \text {. }\end{array}$ & [174] \\
\hline 5. & Rotenone & Rotenone induces mitochondrial dysfunction leading to AD. & [175] \\
\hline 6. & Fipronil & $\begin{array}{l}\text { It is a phenylpyrazole insecticide which is known to show functional remodeling of GABAergic } \\
\text { neurotransmission in AD patients, thereby causing AD. }\end{array}$ & [176] \\
\hline 7. & Pyrethroid & $\begin{array}{c}\text { It induces imbalanced tau phosphorylation, cognitive abnormalities and AD-like pathology in } \\
\text { rats. }\end{array}$ & [177] \\
\hline \multicolumn{4}{|c|}{ Industrial and Commercial Pollutants } \\
\hline 1. & $\begin{array}{l}\text { Polybrominated } \\
\text { Diphenyl Ethers } \\
\text { (PBDEs) }\end{array}$ & $\begin{array}{c}\text { PBDEs are neurotoxic and amyloidogenic, causing amyloid- } \beta \text { peptide release, apoptosis, } \mathrm{Ca}^{2+} \\
\text { ATPase inhibition, reduced hippocampal cholinergic receptors and impaired learning and } \\
\text { memory. }\end{array}$ & {$[178,179]$} \\
\hline 2. & Octylphenol & $\begin{array}{l}\text { Octylphenol increases expression of amyloid-like precursor protein-2 and APP leading to AD } \\
\text { in turtles. }\end{array}$ & [180] \\
\hline 3. & $\begin{array}{l}\text { Tetrachlorodibenzo- } \\
\text { p-dioxin } \\
\text { (TCDD) }\end{array}$ & $\begin{array}{l}\text { TCDD increases calcium levels and tau phosphorylation via up-regulation of } \mathrm{p}-\mathrm{GSK} 3 \beta \text {, } \\
\text { thereby causing AD in patients. }\end{array}$ & {$[181]$} \\
\hline \multirow{2}{*}{\multicolumn{4}{|c|}{ Anti-Microbials }} \\
\hline & & & \\
\hline 1. & Triclocarban & $\begin{array}{c}\text { Triclocarban impairs neurogenesis, neurobehavioral development and disrupts hormone } \\
\text { signaling pathways. }\end{array}$ & [189] \\
\hline 2. & Triclosan & $\begin{array}{l}\text { Triclosan has been shown to cause neurotoxicity, altered neurodevelopment and } \\
\text { neuroplasticity through disruption of the brain } \mathrm{Ca}^{2+} \text { homeostasis by altering ryanodine (Ry) } \\
\text { receptor type } 1 .\end{array}$ & [190] \\
\hline 3. & Parabens & $\begin{array}{l}\text { Paraben exposure has been shown to cause reduced neurotransmitter activity, behavioral } \\
\text { changes, neurodevelopmental disturbances and neurotoxicity in animal studies. }\end{array}$ & [191] \\
\hline
\end{tabular}


TABLE 3: Physiological factors involved in AD.

\begin{tabular}{lll}
\hline S. No & Factors & Effect in AD \\
\hline & & (i) Studies have shown extracellular and intracellular A $\beta$ mediated activation of caspases either
\end{tabular}
through the extrinsic or the intrinsic pathway.

(ii) $\mathrm{A} \beta$ binding to alcohol dehydrogenase can activate mitochondrial stress mediated apoptosis.

(iii) Caspases and Calpains are proteases responsible for Tau proteolysis, and their activation has been found to play a role in apoptosis.

(iv) The lysosomal protease Cathepsin $\mathrm{D}$ expressed in the brain regulates apoptosis, thus contributing to $\mathrm{AD}$.

(v) $\mathrm{P}_{2} \mathrm{X}_{7}$, a purinoreceptor involved in $\mathrm{AD}$ pathogenesis promotes cell death by apoptosis.

(vi) Altered expression of caspase-3, Bax, p53, Bcl-2 and Par-4 apoptotic proteins occurs in AD.

(vii) TRAIL binding to death receptor 5 (DR5) has been shown to initiate Caspase- 8 mediated

1. Apoptosis apoptosis in $\mathrm{AD}$ neurons.

(viii) $\mathrm{A} \beta$-induced synthesis of disialoganglioside GD3 is involved in apoptosis induction in cortical neurons.

(ix) In neurons, over-expression of $\mathrm{RCAN}_{1-1}$ initiates $\mathrm{A} \beta$ mediated apoptosis through activation of caspase- 9 and caspase- 3 . An additional copy of $\mathrm{RCAN}_{1}$ on chromosome 21 promotes $\mathrm{AD}$ pathogenesis.

(x) Regulation of AICD mediated neuronal apoptosis occurs via GSK3 $\beta$ and $\mathrm{p} 53$.

(xi) PSEN1 mutants exhibit increased $\mathrm{A} \beta$ generation, altered calcium homeostasis and an augmented sensitivity to ER stress-induced apoptosis.

(xii) Increased caspase- 4 in AD brains relates to ER stress-induced apoptosis.

(i) Increased levels of lysosomal protease occur in $\mathrm{AD}$ patients.

(ii) In Drosophila melanogaster, age-related down-regulation of expression of atgl, atg8a and atg18 was associated with late onset of AD.

(iii) In ATG7 knockdown mice, significant reduction in $\mathrm{A} \beta$ secretion was followed by intracellular $\mathrm{A} \beta$ accumulation.

(iv) The RAGE-calcium-CaMKK $\beta$-AMPK pathway was found to regulate the $\mathrm{A} \beta$-induced

2. Autophagy

formation of autophagic vacuoles.

(v) Tau hyperphosphorylation is implicated in autophagy dysfunction.

(vi) Tau degradation has been found to be regulated by Nrf2-mediated activation of NDP52 autophagy receptor.

(vii) Beclin-1 deficiency resulted in an elevation of APP, $\mathrm{A} \beta$ and the C-terminal fragment (CTF), while its over-expression caused a reduction in $\mathrm{A} \beta$ accumulation.

(viii) Rapamycin has been shown to reduce $\mathrm{A} \beta$ and Tau pathology and improve cognition.

(i) A decrease in reduced glutathione (GSH) causes excess ROS production leading to oxidative stress, thus favoring $\mathrm{AD}$ pathogenesis.

(ii) $\mathrm{A} \beta$ induces lipid peroxidation and its products.

(iii) Breakdown products of oxidative stress, such as malondialdehyde, acrolein, F2-isoprostanes

3. Oxidative Stress and 4-hydroxy-2,3-nonenal (HNE), are observed in AD brains.

(iv) Localization of increased levels of $8 \mathrm{OHdG}$ and $8 \mathrm{OHD}$ (associated with DNA and RNA oxidation) in $\mathrm{A} \beta$ plaques and NFTs is shown.

(v) In $\mathrm{AD}$, accumulation of extracellular advanced glycation end products (AGEs) occurs due to increased oxidation of glycated proteins.

(i) A significant increase in mtDNA and cytochrome oxidase (COX) in AD neurons is reported.

(ii) Association of mitochondrial pathology in $\mathrm{AD}$ with loss of dendritic branches, dystrophic dendrites and abnormal alteration of the dendritic spines is evident.

(iii) C57B6/SJL Tg AD mice showed increased levels of mtDNA deletion, amyloid deposition, mitochondrial structural abnormalities and oxidative stress markers.

(iv) In $\mathrm{AD}$, accumulation of $\mathrm{A} \beta \mathrm{PP}$ across mitochondrial import channels restricts entry of $\mathrm{COX}$ subunits IV and $\mathrm{Vb}$ leading to a decrease in COX activity and elevated $\mathrm{H}_{2} \mathrm{O}_{2}$ levels. decreased levels of vitamin E and GSH, were observed.

(vi) A $\gamma$-secretase complex, composed by PEN2, APH-1, and NCT, was identified in the rat brain mitochondria and was shown to cleave $\mathrm{A} \beta \mathrm{PP}$ into $\mathrm{A} \beta$ and $\mathrm{A} \beta \mathrm{PP}$ intracellular domain. (vii) In $\mathrm{AD}$, a decrease in dynamin-like protein 1 (DLP1) and OPA1 and increase in Fis1 levels, thereby leading to mitochondrial abnormalities, have been reported. PTP.

(ix) In PC12 cells exposed to $\mathrm{A} \beta_{40}$ and $\mathrm{A} \beta_{25-35}$, inhibition of complexes I, III, and IV of the mitochondrial respiratory chain was observed, thereby leading to mitochondrial dysfunction. 
TABLe 3: Continued.

\begin{tabular}{|c|c|c|c|}
\hline S. No & Factors & Effect in AD & References \\
\hline \multirow{6}{*}{5.} & \multirow{6}{*}{ Inflammation } & (i) Associations between AD pathogenesis and mutations in TREM2, CD33 have been established. & $\begin{array}{l}{[127,244,} \\
245]\end{array}$ \\
\hline & & (ii) $\mathrm{A} \beta$ binding to CD36 or TLR4 leads to the production of inflammatory cytokines. & {$[246,247]$} \\
\hline & & $\begin{array}{l}\text { (iii) In AD animal models, elevated levels of pro-inflammatory markers IL-1, IL-6, GM-CSF, } \\
\text { IL-23, IL-12, and TNF were detected. }\end{array}$ & {$[248-25$} \\
\hline & & $\begin{array}{l}\text { (iv) Microglia from } \mathrm{Tg} \mathrm{AD} \text { mice has shown reduced } \mathrm{A} \beta \text {-binding scavenger receptor and } \\
\mathrm{A} \beta \text {-degrading enzyme levels. }\end{array}$ & [252] \\
\hline & & $\begin{array}{l}\text { (v) Anti-inflammatory factors in neurons such as CD200, CD59, and fractalkine have been shown } \\
\text { to be down-regulated in AD brains. }\end{array}$ & {$[253-25$} \\
\hline & & $\begin{array}{l}\text { (vi) In the human AD brain, endothelial cells have been shown to produce IL- } 1 \beta \text {, CCL2, and IL- } 6 \\
\text { immune molecules. }\end{array}$ & [257] \\
\hline
\end{tabular}

2.2. Targeting Embryonic Stem Cells (ESCs) in AD. ESCs are pluripotent cells derived from the inner cell mass of a blastocyst that possess the capability to differentiate into any cell type and exhibit remarkable long-term proliferative potential. Generation of neurons from ESCs is a promising approach to cell-based replacement therapies [34]. Several factors possessing the ability of neuronal differentiation from ESCs have been identified. The sonic hedgehog (Shh), retinoic acid, and leukemia inhibitory factor (LIF) increase cholinergic differentiation of neuronal cells derived from ESCs [35]. Retinoic acid has been shown to direct the differentiation of human ESCs into basal forebrain cholinergic neurons (BFCNs) [36]. The NKX2-1 is essential for maturation and maintenance of BFCNs derived from NKX2-1 ${ }^{+}$ventral telencephalic progenitors [37]. Differential processing of $\mathrm{A} \beta \mathrm{PP}$ regulates hESC proliferation and differentiation into NPCs [38]. NGF is essential for maintaining cholinergic phenotype, cholinergic synaptic integrity, regulation of dendritic growth, axonal guidance, long-term potentiation (LTP), synaptic plasticity, neurotransmitter release, and induction of expression of cholinergic markers via the PI3-K/Akt pathway in ESCs derived BFCNs [39]. A switch from ESCs to NSCs requires expression of Oct $4^{+}, \operatorname{nanog}^{+}, \operatorname{Sox}^{+}, \mathrm{Sox}^{-}, \mathrm{Sox}^{-}$ to $\operatorname{Sox1} 1^{+}, 2^{+}, 3^{+}$, blbp ${ }^{+}$, hes $5^{+}$, Oct $4^{-}$, and nanog- markers, respectively [40]. Inhibition of BMP by chordin, noggin, and follistatin in association with signaling from bFGF helps to generate neural precursors, while bHLH family proteins such as Mash1, Math1, NeuroD, and neurogenin 1-3 help to induce differentiation of neurons and other cell types [41]. The hormones also play a crucial role in directing the conversion of ESCs into neuronal phenotype. Human chorionic gonadotropin and progesterone hormones provoke the proliferation and differentiation of hESCs via $\mathrm{P} 4$ receptor $A$, resulting in induction of neurulation [42]. It has been reported that progesterone mediated modulation of $\mathrm{A} \beta \mathrm{PP}$ processing drives the conversion of hESCs into NPCs [38].

2.3. Targeting Mesenchymal Stem Cells (MSCs) in AD. MSCs are multipotent stromal cells present in the adult bone marrow that can differentiate into a variety of cell types under appropriate conditions [43]. In A $\beta$-treated SH-SY5Y cells, MSCs increased autophagy induction through an increase in beclin (BECN1) and LC3-II expression, enhancing fusion of autophagosomes and lysosomes and promoting $\mathrm{A} \beta$ clearance and survival of hippocampal neurons [44]. Transplantation of human umbilical cord MSC-derived neuron-like cells caused reduction in $\mathrm{A} \beta$ deposition, reduced microglial activation and neuroinflammation, and improved cognitive functions in AD transgenic mice model [45]. MSC transplantation resulted in decreased levels of potentially toxic $\mathrm{A} \beta * 56$ and preserved levels of glutamine synthetase in a $3 \times \mathrm{Tg}$ AD mouse model [46]. Similarly, transplantation of human umbilical cord blood (hUCB) MSCs into the hippocampus of mouse $\mathrm{AD}$ model reduced $\mathrm{A} \beta$ plaques, increased endogenous adult hippocampal neurogenesis and synaptic activity, and enhanced cognitive function [47]. Adipose-derived MSCs enhanced endogenous neurogenesis in APP/PS1 AD mice [48]. Transplantation of MSCs into $\mathrm{A} \beta_{1-42}$-infused mice activated glial cells, inhibited iNOS and COX-2 expression, downregulated the release of inflammatory cytokines, prevented neuronal cell death, promoted neuronal cell differentiation, and improved cognitive impairment [49]. MSCVEGF treatment in 2xTg-AD APPswe/PS1dE9 mouse model favored neovascularisation and diminished senile plaques in the hippocampus, provided behavioral benefits, and reduced cognitive deficits [50]. In a study on hUCB-MSCs with BV2 microglia under $\mathrm{A} \beta 42$ exposure, it was observed that ICAM1 was released from hUCB-MSCs by coculturing with BV2 cells, and it induced neprilysin (NEP) expression in microglia through sICAM-1/LFA-1 signaling pathway resulting in a decrease in $A \beta$ plaques [51]. In a transgenic mouse model of $\mathrm{AD}, \mathrm{MSC}$-educated T-regulatory cells significantly improved impaired cognition and reduced $\mathrm{A} \beta$ plaque deposition followed by decreased levels of activated microglia and systemic inflammatory factors [52]. In PC12 cells treated by $\mathrm{A} \beta_{25-35}$, BMSCs inhibited apoptosis via TAG1/APP/AICD signal pathway [53]. Thus these studies show the protective action of MSCs against AD pathogenesis.

2.4. Targeting Induced Pluripotent Stem Cells (iPSCs) in AD. The iPSCs are cells generated directly from adult somatic cells by introducing products of specific sets of pluripotencyassociated genes into a given cell type. Thus they hold great promise in the field of regenerative medicine [54]. Several studies have shown their potential in many neurodegenerative disorders [54]. In iPSCs, PI3K-Akt represents a crucial survival signaling pathway [55]. The iPSC-derived NSCs 
TABLE 4: Factors involved in the pathogenesis of MS.

\begin{tabular}{|c|c|c|}
\hline S. No. & Factors & Involvement in MS \\
\hline 1. & Genetics & $\begin{array}{l}\text { (i) HLA-DRB } 1 * 15 \text { is the most common genetic risk factor for MS. } \\
\text { (ii) GWAS have predicted GRIN2A, encoding NR2A subunit of NMDA-type glutamate receptors } \\
\text { a possible candidate in MS. }\end{array}$ \\
\hline 2. & Oxidative Stress & $\begin{array}{l}\text { (i) ROS and RNS such as nitric oxide (NO) produced by macrophages and microglia in MS } \\
\text { lesions lead to inflammation. } \\
\text { (ii) In MS lesions, microglia has shown up-regulation of NOX1, NOX2, and NOX organizer } 1 \\
\text { enzymes responsible for ROS generation. } \\
\text { (iii) Iron accumulation in MS patients further amplified ROS and RNS-mediated injury through } \\
\text { the generation of toxic reactants. } \\
\text { (iv) NRF2 mediated HMOX1 anti-oxidant enzyme levels are known to increase in MS lesions. } \\
\text { (v) Dimethyl fumarate (DMF) induces Nrf2 expression in neurons, thus contributing to } \\
\text { attenuation of MS in patients. }\end{array}$ \\
\hline 3. & $\begin{array}{l}\text { Mitochondrial } \\
\text { Dysfunction }\end{array}$ & $\begin{array}{l}\text { (i) Altered mitochondrial transport, mediated by translocation of HDAC1 from the nucleus to the } \\
\text { axoplasm, thereby hindering kinesin motor protein functions, is evident in experimental } \\
\text { autoimmune encephalomyelitis (EAE) lesions model of MS. } \\
\text { (ii) Resveratrol-mediated attenuation of neuronal damage in optic neuritis in EAE is brought } \\
\text { about by activating SIRT1, thus promoting mitochondrial function. } \\
\text { (iii) Mitochondrial permeability transition (MPT), which is dependent on cyclophilin D (CyPD), } \\
\text { results in equilibration of ionic gradients, loss of mitochondrial transmembrane potential and } \\
\text { termination of oxidative phosphorylation followed by necrosis. } \\
\text { (iv) Due to impaired mitochondrial function in MS hypoxia develops which causes nuclear } \\
\text { translocation of HIF1 } \alpha \text { and its subsequent activation. }\end{array}$ \\
\hline
\end{tabular}

(i) Increased $\mathrm{Na}^{+}$concentration associates with $\mathrm{MS}$ pathology.
(ii) Presence of voltage-gated $\mathrm{Na}^{+}$channel $\left(\mathrm{Na}_{\mathrm{v}}\right) 1.2, \mathrm{Na}_{\mathrm{v}} 1.6$ and

References

$[258,259]$

$[260,261]$

$[262-264]$

$[266,267]$

$[268,269]$

[275-277]

(ii) Presence of voltage-gated $\mathrm{Na}^{+}$channel $\left(\mathrm{Na}_{\mathrm{v}}\right) 1.2, \mathrm{Na}_{\mathrm{v}} 1.6$ and $\mathrm{Na}^{+} / \mathrm{Ca} 2^{+}$exchanger (NCX) subunits is evident in MS lesions.

(iii) Altered expression or activation of voltage-gated $\mathrm{K}^{+}\left(\mathrm{K}_{\mathrm{v}}\right)$ channels, which is evident in MS, is blocked by 4 -aminopyridine (non-specific blocker of $\mathrm{K}_{\mathrm{v}}$ channels) in MS patients.

Ion Channel
Dysfunction

(iv) Altered glutamate levels result in excessive neuronal signaling, thereby leading to $\mathrm{Ca}^{2+}$ mediated excitotoxicity as evident in MS.

(v) The glutamate-mediated axonal injury increases by a reduction in mitochondrial complex IV activity, thereby contributing to EAE pathology.

(vi) Abnormal NMDA receptor function contributes to dysfunctional mitochondrial activity.

Thus, inhibition of NMDA and AMPA receptors leads to improvement in EAE.

(vii) Inhibition of calpains $\left(\mathrm{Ca}^{2+}\right.$ - dependent proteases involved in degradation of axonal components) improved EAE pathology.

(i) Mice overexpressing the antiapoptotic Bcl-2 protein showed attenuated EAE severity and reduced axonal loss.

(ii) Cytokine TRAIL can induce caspase-dependent apoptosis in neurons by binding to death receptors DR4 and DR5.

5. Apoptosis

(iii) Wallerian degeneration is involved in axon loss in MS patients. Expression of Wallerian degeneration slow $\left(\mathrm{Wld}^{\mathrm{s}}\right)$ protein inhibits this process through decreased microglial and macrophage activation levels and increased expression of CD200 glycoprotein, which inactivates monocytes by binding to the CD200 receptor, thereby providing protection.

(i) Genes that encode proteins involved in the actions of vitamin D associate with the risk of developing MS. Polymorphisms in 1 $\alpha$-hydroxylase encoding gene CYP27B1 are coupled with an increased risk of developing MS.

6. Environment (ii) Infection with Epstein Barr virus (EBV) in association with infectious mononucleosis (IM) is linked with increased MS risk. Increased MS risk explicitly associates with higher IgG antibody titers to Epstein-Barr nuclear antigens (EBNA).

(iii) An increased MS risk associated with the interaction between smoking and high anti-EBNA titers is observed.

transplanted in AD model show reduced tau phosphorylation, BACE1 expression, decreased expression of inflammatory mediators, and reduced $\mathrm{A} \beta$ production via Akt/GSK3 $\beta$ signaling [56]. In human iPSCs, the Mfn2 expression is essential for the maintenance of morphology and functioning of mitochondrial network and mitochondrial metabolism, the altered expression of which promotes $\mathrm{AD}$ pathology
[57]. In human iPSCs, it has been shown that intracellular signaling molecules BDNF and cAMP can induce SORL1 expression demonstrating a significant reduction in $\mathrm{A} \beta$ [58]. Studies have shown that in protein-induced iPSCs, apotransferrin significantly promoted the maturation of oligodendrocyte differentiation and decreased plaque depositions in the 5XFAD transgenic AD mouse model [59]. Neurogenin 2 


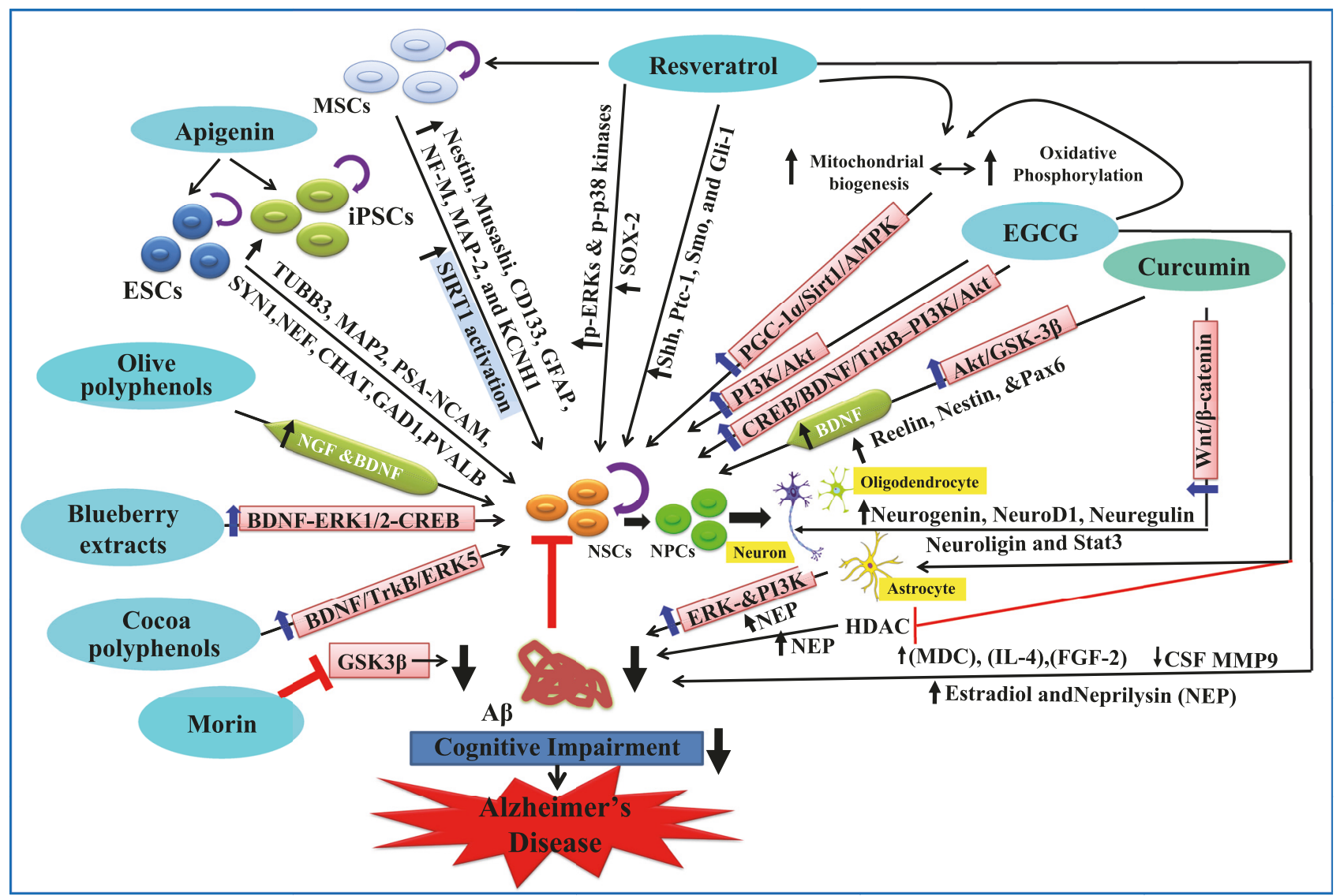

FIGURE 1: The systematic representation for polyphenols targeting stem cells in AD. Polyphenols rich diets, antioxidants, and vitamins play a quintessential role as a defensive tool for AD. Resveratrol, curcumin, olive polyphenols, blueberry extracts, cocoa polyphenols, and apigenin decrease $\mathrm{A} \beta$-induced cellular changes by counteracting ROS through their anti-oxidant characteristics. Increased accumulation of $\mathrm{A} \beta$ in the brain causes synaptic dysfunction and mitochondrial dysfunction, leading to cognitive impairments. Resveratrol stimulates NPCs proliferation, thus accentuating high rates of neuronal survival by mediating SIRT1 activation. Resveratrol in conjunction with tea polyphenols EGCG modulates mitochondrial biogenesis which in turn restores the oxidative phosphorylation. EGCG exerts its neuroprotective action by increasing neuronal plasticity. Curcumin acts through two main pathways: firstly by inducing neuronal differentiation in NSCs through the activation of Wnt signaling and secondly by upregulating the genes required for the cell differentiation, respectively. Other polyphenols, e.g., apigenin, upregulate the levels of neurotrophic factors and expression of neuronal markers in iPSCs and ESCs and result in neuronal differentiation. Cocoa polyphenols, olive polyphenols, and blueberry extracts attenuate the toxic effects of $\mathrm{A} \beta$ deposition through increasing the levels of neurotrophic factors. The arrow line represents promoting effects, and the red line represents inhibitory effect.

(NGN2) is a proneural transcription factor which is essential for the induction of neurons from iPSCs thereby ameliorating $\mathrm{AD}$ pathogenesis [60]. Thus, regenerative and modeling potential of iPSC present it as an indispensable tool in AD therapeutic research.

2.5. Polyphenols Complementing Stem Cell Therapy and Reducing Neurodegeneration in AD. Studies have highlighted the protective role of polyphenols against a wide range of disorders. Here we present a review of studies highlighting the protective effects of different polyphenols against $\mathrm{AD}$. In a study, it has been reported that cocoa polyphenols protect cell viability and cell morphology against $\mathrm{A} \beta$ injury and promote neuronal survival via neuronal survival pathway BDNF/TrkB/ERK5 [61]. Olive polyphenols increased the levels of NGF and BDNF in limbic system and olfactory bulbs promoting proliferation and migration of endogenous progenitor cells in mice [62]. Green tea polyphenol epigallocatechin gallate (EGCG) effectively inhibited sevoflurane-induced neurodegeneration and improved learning and memory ability in mice via activation of $\mathrm{CREB} / \mathrm{BDNF} / \mathrm{TrkB}-\mathrm{PI} 3 \mathrm{~K} / \mathrm{Akt}$ signaling [63]. In $\mathrm{A} \beta$ infused rats it has been shown that curcumin caused neuroprotection via activation of Akt/GSK-3 $\beta$ signaling pathway and increased expression of BDNF [64]. In APP/PS1 transgenic $\mathrm{AD}$ mice fed with blueberry extracts, it was shown that BDNF-ERK1/2-CREB pathway was involved in alleviation of neuronal loss, enhancement of hippocampal neuronal plasticity, and improvement of cognition and memory [65]. In AD mice model, resveratrol significantly increased estradiol and neprilysin levels, which resulted in decrease in $\mathrm{A} \beta$ deposition and reversal in decline of memory [66]. In SAMP8 AD mice, EGCG rescued cognitive deterioration and induced reduction in $\mathrm{A} \beta$ accumulation via 


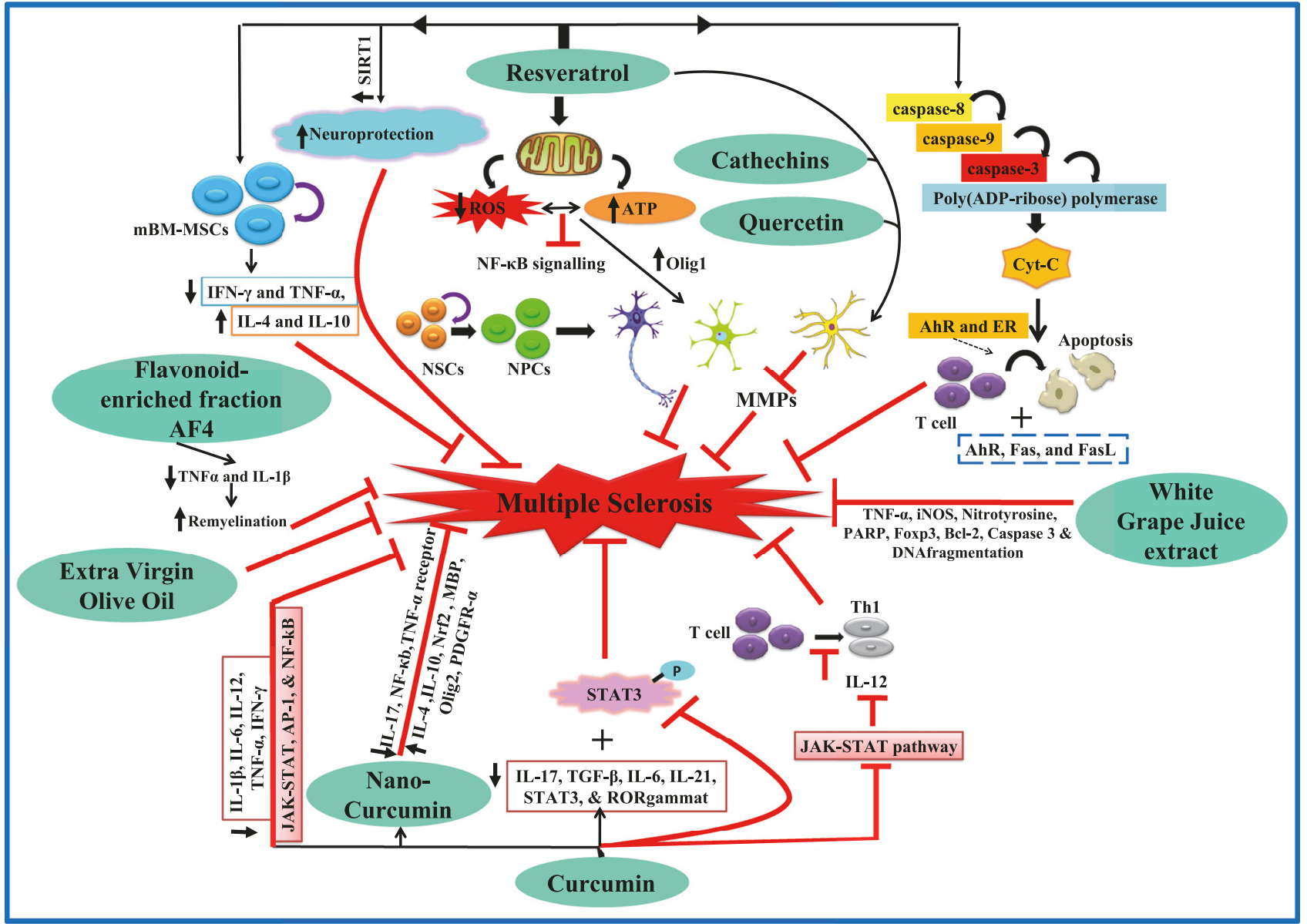

FIGURE 2: The systematic representation for polyphenols targeting stem cells in MS. In case of MS, the proinflammatory cytokines induce an obstructive effect on neural differentiation, whereas anti-inflammatory cytokines have an opposite action. The dietary antioxidants are associated with reduction of MS pathogenesis, by controlling the activation of inflammatory cytokines, reducing oxidative stress and apoptosis, and regulating migration and differentiation of stem cells. Polyphenols such as resveratrol, curcumin, flavanoid enriched fraction AF4, extra virgin olive oil, catechins, quercetin, and white grape juice extract showed neuroprotective potential in MS by targeting NSC proliferation and differentiation and reducing the elevated levels of inflammatory cytokines and oxidative stress. Resveratrol potentiates its protective action through $\mathrm{AhR}$ and ER that activates the T-cells causing apoptosis. Further, resveratrol exerts its neuroprotective role by reducing the oxidative stress and improving mitochondrial functions through inhibition of NF- $\kappa \mathrm{B}$ signaling which also results in remyelination. Quercetin and catechins along with resveratrol show an inhibitory effect on MMPs that inhibits cell migration and EGFR kinase activity.

elevated neprilysin expression [67]. In rat AD model, EGCG facilitated $\mathrm{A} \beta$ degradation by increasing astrocyte secretion of neprilysin via activation of ERK- and PI3K-mediated pathways [68]. Green tea extracts lead to an increase in neprilysin activity and degradation of plaque-forming peptides in SK-N-SH neuroblastoma cell line [69]. Isorhamnetin (flavonol aglycone isolated from the leaves of Ginkgo biloba L.) potentiated NGF induced neurite outgrowth and increased expression of neurofilament in PC12 cells [70]. In one clinical study on the human subjects with mild to moderate $\mathrm{AD}$, resveratrol significantly reduced cerebrospinal fluid (CSF) MMP9 levels and increased macrophage-derived chemokine (MDC), IL-4, and FGF-2 levels (Trial Registration: ClinicalTrials.gov NCT01504854) [71]. EGCG enhanced neuroregeneration via significant increase in the gene expression of growth factors FGF2 and VEGF in male rats with spinal cord injury [72]. Quercetin promotes neurite growth by significantly increasing the expression of cellular cAMP and GAP-43 in neuroblastoma N1E-115 cells [73]. EGCG and resveratrol restore oxidative phosphorylation and mitochondrial biogenesis and improve proliferation of NPCs via the activation of PGC-1 $\alpha /$ Sirt1/AMPK axis in Ts65Dn mouse model of Down syndrome [74]. Resveratrol rescued the decrease in the number of Sox2 positive hippocampal neuron progenitors in C57/BL6 mice [75]. Treatment of NSCs with apigenin resulted in increased number of NPCs and induced expression of neuronal markers and increased neurogenesis [76]. Resveratrol reversed lipopolysaccharide-induced decreased Sox 2 expression in hippocampal NSCs [77]. In the hippocampus of aged rats, resveratrol stimulated NPCs proliferation mediated by increased phosphorylation of ERKs and $\mathrm{p} 38$ kinases. Further, resveratrol increased the number of newly generated cells in the hippocampus with up-regulation of p-CREB and SIRT1 proteins responsible for neuronal 
survival and lifespan extension, respectively [78]. Curcumin has been shown to promote neurogenesis by increasing the expression of reelin, nestin, and Pax6 (genes involved in cell proliferation) and neurogenin, neuroD1, neuregulin, neuroligin, and Stat3 (genes involved in cell differentiation) via activation of the $\mathrm{Wnt} / \beta$-catenin pathway in $\mathrm{AD}$ rat model $[79,80]$. Resveratrol increased the expression of neuronspecific genes nestin, Musashi, CD133, GFAP, NF-M, MAP2, and KCNH1 and exhibited neuroprotection via SIRT1 activation in hBM-MSCs [81]. EGCG, an HDAC inhibitor reduces $\mathrm{A} \beta$ accumulation and elevates NEP expression, thereby rescuing cognitive deterioration in SAMP8 mice [67]. In NSE/hAPP-C105 Tg mice, GTC treatment was shown to activate Wnt signaling and rescue neurodegeneration in the brain [82]. In the developing rat brain, BPA-mediated impaired neurogenesis and cognitive dysfunctions were rescued by curcumin via activation of the $\mathrm{Wnt} / \beta$-catenin signaling pathway [83]. In one study, it was reported that flavonoid morin attenuated $\mathrm{A} \beta$-induced tau phosphorylation via inhibiting GSK3 $\beta$ activity, both in vitro and in vivo [84]. In mice it was shown that EGCG caused up-regulation of Shh receptor and Shh transcriptional target Glil, which resulted in improved hippocampal neurogenesis and spatial cognition [85]. Similarly in rats, after ischemic cerebral stroke, resveratrol pre-treatment significantly increased expression of Shh, Ptc-1, Smo, and Gli-1 mRNAs, thereby improving neurological function, enhancing vitality, and reducing apoptosis of neurons [86]. Thus polyphenols have a wide scope in regenerative medicine by targeting factors responsible for stem cell proliferation and differentiation, against AD.

2.6. Targeting NSCs in MS. Several studies have highlighted the potential role of NSCs in the treatment of MS pathology. The pre-treatment with vitamin $\mathrm{D}$ depicted positive effect in triggering NSCs, thereby preventing the development and progression of disease and also hindering apoptosis in a mice model of MS [87]. The inhibition of Glil led to the mobilization of endogenous NSCs for the repair of demyelinated lesions in a relapsing/remitting model of RR-EAE [88]. In C57/BL6 mice with EAE, administration of glycosyltransferase-programmed stereo-substitution NSCs (GPS-NSCs) resulted in markedly decreased inflammation and improved oligodendroglial and axonal integrity [89]. Activation of either the parenchymal oligodendrocyte progenitor cells (OPCs) or the sub-ventricular zonederived NSCs to ameliorate cognitive disability is a promising perspective for future therapy of MS [90]. Natural killer cells contribute to the rejection of allogeneic NPCs through an NKG2D/RAE-1 signaling pathway in a viral-induced demyelination model [91]. In C57BL/6 and Thyl-YFP mice infected intracranially with plaque-forming units of JHMV strain $\mathrm{J} 2.2 \mathrm{v}-1$, NPCs engrafted into spinal cords exhibited diminished migration velocities and increased proliferation [92]. NPCs particularly accumulated within areas of axonal damage, initiating direct contact with axons and consequently expressing the myelin PLP gene, thereby initiating remyelination [92]. Treatment with minocycline, an inhibitor of microglia activation, was shown to increase stem cell proliferation in both naïve and EAE animals, thereby improving the proliferation and differentiation of Sox 2 stem cells and NG2 oligodendrocyte precursor cells originating in the SVZ [93]. Transplantation of PC12-derived neural-like cells into the brain lateral ventricles of EAE mice showed attenuation of the inflammatory process, thereby resulting in the reduction of both axonal damage and demyelination [94].

In primary progressive and secondary progressive MS patients, the CNS environment stimulated the endogenous pool of NPCs to differentiate into neurons and oligodendrocytes [95]. NSCs treated with $1,25(\mathrm{OH}) 2 \mathrm{D} 3$ showed elevated levels of neurotrophic factors vital for neural cell survival and differentiation, thereby exhibiting a direct effect of 1,25(OH)2D3 on NSC proliferation, survival, and neuron/oligodendrocyte differentiation, remyelination, and neuroprotection in MS [96]. Overexpression of Zfp488, the oligodendrocyte-specific zinc finger transcription repressor, has been shown to increase the differentiation of SVZ NPCs into oligodendrocytes within the demyelinated corpus callosum, thereby promoting functional recovery [97]. Electromagnetic fields have been shown to significantly reduce the extent of demyelinated area and increase the levels of MBP thereby potentiating proliferation and migration of NSCs and enhancing the repair of myelin in demyelination [98]. Overexpression of NFIX in NSCs has been shown to inhibit oligodendrogenesis and loss of NFIX significantly increased the number of oligodendrocytes derived from SVZ-NSCs [99]. Similarly, transcription factor Proxl drives NSCs oligodendrogenesis in the SVZ [100]. Deletion of neurofibromin-1 was found to direct ectopic oligodendrogenesis from SGZNSCs [101]. CNTF influences the migration of NSC progeny toward the demyelinated corpus callosum via activation of the JAK/STAT3 pathway [102]. The transcription factor Ascl1/Mash1 plays a significant role in neurogenesis, and its deletion leads to loss of neuronal progenitors [103]. In both the corpus callosum and spinal cord, Emxl-expressing dorsal SVZ-NSCs were found to undergo increased proliferation, recruitment, and differentiation into oligodendrocytes in response to demyelination [104].

The CXCL8 expression in the CNS has been shown to drive recruitment of NSCs and OPCs to the sites of inflammation [105]. In EAE rodents it was observed that selectively blocking CXCR4, CCR2, or c-Met partially inhibited NPCs migration while blocking all three receptors had an additive effect and resulted in significant inhibition of NPCs migration in EAE brains [106]. In a diphtheria-toxin inducible genetic model for demyelination, Ascll-mediated conversion of hippocampal NSCs into mature oligodendrocytes enhances remyelination [107]. Bioliberation of gold ions from metallic gold implants in an EAE rodent model of MS showed reduced apoptotic cell death, upregulation of neuroprotective proteins Metallothionein-1 and -2 in the corpus callosum, significant upregulation of NSCs migrating from the SVZ, and significant slowing of disease progression [108]. FTY720 (fingolimod), an FDA-approved drug for the treatment of MS, has been shown to exhibit survival and differentiation of NPCs, as well as remyelination and repair following brain injury [109]. It was found that LINGO-1 is a negative regulator of OPCs differentiation whereas RXRs are positive regulators of OPCs differentiation [110]. In one 
study on Focal experimental Auto-immune encephalomyelitis (fEAE), valproic acid administration resulted in increased recruitment of NSCs and oligodendrocyte precursors within the lesion leading to an increase in the number of remyelinated axons [111]. In another study it has been reported that IL-17 blocks proliferation of NSCs, resulting in significantly reduced numbers of OPCs, thereby blocking remyelination and neural repair in the CNS [112].

Genetically engineered NSCs programmed to produce therapeutic cocktail comprising IL-10, NT-3, and LINGO-1Fc mediated recovery through inducing M2 macrophages/ microglia, reducing astrogliosis, and promoting axonal integrity and endogenous oligodendrocyte/neuron differentiation, thereby demonstrating a new and potentially efficient therapy against the chronic stage of MS [296]. NOinduced neuronal to glial fate conversion is shown to rely on transcription factor NRSF/REST, a key factor in NPCs specific response to innate immunity, and suggests a novel mechanism by which signaling from inflamed tissue induces the formation of glial cells [297]. The dbcAMP has been shown to suppress EAE progression, decrease the extent of demyelinated plaques, and increase the recruitment of NSCs into the olfactory bulb and brain parenchyma of EAE mice [298]. The PDGFRA/NG2-expressing glia, a dispersed population of stem/progenitor cells in the adult CNS, generates oligodendrocytes and Schwann cells in chemically induced demyelination in mice [299]. In EAE mice, adult $\mathrm{NG}^{+}$cells represent a valuable cell population for initiation of neural repair in demyelinating diseases such as MS [300]. The CXCL12:CXCR4 pathway has been shown to be involved in regulating engrafted NSCs to sites of tissue damage within the CNS of JHMV mice model of MS [301]. In TMEV murine MS model, loss of galectin-3 (Gal-3) inhibited an increase in chemokine levels, reduced immune cell migration into SVZ, restored SVZ proliferation, and increased the number of progenitors in the corpus callosum, thereby modulating the SVZ neurogenic niche's response to MS [302]. A study reported a dose-dependent response of hNPCs to IFN $\beta$-1b treatment via sustained proliferation and differentiation in MS [303]. In a study, intraventricularly injected Olig2-NSCs significantly reduced the clinical signs of acute and relapsing disease, thereby ameliorating CREAE in mice MS model [304]. In chronic/non-remitting EAE MS model, a reduction in NSCs/NPCs proliferation in the SVZ and hippocampal subgranular zone of the dentate gyrus was reported [305]. Olig1 function has been reported to be essential for the remyelination potential of NPCs after transplant in JHMV MS model [306]. Olig2-transfected NSCs induced development of fully mature oligodendrocytes expressing the transcription factor NKX2-2 and all major myelin-specific proteins, thereby developing into actively remyelinating oligodendrocytes [307]. NG2-targeted LIFnanoparticles bound to OPCs activated pSTAT-3 signaling and induced OPC differentiation into oligodendrocytes [308]. In a model of CNS demyelination, NG2-targeted LIF-nanoparticles increased myelin repair, the number of myelinated axons, and thickness of myelin per axon [308]. SIRT1 inactivation, mediated at least in part by Akt and p38 MAPK-signaling molecules downstream of PDGFR $\alpha$, has been shown to increase oligodendrocyte expansion, thereby ameliorating remyelination [309]. FGF8 is a novel factor shown to induce OPCs activation, migration, and proliferation [310].

The Shh Glil pathway is an important signaling pathway for NSCs in EAE and MS [311]. Mild hypoxia has been shown to favor NSCs proliferation and neuronal and oligodendroglial differentiation in neurodegenerative disorders [312]. Donepezil has been shown to promote oligodendrocyte differentiation and myelin-related gene expression via nAChRs in NSCs-derived OPCs [313]. Grafted OPCs migrate toward areas of inflammation in the adult rat spinal cord, where they survive and differentiate into myelinating oligodendrocytes [314]. CCL19 has been shown to abolish OPCs differentiation observed in patients with high remyelination pattern [315]. In the presence of Ephrin-B3, a transmembrane signaling protein, OPCs fail to differentiate, thereby inhibiting remyelination. Thus Ephrin-B3 in MS lesions inhibits OPC differentiation, while antibody-mediated masking of EphrinB3 epitopes promotes it [316]. FGF2 enhances hippocampal myelination and potentiates the recruitment of OPCs and NSCs to the lesion area [317]. Indomethacin, a non-steroidal anti-inflammatory drug (NSAID) modulates the Wnt/ $\beta$ catenin pathway and thereby promotes differentiation of human and murine oligodendrocytes and remyelination in cuprizone-induced demyelination MS model [318]. IL1 $\beta$ and CCL2 enhance the mobilization of OPCs, thus contributing to remyelination [319]. Expression of PH20, a hyaluronidase, inhibits OPC maturation and remyelination, the pharmacological inhibition of which promotes remyelination in MS [320]. Galanin, a bioactive neuropeptide widely distributed throughout the nervous system, is a regulator of myelination and one of the myelination promoters [321]. Klotho, an antiaging protein, increases OPC maturation and represents a useful therapeutic target in efforts to protect brain myelin against age-dependent changes and promote repair in MS [322]. Anti-EGF Ab treatment ameliorates EAE via induction of neurogenesis and oligodendrogenesis [323]. The increased Mytl expression in both the periplaque white matter adjacent to lesions and within early remyelinating lesions was observed in MS lesions, suggesting a potential role for Mytl in the regeneration of oligodendrocyte in response to demyelination [324]. Following activation by TNF, TNFR2 initiates pathways that drive oligodendrocytes generation and remyelination; thereby TNFR2 serves as a novel therapeutic target in MS [325]. Exogenous addition of ganglioside GDlalpha overcomes the inhibiting effect of aggregated fibronectin on OPC maturation, both in vitro and in vivo, by activating a PKA-dependent signaling pathway, thereby acting as a potential novel molecular tool against MS [326]. Fluvoxamine, an antidepressant drug, stimulates proliferation and differentiation of NSCs particularly toward oligodendrocytes in animal model of MS [327]. Thus these studies suggest a prospective role of NSCs therapy against MS disease.

2.7. Targeting MSCs in MS. Clinical trials using MSCs therapy in MS patients have shown tolerability and safety [328]. MSC transplantation is an approach to regulate the immune system 
in MS [329]. In relapsing-remitting MS patients bone marrow MSCs proved to be safe and reduced inflammatory parameters (ClinicalTrials.gov Reg. No. NCT01228266) [330]. Similarly, autologous MSCs given to patients with secondary progressive MS showed structural, functional, and physiological improvement suggesting neuroprotection (ClinicalTrials.gov, Reg. No. NCT00395200) [331]. The human umbilical cord MSCs treatment demonstrated high potential in MS patients [332]. Mice treated with human bone marrow-derived MSCs showed inhibition of EAE onset with decreased demyelination in the lumbar spinal cord and enhancement of immunomodulatory effects, which suppressed proinflammatory cytokines IFN- $\gamma$ and TNF- $\alpha$ and increased antiinflammatory cytokines IL-4 and IL-10 levels [333]. SJLAdMSCs have been shown to ameliorate EAE course and modulation in disease progression [334]. Active MSCs condition medium containing HGF promoted recovery in EAE and markedly accelerated remyelination [335]. Intraperitoneal administration of MSCs expressing vasoactive intestinal peptide (VIP) stopped progression and reduced symptoms in EAE when administered at the peak of disease [336]. Interestingly, MSCs did not exert regenerative functions in EAE where peripheral immune cells and T lymphocytes were not involved, implying that the peripheral immune system is required for MSC to exercise their effects [337].

Combination of MSCs-IFN- $\beta$ and minocycline on EAE mice considerably alleviated the clinical severity by sustaining the integrity of blood-spinal cord barrier through inhibition of microvascular disruption, neuroinflammation, and augmentation of immunomodulatory effects [338]. Human embryonic stem cell-derived mesenchymal stem cells (HESMSCs), as compared to bone marrow MSCs, have been shown to significantly reduce clinical symptoms and prevent neuronal demyelination in a mouse EAE model of MS [339]. Transplantation of MSCs has been shown to stop the development of EAE by affecting $\mathrm{CD} 4^{+}, \mathrm{CD} 25^{+}, \mathrm{Foxp}^{+}$, T-cell, Foxp3, TGF- $\beta 1$, and IL-10 [340]. Therapeutic potential of bone marrow MSCs for MS is dependent on their immunosuppressive and immunomodulatory nature and their ability to enhance endogenous repair and remyelination [341]. In EAE mice, intrathecal injection of MSCs-derived neural progenitors improved neurological function with reduced immune cell infiltration, reduced area of demyelination, and increased number of endogenous NPCs [342]. EAE mice transplanted intracerebrally with human placental MSCs caused a decrease in disease severity by reduction of anti-inflammatory proteins [343]. In EAE rats treated with adipose-derived-MSCs, the human HLA-G gene was significantly expressed in the brain, thereby demonstrating striking therapeutic effects and unique immunomodulatory capacities [344]. Co-administration of $17 \beta$-estradiol (E2) and adipose-derived MSCs in a mouse cuprizone model of MS showed increased expression of Iba-1, Olig2, and O4 and enhanced efficacy in remyelination [345].

MSCs induced to differentiate into neurotrophic factorgenerating cells exhibited the ability to suppress immune cells and protect neuronal cells from oxidative abuse, thereby delaying the symptoms of EAE in mice [346]. MSCs differentially modulate $\mathrm{CD}^{+}$T-cell development leading to worsening of EAE disease [347]. Aspirin treatment upregulates telomerase activity and stimulates TERT to improve the immunomodulatory capacity of bone marrow MSCs [348]. Inhibition of autophagy by knockdown of beclin-1 was found to significantly alleviate the therapeutic effects of MSCs in EAE model [349]. The ability of MSCs to cross oligolineage boundaries between mesodermal and ectodermal lineages leads to their differentiation into Schwann cells [350]. Transplantation of hWJ-MSCs-derived OPCs significantly reduced the clinical signs of EAE and enhanced remyelination [351]. MSCs can prime NPCs to the oligodendroglial fate leading to the formation of CNPase and MBP expressing oligodendrocytes and reducing the antioligodendrogenic determinant Id2 in proliferating NPCs [352]. The bone marrow hMSCs reduced interferon gammaproducing inflammatory cells, but increased IL-4 producing anti-inflammatory cells, thereby increasing oligodendrocyte lineage in EAE mouse model of MS [353]. In MS patients, after MSCs therapy, the expression of Foxp3 was reported to be significantly higher than the levels before treatment associated with clinical stability [354]. Co-transplantation with MSCs increased OPCs engraftment, migration, and maturation in myelinating oligodendrocytes, which produced widespread myelination in the host corpus callosum while reducing microglia activation and astrocytosis in the brain of transplanted animals [355]. Transplantation of Adi-IL10-MSCs delayed the development of EAE with the reduction in peripheral T-cell proliferative responses, a decrease in proinflammatory cytokine secretion, and inhibition of Th17-mediated neuroinflammation [356]. Genetically modified AD-MSCs expressing murine interferon beta (MSCsVP/IFN- $\beta$ ) showed significant induction of Tregs and IL-10 and reduction of IL-17 in EAE MS model [357]. Similarly, administration of Ad-IL4-MSCs in mice with EAE attenuated clinical symptoms leading to a decrease in peripheral MOGspecific T-cell responses and a shift from a pro- to antiinflammatory cytokine response [358].

Combination of human bone marrow MSCs and minocycline in EAE promoted immunomodulatory effects, which suppressed proinflammatory cytokines IFN- $\gamma$ and TNF- $\alpha$ and increased anti-inflammatory cytokines IL-4 and IL-10, thereby providing novel therapeutic potential against MS [359]. $\mathrm{NG}^{+}$cells stimulated endogenous repair by differentiating into oligodendrocytes, thus promoting neural repair in MS [300]. The umbilical cord blood MSCs-derived NPC reduced CNS leukocyte infiltration in EAE MS model [360]. RANTES and IP-10 promote hMSCs proliferation in MS lesions [361]. Treatment of EAE mice with MSCs engineered with PSGL-1/SLeX/IL-10 exhibited a superior therapeutic potential [362]. SOD3 secretion by MSCs holds potential in the treatment of MS [363]. MSCs showed antioxidant and neuroprotective activity in EAE MS model [364]. Treatment of EAE mice with the secreted ectodomain of sialic acidbinding Ig-like lectin-9 and SHED-CM is a novel therapy for MS [365]. In EAE, maintenance of GSK3 $\beta$ in its inactive status plays a role in preserving the normal physiology of the spinal cord and amelioration of EAE following MSCs therapy [366]. Combined treatment of Methylprednisolone and MSCs-IFN $\beta$ had enhanced therapeutic effects on EAE mice 
[367]. Nicotine has been shown to augment the beneficial effects of MSCs based therapy in the rat model of MS [368]. Addition of rapamycin to bone marrow MSCs ameliorated neurological deficits and provided neuroprotective effects in EAE [369]. Pro-oligodendroglial factors derived from human fetal MSCs instruct human iPSC-derived NSCs to differentiate into $\mathrm{O} 4$ positive oligodendrocytes [370]. Thus the above studies highlight the important therapeutic role of MSCs in MS.

2.8. Targeting HSCs in MS. HSCs have proved to be a potential therapeutic tool against MS pathology. Autologous stem cell transplantation has proved to be beneficial in progressive forms of MS [371]. Autologous HSCs transplantation has been shown to completely halt disease activity in the majority of patients with aggressive MS [372]. In 3 patients with clinical MS, reconstitution of hematopoiesis and functional improvements were achieved with CD34-enriched stem cells even after withdrawal of all immunosuppressive medications [373]. In one study it was reported that HSCs expand regulatory cells and deplete IL-17 T-cells in MS [374]. Granulocyte colony-stimulating factor and cyclophosphamide resulted in an efficient HSC mobilization in MS patients [375]. In patients with relapsing-remitting MS, HSCs transplantation resulted in improvement in neurological disability [376]. In a patient suffering from large granular lymphocyte leukemia and concomitant primary progressive MS, allogeneic HSCs resulted in marked improvement in neurological conditions [377]. Autologous hematopoietic stem cell transplantation (AHSCT) restores immune tolerance in MS patients through increased numbers of regulatory T-cell subsets and PD-1 inhibitory signaling [378]. It was observed that a significant decrease in MMP-9 levels occurred after AHSCT in patients with MS [379]. In one study, normalization of apoptosisrelated molecules resulted in therapeutic effects of AHSCT in MS patients [380]. Thus these studies highlight the emerging potential of HSCs in clinical MS.

2.9. Targeting iPSCs in MS. The iPSCs are a new area of research and hold a promising target in the treatment of many neurodegenerative disorders including MS. In a non-human primate (marmoset) model for progressive MS, hiPSCs derived OPCs after intracortical implantation; they specifically migrated toward the MS-like lesions in the corpus callosum where they myelinated the axons [381]. In a study, renal proximal tubule epithelial cells were isolated from MS patients urine and transfected with pluripotency-inducing episomal factors to give rise to iPSCs and eventually patient specific NPCs [382]. Transplantation of iPSC-derived NSCs significantly reduced $\mathrm{T}$-cell infiltration and ameliorated white matter damage in the treated EAE mice indicating the effectiveness of iPSC-NSCs in treating MS [383]. The iPSCs have been used to generate OPCs that mature to form functional myelinating oligodendrocytes [384]. The iPSCs lines derived from MS patients (using defined factors Oct4, Sox2, Klf4, and c-Myc) successfully differentiated into mature astrocytes, oligodendrocytes, and neurons, thus representing a novel approach in the study of MS [385]. Human MAIT cells reprogrammed into iPSCs through Sendai virus harboring standard reprogramming factors efficiently redifferentiate into MAIT-like lymphocytes expressing the T-cell receptor V $\alpha 7.2$, CD161, and IL-18 receptor chain- $\alpha$ which then migrate to the bone marrow in MS [386]. Characterization of differentiation of iPSCs to oligodendrocytes involves several suppressive histone tags, deacetylation of lysine residues on histone $\mathrm{H} 3$, and trimethylation of residues $\mathrm{K} 9$ and $\mathrm{K} 27$, thus being relevant in MS [387]. The intrathecally transplanted iPSC derived NPCs after disease onset-ameliorated clinical and pathological features of EAE by exerting a neuroprotective effect through the secretion of LIF that promotes survival, differentiation, and remyelination capacity of both endogenous oligodendrocyte precursors and mature oligodendrocytes, thereby possessing therapeutic potential against MS [388]. OPCs derived from hiPSCs by forced expression of Sox10 and Olig2 differentiate into mature oligodendrocytes and thus have implications in MS [389].

2.10. Targeting ESCs in MS. ESCs prove to be a promising option for the generation and replacement of mature oligodendrocytes. Transplantation of ESCs expressing MOG antigen enhanced $\mathrm{T}$-cell regeneration, long-term expression of MOG in the thymus, prevention of EAE development, and remission of established EAE [390]. Analysis of the changes in proteome pattern of EAE mouse model after ESCs derived NPCs transplantation demonstrated that the expression levels of various altered proteins in EAE samples returned to normal levels after transplantation, which implied a possible correlation between changes at the proteome level and decreased clinical signs of EAE in transplanted mice [391]. In EAE mice, transplanted hESCs derived OPCs were shown to generate TREM2-positive CD45 cells, amplified TIMP-1 expression, restricted inflammatory cells to the subarachnoid space, and augmented the number of Foxp3-positive regulatory T-cells, potentially providing new avenues for stem cell-based treatment of MS [392]. Intraspinal transplantation of embryoid body intermediate stage neural progenitor cells (EB-NPCs) into JHMV mice resulted in decreased accumulation of $\mathrm{CD} 4^{+} \mathrm{T}$-cells in the CNS, thereby causing reduced demyelination. However, reduced neuroinflammation and remyelination were linked with a transient enhancement in $\mathrm{CD}+\mathrm{FOXP}^{+}{ }^{+}$regulatory T-cells (Tregs) [393]. In hESCs derived OPCs, the addition of CNTF upregulated the Olig2 mRNA levels and this OPC population is shown to express Olig1/2, Sox10, PDGFR, NKX2-2, NKX6-2, oligodendrocytemyelin glycoprotein, MBP, and PLP, ultimately maturing into oligodendrocytes [394]. The predicted targets of miRNAs expressed in oligodendrocytes from hESCs (involved in cellular differentiation and maintenance) include C11Orf9, CLDN11, MYTL1, MBOP, MPZL2, and DDR1, having roles in oligodendrocyte development and myelination [395]. Patients with MS treated with hESCs therapy showed an improvement in factors such as sleeping disorders, paralysis, muscle weakness, memory, language, irritability, eye pain, depression and coordination, communication, and appetite associated with MS [396]. These studies justify the role of ESCs in MS stem cell therapy. 
2.11. Polyphenols Complementing Stem Cell Therapy and Reducing Neurodegeneration in MS. Many studies have highlighted the positive role of polyphenols in MS. Quercetin has been shown to ameliorate EAE by blocking IL-12induced tyrosine phosphorylation of TYK2, JAK2, STAT3, and STAT4, leading to a decrease in IL-12-induced Tcell proliferation and Th1 differentiation [397]. Curcumin decreases T-cell production of IFN- $\gamma$ [398], prevents the differentiation of Th1 cells [399], and decreases the amount of Th17- differentiated cells [400]. Resveratrol has been shown to induce neuroprotective effects through sirtuin 1 activation [401]. Lipopolysaccharide-activated primary rat astrocytes treated with flavonoids quercetin and catechins and the non-flavonoid resveratrol exert inhibitory effect on MMPs and represent a powerful tool for the downregulation of MMPs in the course of MS [402]. Nano-curcumin attenuated symptoms in EAE MS model, through downregulation of IL$17, \mathrm{NF}-\kappa \mathrm{b}$, and TNF- $\alpha$ receptor expression and upregulation of anti-inflammatory genes and Nrf2, and increased MBP, Olig2, and PDGFR- $\alpha$ expression [403]. Polyphenolic white grape juice extract has been shown to neutralize the alteration of TNF- $\alpha$, iNOS, Nitrotyrosine, PARP, Foxp3, Bcl-2, Caspase 3 , and DNA fragmentation, thus acting as a novel tool in MS therapy [404]. The flavonoid-enriched fraction AF4 in mouse EAE MS model demonstrated disease recovery from EAE and reduced neuropathology in the cerebellum and spinal cord [405]. In a study on EAE mice, curcumin treatment significantly decreased elevated levels of IFN- $\gamma$ and IL-17, IL12 , and IL-23, and this decrease was associated with upregulation of IL-10, PPAR- $\gamma$, and CD $4^{+}, \mathrm{CD}_{2} 5^{+}$, and Foxp $3^{+}$Treg cells, thus highlighting a differential regulation by curcumin [406]. The inhibition of MS by curcumin is mainly by the regulation of inflammatory cytokines such as IL- $1 \beta$, IL-6, IL12 , TNF- $\alpha$, IFN- $\gamma$ and associated JAK-STAT, AP-1, and NFkappaB signaling pathways [407]. Curcumin dramatically decreased IL-17, TGF- $\beta$, IL-6, IL-21, and STAT3 expression and also inhibited STAT-3 phosphorylation, thus suggesting neuroprotective role in EAE MS model [400]. The combined treatment of bone marrow-derived MSCs and resveratrol in EAE MS model was shown to suppress proinflammatory cytokines IFN- $\gamma$ and TNF- $\alpha$ and increase anti-inflammatory cytokines IL- 4 and IL-10, thus alleviating EAE symptoms [408]. Curcumin treatment of animals with EAE resulted in decrease in IL-12-induced STAT4 phosphorylation, IFN$\gamma$ production, and IL-12 Rbetal and beta 2 expression and an increase in IFN-beta-induced STAT4 phosphorylation, IL10 production, and IFN receptor (IFNAR) subunits 1 and 2 expression [409]. Resveratrol-mediated protection against EAE was found to be associated with rise in $\mathrm{IL}-17^{+} / \mathrm{IL}-10^{+}$ T-cells and suppression of macrophage IL- 6 and IL-12/23 p40 expression [410]. Resveratrol significantly downregulated TNF- $\alpha$, IFN- $\gamma$, IL-2, 9, 12, 17, MIP- $1 \alpha$, MCP-1, and RANTES in EAE MS model and, thereby, proved to be a useful tool against MS [411]. Similarly, curcumin treatment caused inhibition of JAK-STAT pathway which resulted in a decrease in IL-12-induced T-cell proliferation and Th1 differentiation; thus curcumin may serve as a potential polyphenol against MS [399]. In a cuprizone model of MS, resveratrol enhanced motor coordination and balance, reversed cuprizone-induced demyelination, improved mitochondrial function, alleviated oxidative stress, and inhibited NF- $\kappa \mathrm{B}$ signaling, while increasing Olig1 expression that is positively correlated to active remyelination [412]. Extra virgin olive oil and its polyphenols have been shown to improve MS disease symptoms [413]. Thus these studies provide new avenues as to how polyphenols cause neuroprotection against MS pathology and how they can utilize stem cells against MS regulating the same or different factors involved.

\section{Mechanism of Action of Polyphenols for Neuroprotection}

Neurodegenerative diseases such as AD and multiple sclerosis are multifactorial disorders possessing no single particular cause or pathophysiologic mechanism. However, chronic neuroinflammation is a common mechanism that is shared by multiple neurodegenerative diseases including $\mathrm{AD}$ and MS and is a general cause of the initiation and progression of neurodegeneration. The increase in inflammatory signaling results in an upregulation of nuclear factor-kappa $\mathrm{B}(\mathrm{NF}-\kappa \mathrm{B})$ transcription factor $[414,415]$. Increase in an abnormal accumulation of $\mathrm{A} \beta_{1-42}$ stimulates microglial cells and augments NF- $\kappa \mathrm{B}$ induced activation of inflammatory cytokines and neurotoxic molecules such as reactive oxygen species (ROS) and induced nitric oxide synthase (iNOS) [416]. Similarly, several NF- $\kappa$ B polymorphisms are associated with an increased vulnerability to MS [414]. NF- $\kappa$ B signaling plays a vital role in the activation of peripheral inflammatory cells and the CNS dwelling glial cells that eventually mediate inflammatory demyelination [414].

Polyphenols share a common mechanism of action for modulation of neuroinflammation by targeting the NF$\kappa \mathrm{B}$ signaling [417]. Plant polyphenols including flavonoids inhibit the activation of NF- $\kappa \mathrm{B}$ through binding on tolllike receptor (TLR), specifically TLR4, thus reducing the chronic neuroinflammation [417]. In this line, tea polyphenol epigallocatechin-3-gallate has been reported to modulate the expression of Toll interacting protein. Resveratrol is shown to exert neuroprotective effects through oligomerization of TLR4 and activating TLR4/NF- $\kappa$ B/STAT pathway [417]. Curcumin reduces the expression of inflammatory cytokines and neuronal apoptosis via inhibiting TLR4-MAPK/NF- $\kappa \mathrm{B}$ and TLR4/MyD88/NF- $\kappa \mathrm{B}$ signaling pathway [417]. Thus, polyphenol's mediated targeting of TLR4- NF- $\kappa \mathrm{B}$ signaling could be a potential therapeutic strategy for inhibiting neuroinflammation in $\mathrm{AD}$ and MS.

Apart from this common mechanism of action, polyphenols act through various receptors and pathways directly or indirectly. Resveratrol causes inhibition of MAPK and activation of SIRT1 pathway, thereby leading to suppression of NF- $\kappa \mathrm{B}$ signaling $[418,419]$. In EAE, resveratrol ameliorates disease via apoptosis of activated T-cells and suppressing proinflammatory responses [410]. Demethoxycurcumin inhibits NF- $\kappa \mathrm{B}$ activation and suppresses proinflammatory gene expression in stimulated microglial cells [420]. Treatment with curcumin ameliorates EAE by preventing proinflammatory cytokine responses in microglial cells $[399,400]$. 
EGCG interferes with IKK $\beta$ activation and suppresses NF$\kappa \mathrm{B}$ mediated activation of $\beta$-secretase, thereby inhibiting $\mathrm{A} \beta$ fibrillization [421].

Polyphenols are also known to modulate neurotrophic signaling pathways essential for neuronal growth, proliferation, differentiation, and survival [422]. Quercetin, resveratrol, and other polyphenols promote augmentation of neurotrophic factors such as NGF and BDNF [422]. The ERK pathway is involved in various physiological activities of neurons, including proliferation and differentiation [423]. Resveratrol and curcuminoids contribute to the regulation of ERK1/2 activation $[424,425]$. A $\beta$-induced neuronal toxicity attenuates in response to activation of the ERK1/2 pathway [422]. PI3K and its downstream effector Akt are implicated in neuronal survival [422]. Polyphenols such as curcumin and ferulic acid are involved in improvement of $A \beta$-induced cognitive impairment and provide antidepressant effects, respectively, via the modulation of PI3K/Akt signaling [64] [426]. Polyphenols possess antioxidant properties and exert their antioxidant effects through activation of Nrf2 pathway, increase in expression of antioxidant enzymes, and induction of HIF-1- $\alpha$ pathway $[427,428]$. Thus, these are the major common pathways that are utilized by polyphenols to exert their neuroprotective effects against neurodegenerative disorders such as $\mathrm{AD}$ and MS.

\section{Conclusion and Future Perspectives}

$\mathrm{AD}$ and MS are the most widespread neurodegenerative disorders characterized by the accumulation of abnormal proteins which give rise to the formation of pathogenic lesions. The severity of these disorders gradually increases with age of the individual. There exists no permanent treatment for these disorders. Therapies include anti-symptomatic drugs, monoclonal antibodies, stem cell therapy, and disease management. Studies are being carried out thoroughly on the use of stem cells as therapeutics against neurodegenerative disorders, and they are presenting promising results validating the safety and tolerability of stem cells in medicine. The use of therapeutic compounds coupled with stem cells for their stimulation is also being analyzed in regenerative medicine. Synthetic drugs and natural compounds such as polyphenols are being used for their potential stimulatory effect on stem cells against neurodegenerative diseases. The key focus of this review is, thus, to highlight the important factors involved in the pathogenesis of AD and MS and stem cell therapies currently utilized in the cure of these disorders and to appreciate the role of polyphenolic compounds in stimulating stem cell proliferation and differentiation as therapeutics against neurodegeneration.

$\mathrm{AD}$ is a complex neurodegenerative disorder involving abnormal accumulation of pathogenic amyloid beta species leading to impaired neurogenesis and neuronal death. The presence of mutant APOE $\varepsilon 4$, PSEN1, and PSEN2 genes increases the susceptibility of $A \beta$ accumulation in individuals and presents a genetic predisposition to AD. Apart from the genetic factor, exposure to environmental toxicants further aggravates the disease pathogenesis. Harmful exposure to toxic metals like lead and mercury, pesticides like rotenone and paraquat, and xenoestrogens like bisphenols results in elevated aggregation of pathogenic $\mathrm{A} \beta$. This aggregation further impairs the physiological and metabolic functions of the body. Increased levels of apoptotic caspases and proinflammatory factors, elevation of ROS and oxidative stress, and dysfunction of autophagy and mitochondrial biogenesis are all end results of the AD pathophysiology ultimately causing neuronal loss and neurodegeneration. The rescue of the loss of neurons via promoting neurogenesis is promising, and this is where stem cell therapy comes into play. The utilization of endogenous and exogenous NSCs, ESCs, MSCs, and iPSCs has depicted promising results against AD. These stem cells either are engrafted directly or further release factors which in turn stimulate the endogenous NSCs population, thereby bringing about neurogenesis. Stimulation of factors such as BDNF, NGF, VEGF, FGF2, Oct4, Sox2, Pax6, MAP2, and DCX; regulation of Wnt $/ \beta$-catenin, sonic hedgehog, Notch, and autophagy pathways; and activation of $\mathrm{A} \beta$ digesting enzymes such as neprilysin are central to stem cell-induced therapy. Although stem cells cause neurogenesis and neuroprotection in $\mathrm{AD}$, there is wide appreciation of the role of polyphenols in regulating stem cell proliferation and differentiation. Curcumin, resveratrol, green tea extracts, quercetin, and epigallocatechin gallate have been shown to cause neuroprotection in $\mathrm{AD}$ via regulation of the abovementioned NSC markers and stem cell proliferation and differentiation pathways and downregulation of the apoptotic and oxidative stress, thus complementing the stem cell therapy in the treatment of AD.

MS is another neurodegenerative disease, which is also caused by the accumulation of pathogenic proteins. It is more of an autoimmune disorder which ultimately leads to neuronal cell death. Genetic factors like presence of an abnormal HLA-DRB $1 * 15$ gene, elevated apoptosis, and oxidative stress; increase in mitochondrial and ion-channel dysfunction; and exposure to environmental toxicants all lead to the pathogenesis of MS. Stem cell therapies complemented with polyphenol treatment have shown promising results in MS pathology although much work remains to be done. Quercetin, resveratrol, and curcumin have depicted positive results with MS by targeting the proinflammatory factors such as TNF- $\alpha$, IFN- $\gamma$, and IL-2 and downregulating their expression. However, a great deal of research still needs to be carried out in studying the involvement of the role of polyphenols in regulating stem cells against MS.

The future perspectives involve further studies on the insights into mechanisms underlying the action of polyphenols in regulating stem cells against neurodegenerative disorders. A lot of polyphenols are still left unexplored, and very little research has been carried out to study their role in neurodegenerative disorders. Also, the role of polyphenols against other diseases such as disorders of the metabolism can be tested in case of neurodegeneration. Targeting of new molecular pathways and study of new physiological mechanisms need to be done pertaining to polyphenols and stem cells and how this can be useful in neurodegeneration. The notion of ineffectiveness of polyphenols due to natural origin needs to be abolished as these compounds hold potential promise in the area of medicine. 


\section{Disclosure}

The authors apologize for the inability to cite several articles due to space limitations. CSIR-IITR manuscript communication number is 3533 .

\section{Conflicts of Interest}

The authors declare no conflicts of interest.

\section{Acknowledgments}

This work was supported by the Lady Tata Memorial-UK Young Scientist Grant, Science and Engineering Research Board (SERB), New Delhi, EMR Grant (EMR/2016/001933), Department of Biotechnology, New Delhi Research Grant (BT/PR15819/MED/31/322/2015), and CSIR Network Projects (BSC-0115 and BSC-0111) to RKC. The authors are thankful to the Director of CSIR-IITR for constant support during this study.

\section{References}

[1] L. Migliore and F. Coppedè, "Genetics, environmental factors and the emerging role of epigenetics in neurodegenerative diseases," Mutation Research, vol. 667, no. 1-2, pp. 82-97, 2009.

[2] S. Oddo, "The ubiquitin-proteasome system in Alzheimer's disease," Journal of Cellular and Molecular Medicine, vol. 12, no. 2, pp. 363-373, 2008.

[3] A. M. Bond, G. L. Ming, and H. Song, "Adult mammalian neural stem cells and neurogenesis: five decades later," Cell Stem Cell, vol. 17, no. 4, pp. 385-395, 2015.

[4] D. K. Ma, M. A. Bonaguidi, G.-L. Ming, and H. Song, "Adult neural stem cells in the mammalian central nervous system," Cell Research, vol. 19, no. 6, pp. 672-682, 2009.

[5] S. U. Kim, H. J. Lee, and Y. B. Kim, "Neural stem cell-based treatment for neurodegenerative diseases," Neuropathology, vol. 33, no. 5, pp. 491-504, 2013.

[6] K. B. Pandey and S. I. Rizvi, "Plant polyphenols as dietary antioxidants in human health and disease," Oxidative Medicine and Cellular Longevity, vol. 2, no. 5, pp. 270-278, 2009.

[7] L. G. Apostolova, "Alzheimer disease," Continuum: Lifelong Learning in Neurology, vol. 22, no. 2, pp. 419-434, 2016.

[8] A. L. Gross, R. N. Jones, D. A. Habtemariam et al., "Delirium and long-term cognitive trajectory among persons with dementia," JAMA Internal Medicine, vol. 172, no. 17, pp. 1324-1331, 2012.

[9] H. Braak and K. Del Tredici, "Where, when, and in what form does sporadic Alzheimer's disease begin?" Current Opinion in Neurology, vol. 25, no. 6, pp. 708-714, 2012.

[10] S. C. Waring and R. N. Rosenberg, "Genome-wide association studies in Alzheimer disease," JAMA Neurology, vol. 65, no. 3, pp. 329-334, 2008.

[11] J. L. Shaffer, J. R. Petrella, F. C. Sheldon et al., "Predicting cognitive decline in subjects at risk for Alzheimer disease by using combined cerebrospinal fluid, MR imaging, and PET biomarkers," Radiology, vol. 266, no. 2, pp. 583-591, 2013.

[12] C. Liu, T. Kanekiyo, H. Xu, and G. Bu, "Apolipoprotein e and Alzheimer disease: risk, mechanisms and therapy," Nature Reviews Neurology, vol. 9, no. 2, pp. 106-118, 2013.
[13] A. Chaudhuri, "Multiple sclerosis is primarily a neurodegenerative disease," Journal of Neural Transmission, vol. 120, no. 10, pp. 1463-1466, 2013.

[14] Disease G. B. D., Injury I., Prevalence C., "Global, regional, and national incidence, prevalence, and years lived with disability for 310 diseases and injuries, 1990-2015: a systematic analysis for the Global Burden of Disease Study 2015", Lancet, vol. 388, pp. $1545-1602,2016$

[15] R. Dutta and B. D. Trapp, "Relapsing and progressive forms of multiple sclerosis: Insights from pathology," Current Opinion in Neurology, vol. 27, no. 3, pp. 271-278, 2014.

[16] A. Compston and A. Coles, "Multiple sclerosis," The Lancet, vol. 372, no. 9648, pp. 1502-1517, 2008.

[17] J. Nakahara, M. Maeda, S. Aiso, and N. Suzuki, "Current concepts in multiple sclerosis: autoimmunity versus oligodendrogliopathy," Clinical Reviews in Allergy \& Immunology, vol. 42, no. 1, pp. 26-34, 2012.

[18] S. Saidha, C. Eckstein, and P. A. Calabresi, "New and emerging disease modifying therapies for multiple sclerosis," Annals of the New York Academy of Sciences, vol. 1247, no. 1, pp. 117-137, 2012.

[19] S. M. Gold and R. R. Voskuhl, "Estrogen treatment in multiple sclerosis," Journal of the Neurological Sciences, vol. 286, no. 1-2, pp. 99-103, 2009.

[20] E. Rockenstein, P. Desplats, K. Ubhi et al., "Neuro-peptide treatment with Cerebrolysin improves the survival of neural stem cell grafts in an APP transgenic model of Alzheimer disease," Stem Cell Research, vol. 15, no. 1, pp. 54-67, 2015.

[21] M. Blurton-Jones, B. Spencer, S. Michael et al., "Neural stem cells genetically-modified to express neprilysin reduce pathology in Alzheimer transgenic models," Stem Cell Research \& Therapy, vol. 5, no. 2, article no. 46, 2014.

[22] Y. Chen, C. Pan, A. Xuan et al., "Treatment efficacy of NGF nanoparticles combining neural stem cell transplantation on alzheimer's disease model rats," Medical Science Monitor, vol. 21, pp. 3608-3615, 2015.

[23] I.-S. Lee, K. Jung, I.-S. Kim et al., "Human neural stem cells alleviate Alzheimer-like pathology in a mouse model," Molecular Neurodegeneration, vol. 10, no. 1, article no. 38, 2015.

[24] W. Zhang, G. M. Wang, P. J. Wang, Q. Zhang, and S. H. Sha, "Effects of neural stem cells on synaptic proteins and memory in a mouse model of Alzheimer's disease," Journal of Neuroscience Research, vol. 92, no. 2, pp. 185-194, 2014.

[25] N. A. Koon, Y. Itokazu, and R. K. Yu, "Ganglioside-dependent neural stem cell proliferation in alzheimer's disease model mice," ASN Neuro, vol. 7, no. 6, 2015.

[26] L. K. Hamilton, M. Dufresne, S. E. Joppé et al., "Aberrant lipid metabolism in the forebrain niche suppresses adult neural stem cell proliferation in an animal model of Alzheimer's disease," Cell Stem Cell, vol. 17, no. 4, pp. 397-411, 2015.

[27] W. Zhang, P.-J. Wang, H.-Y. Sha, J. Ni, M.-H. Li, and G.-J. $\mathrm{Gu}$, "Neural stem cell transplants improve cognitive function without altering amyloid pathology in an APP/PS1 double transgenic model of Alzheimer's disease," Molecular Neurobiology, vol. 50, no. 2, pp. 423-437, 2014.

[28] A. M. Lilja, L. Malmsten, J. Röjdner et al., "Neural Stem Cell Transplant-Induced Effect on Neurogenesis and Cognition in Alzheimer Tg2576 Mice Is Inhibited by Concomitant Treatment with Amyloid-Lowering or Cholinergic $\alpha 7$ Nicotinic Receptor Drugs," Neural Plasticity, vol. 2015, Article ID 370432, 2015.

[29] L. Sun, J. Lee, and H. A. Fine, "Neuronally expressed stem cell factor induces neural stem cell migration to areas of brain 
injury," The Journal of Clinical Investigation, vol. 113, no. 9, pp. 1364-1374, 2004.

[30] A. M. D. Adefuin, A. Kimura, H. Noguchi, K. Nakashima, and M. Namihira, "Epigenetic mechanisms regulating differentiation of neural stem/precursor cells," Epigenomics, vol. 6, no. 6, pp. 637-649, 2014.

[31] J. Hsieh, K. Nakashima, T. Kuwabara, E. Mejia, and F. H. Gage, "Histone deacetylase inhibition-mediated neuronal differentiation of multipotent adult neural progenitor cells," Proceedings of the National Acadamy of Sciences of the United States of America, vol. 101, no. 47, pp. 16659-16664, 2004.

[32] I. S. Samuels, J. C. Karlo, A. N. Faruzzi et al., "Deletion of ERK2 mitogen-activated protein kinase identifies its key roles in cortical neurogenesis and cognitive function," The Journal of Neuroscience, vol. 28, no. 27, pp. 6983-6995, 2008.

[33] C.-L. Zhang, Y. Zou, W. He, F. H. Gage, and R. M. Evans, “A role for adult TLX-positive neural stem cells in learning and behaviour," Nature, vol. 451, no. 7181, pp. 1004-1007, 2008.

[34] W. Yue, Y. Li, T. Zhang et al., "ESC-derived basal forebrain cholinergic neurons ameliorate the cognitive symptoms associated with Alzheimer's disease in mouse models," Stem Cell Reports, vol. 5, no. 5, pp. 776-790, 2015.

[35] F. H. Moghadam, H. Alaie, K. Karbalaie, S. Tanhaei, M. H. Nasr Esfahani, and H. Baharvand, "Transplantation of primed or unprimed mouse embryonic stem cell-derived neural precursor cells improves cognitive function in Alzheimerian rats," Differentiation, vol. 78, no. 2-3, pp. 59-68, 2009.

[36] C. J. Bissonnette, L. Lyass, B. J. Bhattacharyya, A. Belmadani, R. J. Miller, and J. A. Kessler, "The controlled generation of functional basal forebrain cholinergic neurons from human embryonic stem cells," Stem Cells, vol. 29, no. 5, pp. 802-811, 2011.

[37] L. Magno, O. Kretz, B. Bert et al., "The integrity of cholinergic basal forebrain neurons depends on expression of Nkx2-1," European Journal of Neuroscience, vol. 34, no. 11, pp. 1767-1782, 2011.

[38] P. Porayette, M. J. Gallego, M. M. Kaltcheva, R. L. Bowen, S. V. Meethal, and C. S. Atwood, "Differential processing of amyloid- $\beta$ precursor protein directs human embryonic stem cell proliferation and differentiation into neuronal precursor cells," The Journal of Biological Chemistry, vol. 284, no. 35, pp. 23806-23817, 2009.

[39] L. Wicklund, R. N. Leão, A.-M. Strömberg et al., "Beta-amyloid 1-42 oligomers impair function of human embryonic stem cellderived forebrain cholinergic neurons," PLoS ONE, vol. 5, no. 12, Article ID e15600, 2010.

[40] E. Abranches, M. Silva, L. Pradier et al., "Neural differentiation of embryonic stem cells in vitro: a road map to neurogenesis in the embryo," PLoS ONE, vol. 4, no. 7, Article ID e6286, 2009.

[41] E. Theodorou, G. Dalembert, C. Heffelfinger et al., "A high throughput embryonic stem cell screen identifies Oct-2 as a bifunctional regulator of neuronal differentiation," Genes \& Development, vol. 23, no. 5, pp. 575-588, 2009.

[42] M. Gallego, P. Porayette, M. M. Kaltcheva, R. L. Bowen, S. Vadakkadath Meethal, and C. S. Atwood, "The pregnancy hormones human chorionic gonadotropin and progesterone induce human embryonic stem cell proliferation and differentiation into neuroectodermal rosettes," Stem Cell Research \& Therapy, vol. 1, no. 4, article no. 28, 2010.

[43] P. Bianco, “Mesenchymal' stem cells," Annual Review of Cell and Developmental Biology, vol. 30, no. 1, pp. 677-704, 2014.
[44] J. Y. Shin, H. J. Park, H. N. Kim et al., "Mesenchymal stem cells enhance autophagy and increase $\beta$-amyloid clearance in Alzheimer disease models," Autophagy, vol. 10, no. 1, pp. 32-44, 2014.

[45] H. Yang, Z. Xie, L. Wei et al., "Human umbilical cord mesenchymal stem cell-derived neuron-like cells rescue memory deficits and reduce amyloid-beta deposition in an AbetaPP/PS1 transgenic mouse model," Stem cell research \& Therapy, vol. 4, no. 76, 2013.

[46] J. Ruzicka, M. Kulijewicz-Nawrot, J. J. Rodrigez-Arellano, P. Jendelova, and E. Sykova, "Mesenchymal stem cellreserve working memory in the 3xTg-AD mousodel of Alzheimer's disease," International Journal of Molecular Sciences, vol. 17, no. 2, article no. 152,2016

[47] D. H. Kim, D. Lee, E. H. Chang et al., "GDF-15 secreted from human umbilical cord blood mesenchymal stem cells delivered through the cerebrospinal fluid promotes hippocampal neurogenesis and synaptic activity in an Alzheimer's disease model," Stem Cells and Development, vol. 24, no. 20, pp. 2378-2390, 2015.

[48] Y. Yan, T. Ma, K. Gong, Q. Ao, X. Zhang, and Y. Gong, "Adiposederived mesenchymal stem cell transplantation promotes adult neurogenesis in the brains of Alzheimer's disease mice," Neural Regeneration Research, vol. 9, no. 8, pp. 798-805, 2014.

[49] H. M. Yun, H. S. Kim, K. R. Park et al., "Placenta-derived mesenchymal stem cells improve memory dysfunction in an Abetal-42-infused mouse model of Alzheimer's disease," Cell death \& Disease, vol. 4, Article ID e958, 2013.

[50] K. O. Garcia, F. L. M. Ornellas, P. K. Matsumoto Martin et al., "Therapeutic effects of the transplantation of VEGF overexpressing bone marrow mesenchymal stem cells in the hippocampus of murine model of alzheimer's disease," Frontiers in Aging Neuroscience, vol. 6, 2014.

[51] J.-Y. Kim, D. H. Kim, J. H. Kim et al., "Soluble intracellular adhesion molecule-1 secreted by human umbilical cord bloodderived mesenchymal stem cell reduces amyloid-B plaques," Cell Death \& Differentiation, vol. 19, no. 4, pp. 680-691, 2012.

[52] H. Yang, H. Yang, Z. Xie, L. Wei, J. Bi, and P. Fiorina, "Systemic Transplantation of Human Umbilical Cord Derived Mesenchymal Stem Cells-Educated T Regulatory Cells Improved the Impaired Cognition in A $\beta$ PPswe/PS1dE9 Transgenic Mice," PLoS ONE, vol. 8, no. 7, p. e69129, 2013.

[53] Y.-Z. Zhang, J.-Y. Lou, H.-Y. Bai, Y.-L. Wang, J.-F. Li, and H.L. Yin, "Protective effect of bone marrow mesenchymal stem cells on PC12 cells apoptosis mediated by TAG1," International Journal of Clinical and Experimental Pathology, vol. 8, no. 10, pp. 12093-12100, 2015.

[54] C. A. Ross and S. S. Akimov, "Human-induced pluripotent stem cells: potential for neurodegenerative diseases," Human Molecular Genetics, vol. 23, no. 1, pp. R17-R26, 2014.

[55] A. M. Hossini, A. S. Quast, M. Plötz et al., "PI3K/AKT signaling pathway is essential for survival of induced pluripotent stem cells," PLoS ONE, vol. 11, no. 5, Article ID e0154770, 2016.

[56] J. Yang, S. Li, X.-B. He, C. Cheng, and W. Le, "Induced pluripotent stem cells in Alzheimer's disease: Applications for disease modeling and cell-replacement therapy," Molecular Neurodegeneration, vol. 11, no. 1, article no. 39, 2016.

[57] D. Fang, S. Yan, Q. Yu, D. Chen, and S. S. Yan, "Mfn2 is required for mitochondrial development and synapse formation in human induced pluripotent stem cells/hiPSC derived cortical neurons," Scientific Reports, vol. 6, 2016.

[58] J. E. Young, J. Boulanger-Weill, D. A. Williams et al., "Elucidating molecular phenotypes caused by the SORL1 Alzheimer's 
disease genetic risk factor using human induced pluripotent stem cells," Cell Stem Cell, vol. 16, no. 4, pp. 373-385, 2015.

[59] M.-Y. Cha, Y.-W. Kwon, H.-S. Ahn et al., "Protein-induced pluripotent stem cells ameliorate cognitive dysfunction and reduce $\mathrm{A} \beta$ deposition in a mouse model of alzheimer's disease," Stem Cells Translational Medicine, vol. 6, no. 1, pp. 293-305, 2017.

[60] C. Wang, M. E. Ward, R. Chen et al., "Scalable Production of iPSC-Derived Human Neurons to Identify Tau-Lowering Compounds by High-Content Screening," Stem Cell Reports, vol. 9, no. 4, pp. 1221-1233, 2017.

[61] A. Cimini, R. Gentile, B. D’Angelo et al., "Cocoa powder triggers neuroprotective and preventive effects in a human Alzheimer's disease model by modulating BDNF signaling pathway," Journal of Cellular Biochemistry, vol. 114, no. 10, pp. 2209-2220, 2013.

[62] S. De Nicoló, L. Tarani, M. Ceccanti et al., "Effects of olive polyphenols administration on nerve growth factor and brainderived neurotrophic factor in the mouse brain," Nutrition Journal, vol. 29, no. 4, pp. 681-687, 2013.

[63] M.-L. Ding, H. Ma, Y.-G. Man, and H.-Y. Lv, "Protective effects of a green tea polyphenol, epigallocatechin- 3-gallate, against sevoflurane-induced neuronal apoptosis involve regulation of $\mathrm{CREB} / \mathrm{BDNF} / \mathrm{TrkB}$ and PI3K/Akt/mTOR signalling pathways in neonatal mice," Canadian Journal of Physiology and Pharmacology, vol. 95, no. 12, pp. 1396-1405, 2017.

[64] J. B. Hoppe, K. Coradini, R. L. Frozza et al., "Free and nanoencapsulated curcumin suppress $\beta$-amyloid-induced cognitive impairments in rats: Involvement of BDNF and Akt/GSK-3 $\beta$ signaling pathway," Neurobiology of Learning and Memory, vol. 106, pp. 134-144, 2013.

[65] L. Tan, H. Yang, W. Pang et al., "Investigation on the Role of BDNF in the Benefits of Blueberry Extracts for the Improvement of Learning and Memory in Alzheimer's Disease Mouse Model," Journal of Alzheimer's Disease, vol. 56, no. 2, pp. 629640, 2017.

[66] N. S. El-Sayed and Y. Bayan, "Possible role of Resveratrol targeting Estradiol and Neprilysin pathways in Lipopolysaccharide model of Alzheimer disease," Advances in Experimental Medicine and Biology, vol. 822, pp. 107-118, 2015.

[67] X. Chang, C. Rong, Y. Chen et al., “(-)-Epigallocatechin-3gallate attenuates cognitive deterioration in Alzheimer's disease model mice by upregulating neprilysin expression," Experimental Cell Research, vol. 334, no. 1, pp. 136-145, 2015.

[68] N. Yamamoto, M. Shibata, R. Ishikuro et al., "Epigallocatechin gallate induces extracellular degradation of amyloid $\beta$-protein by increasing neprilysin secretion from astrocytes through activation of ERK and PI3K pathways," Neuroscience, vol. 362, pp. 70-78, 2017.

[69] S. Ayoub and M. F. Melzig, "Induction of neutral endopeptidase (NEP) activity of SK-N-SH cells by natural compounds from green tea," Journal of Pharmacy and Pharmacology, vol. 58, no. 4, pp. 495-501, 2006.

[70] S. L. Xu, R. C. Y. Choi, K. Y. Zhu et al., "Isorhamnetin, a flavonol aglycone from Ginkgo biloba L., induces neuronal differentiation of cultured PC12 cells: potentiating the effect of nerve growth factor," Evidence-Based Complementary and Alternative Medicine, vol. 2012, Article ID 278273, 11 pages, 2012.

[71] C. Moussa, M. Hebron, X. Huang et al., "Resveratrol regulates neuro-inflammation and induces adaptive immunity in Alzheimer's disease," Journal of Neuroinflammation, vol. 14, no. 1, article no. 1, 2017.
[72] L. Machova Urdzikova, J. Ruzicka, K. Karova et al., "A green tea polyphenol epigallocatechin-3-gallate enhances neuroregeneration after spinal cord injury by altering levels of inflammatory cytokines," Neuropharmacology, vol. 126, pp. 213-223, 2017.

[73] M.-M. Chen, Z.-Q. Yin, L.-Y. Zhang, and H. Liao, "Quercetin promotes neurite growth through enhancing intracellular cAMP level and GAP-43 expression," Chinese Journal of Natural Medicines, vol. 13, no. 9, pp. 667-672, 2015.

[74] D. Valenti, L. de Bari, D. de Rasmo et al., "The polyphenols resveratrol and epigallocatechin-3-gallate restore the severe impairment of mitochondria in hippocampal progenitor cells from a Down syndrome mouse model," Biochimica et Biophysica Acta (BBA) - Molecular Basis of Disease, vol. 1862, no. 6, pp. 1093-1104, 2016.

[75] G. P. Dias, G. Cocks, M. C. Do Nascimento Bevilaqua, A. E. Nardi, and S. Thuret, "Resveratrol: A Potential Hippocampal Plasticity Enhancer," Oxidative Medicine and Cellular Longevity, vol. 2016, Article ID 9651236, 2016.

[76] P. Taupin, "Apigenin and related compounds stimulate adult neurogenesis - Mars, Inc., the Salk Institute for Biological Studies: WO2008147483," Expert Opinion on Therapeutic Patents, vol. 19, no. 4, pp. 523-527, 2009.

[77] L. Liu, Q. Zhang, Y. Cai et al., "Resveratrol counteracts lipopolysaccharide-induced depressivelike behaviors via enhanced hippocampal neurogenesis," Oncotarget, vol. 7, no. 35, pp. 56045-56059, 2016.

[78] V. Kumar, A. Pandey, S. Jahan et al., "Differential responses of Trans-Resveratrol on proliferation of neural progenitor cells and aged rat hippocampal neurogenesis," Scientific Reports, vol. 6, 2016.

[79] S. K. Tiwari, S. Agarwal, B. Seth et al., "Curcumin-loaded nanoparticles potently induce adult neurogenesis and reverse cognitive deficits in Alzheimer's disease model via canonical Wnt/ $\beta$-catenin pathway," ACS Nano, vol. 8, no. 1, pp. 76-103, 2014.

[80] R. Wang, S. Tian, X. Yang, J. Liu, Y. Wang, and K. Sun, "Celecoxib-induced inhibition of neurogenesis in fetal frontal cortex is attenuated by curcumin via Wnt/ $\beta$-catenin pathway," Life Sciences, vol. 185, pp. 95-102, 2017.

[81] I.-S. Joe, S.-G. Jeong, and G.-W. Cho, "Resveratrol-induced SIRT1 activation promotes neuronal differentiation of human bone marrow mesenchymal stem cells," Neuroscience Letters, vol. 584, pp. 97-102, 2015.

[82] H. J. Lim, S. B. Shim, S. W. Jee et al., "Green tea catechin leads to global improvement among Alzheimer's disease-related phenotypes in NSE/hAPP-C105 Tg mice," The Journal of Nutritional Biochemistry, vol. 24, no. 7, pp. 1302-1313, 2013.

[83] S. K. Tiwari, S. Agarwal, A. Tripathi, and R. K. Chaturvedi, "Bisphenol-a mediated inhibition of hippocampal neurogenesis attenuated by curcumin via canonical Wnt pathway," Molecular Neurobiology, 2015.

[84] E. J. Gong, H. R. Park, M. E. Kim et al., "Morin attenuates tau hyperphosphorylation by inhibiting GSK $3 \beta$," Neurobiology of Disease, vol. 44, no. 2, pp. 223-230, 2011.

[85] Y. Wang, M. Li, X. Xu, M. Song, H. Tao, and Y. Bai, "Green tea epigallocatechin-3-gallate (EGCG) promotes neural progenitor cell proliferation and sonic hedgehog pathway activation during adult hippocampal neurogenesis," Molecular Nutrition \& Food Research, vol. 56, no. 8, pp. 1292-1303, 2012.

[86] P. Yu, L. Wang, F. Tang et al., "Resveratrol Pretreatment Decreases Ischemic Injury and Improves Neurological Function 
Via Sonic Hedgehog Signaling After Stroke in Rats," Molecular Neurobiology, vol. 54, no. 1, pp. 212-226, 2017.

[87] S.-G. Guo, C.-J. Wang, G. Zhao, and G.-Y. Li, "Role of Vitamin D in regulating the neural stem cells of mouse model with multiple sclerosis," European Review for Medical and Pharmacological Sciences, vol. 19, no. 21, pp. 4004-4011, 2015.

[88] J. Samanta, E. M. Grund, H. M. Silva, J. J. Lafaille, G. Fishell, and J. L. Salzer, "Inhibition of Glil mobilizes endogenous neural stem cells for remyelination," Nature, vol. 526, no. 7573, pp. 448452, 2015.

[89] J. S. Merzaban, J. Imitola, S. C. Starossom et al., "Cell surface glycan engineering of neural stem cells augments neurotropism and improves recovery in a murine model of multiple sclerosis," Glycobiology, vol. 25, no. 12, pp. 1392-1409, 2015.

[90] I. Michailidou, H. E. de Vries, E. M. Hol, and M. E. van Strien, "Activation of endogenous neural stem cells for multiple sclerosis therapy," Frontiers in Neuroscience, vol. 9, 2015.

[91] J. G. Weinger, W. C. Plaisted, S. M. Maciejewski, L. L. Lanier, C. M. Walsh, and T. E. Lane, "Activating receptor NKG2D targets RAE-1-expressing allogeneic neural precursor cells in a viral model of multiple sclerosis," Stem Cells, vol. 32, no. 10, pp. 26902701, 2014.

[92] M. L. Greenberg, J. G. Weinger, M. P. Matheu et al., “Twophoton imaging of remyelination of spinal cord axons by engrafted neural precursor cells in a viral model of multiple sclerosis," Proceedings of the National Acadamy of Sciences of the United States of America, vol. 111, no. 22, pp. E2349-E2355, 2014.

[93] S. Rasmussen, J. Imitola, A. Ayuso-Sacido et al., "Reversible neural stem cell niche dysfunction in a model of multiple sclerosis," Annals of Neurology, vol. 69, no. 5, pp. 878-891, 2011.

[94] E. Hoveizi, S. Tavakol, and S. Ebrahimi-Barough, "Neuroprotective Effect of Transplanted Neural Precursors Embedded on PLA/CS Scaffold in an Animal Model of Multiple Sclerosis," Molecular Neurobiology, vol. 51, no. 3, pp. 1334-1342, 2015.

[95] M. Cristofanilli, B. Cymring, A. Lu, H. Rosenthal, and S. A. Sadiq, "Cerebrospinal fluid derived from progressive multiple sclerosis patients promotes neuronal and oligodendroglial differentiation of human neural precursor cells in vitro," Neuroscience, vol. 250, pp. 614-621, 2013.

[96] H. A. Shirazi, J. Rasouli, B. Ciric, A. Rostami, and G.-X. Zhang, "1,25-Dihydroxyvitamin D3 enhances neural stem cell proliferation and oligodendrocyte differentiation," Experimental and Molecular Pathology, vol. 98, no. 2, pp. 240-245, 2015.

[97] M. M. Soundarapandian, V. Selvaraj, U.-G. Lo et al., "Zfp488 promotes oligodendrocyte differentiation of neural progenitor cells in adult mice after demyelination," Scientific Reports, vol. 1, article no. 2, 2011.

[98] M. A. Sherafat, M. Heibatollahi, S. Mongabadi, F. Moradi, M. Javan, and A. Ahmadiani, "Electromagnetic field stimulation potentiates endogenous myelin repair by recruiting subventricular neural stem cells in an experimental model of white matter demyelination," Journal of Molecular Neuroscience, vol. 48, no. 1, pp. 144-153, 2012.

[99] B. Zhou, J. M. Osinski, J. L. Mateo et al., "Loss of NFIX Transcription Factor Biases Postnatal Neural Stem/Progenitor Cells Toward Oligodendrogenesis," Stem Cells and Development, vol. 24, no. 18, pp. 2114-2126, 2015.

[100] E. C. Bunk, G. Ertaylan, F. Ortega et al., "Proxl Is Required for Oligodendrocyte Cell Identity in Adult Neural Stem Cells of the Subventricular Zone," Stem Cells, vol. 34, no. 8, pp. 2115-2129, 2016.
[101] G. J. Sun, Y. Zhou, S. Ito et al., "Latent tri-lineage potential of adult hippocampal neural stem cells revealed by Nf1 inactivation," Nature Neuroscience, vol. 18, no. 12, pp. 1722-1724, 2015.

[102] J. Vernerey, M. Macchi, K. Magalon, M. Cayre, and P. Durbec, "Ciliary neurotrophic factor controls progenitor migration during remyelination in the adult rodent brain," The Journal of Neuroscience, vol. 33, no. 7, pp. 3240-3250, 2013.

[103] S. Casarosa, C. Fode, and F. Guillemot, "Mash1 regulates neurogenesis in the ventral telencephalon," Development, vol. 126, no. 3, pp. 525-534, 1999.

[104] A. H. Crawford, R. B. Tripathi, W. D. Richardson, and R. J. M. Franklin, "Developmental Origin of Oligodendrocyte Lineage Cells Determines Response to Demyelination and Susceptibility to Age-Associated Functional Decline," Cell Reports, vol. 15, no. 4, pp. 761-773, 2016.

[105] E. E. Kelland, W. Gilmore, L. P. Weiner, and B. T. Lund, "The dual role of CXCL8 in human CNS stem cell function: Multipotent neural stem cell death and oligodendrocyte progenitor cell chemotaxis," Glia, vol. 59, no. 12, pp. 1864-1878, 2011.

[106] M. E. Cohen, N. Fainstein, I. Lavon, and T. Ben-Hur, "Signaling through three chemokine receptors triggers the migration of transplanted neural precursor cells in a model of multiple sclerosis," Stem Cell Research, vol. 13, no. 2, pp. 227-239, 2014.

[107] S. M. G. Braun, G.-A. Pilz, R. A. C. Machado et al., "Programming Hippocampal Neural Stem/Progenitor Cells into Oligodendrocytes Enhances Remyelination in the Adult Brain after Injury," Cell Reports, vol. 11, no. 11, pp. 1679-1685, 2015.

[108] D. S. Pedersen, P. M. Fredericia, M. O. Pedersen et al., "Metallic gold slows disease progression, reduces cell death and induces astrogliosis while simultaneously increasing stem cell responses in an EAE rat model of multiple sclerosis," Histochemistry and Cell Biology, vol. 138, no. 5, pp. 787-802, 2012.

[109] A. M. Stessin, D. B. Gursel, A. Schwartz et al., "FTY720, sphingosine 1-phosphate receptor modulator, selectively radioprotects hippocampal neural stem cells," Neuroscience Letters, vol. 516, no. 2, pp. 253-258, 2012.

[110] J. K. Huang and R. J. M. Franklin, "Regenerative medicine in multiple sclerosis: Identifying pharmacological targets of adult neural stem cell differentiation," Neurochemistry International, vol. 59, no. 3, pp. 329-332, 2011.

[111] S. Pazhoohan, L. Satarian, A.-A. Asghari et al., "Valproic acid attenuates disease symptoms and increases endogenous myelin repair by recruiting neural stem cells and oligodendrocyte progenitors in experimental autoimmune encephalomyelitis," Neurodegenerative Diseases, vol. 13, no. 1, pp. 45-52, 2013.

[112] Z. Li, K. Li, L. Zhu et al., "Inhibitory effect of IL-17 on neural stem cell proliferation and neural cell differentiation," $B M C$ Immunology, vol. 14, no. 1, article no. 20, 2013.

[113] O. Korvatska, J. B. Leverenz, S. Jayadev et al., "R47H variant of TREM2 associated with Alzheimer disease in a large late-onset family clinical, genetic, and neuropathological study," JAMA Neurology, vol. 72, no. 8, pp. 920-927, 2015.

[114] D. G. Murdock, Y. Bradford, N. Schnetz-Boutaud et al., "KIAA1462, a coronary artery disease associated gene, is a candidate gene for late onset Alzheimer disease in APOE carriers," PLoS ONE, vol. 8, no. 12, Article ID e82194, 2013.

[115] R. Scacchi, G. Gambina, G. Moretto, and R. M. Corbo, "P21 gene variation and late-onset Alzheimer's disease in the Italian population," Dementia and Geriatric Cognitive Disorders, vol. 35, no. 1-2, pp. 51-57, 2013.

[116] E. Louwersheimer, A. Ramirez, C. Cruchaga et al., "The influence of genetic variants in SORL1 gene on the manifestation of 
Alzheimer's disease," Neurobiology of Aging, vol. 36, no. 3, pp. 1605-e20, 2015.

[117] R. J. Kelleher and J. Shen, "Presenilin-1 mutations and Alzheimer's disease," Proceedings of the National Acadamy of Sciences of the United States of America, vol. 114, no. 4, pp. 629631, 2017.

[118] W. P. Esler and M. S. Wolfe, "A portrait of Alzheimer secretases-new features and familiar faces," Science, vol. 293, no. 5534, pp. 1449-1454, 2001.

[119] T. Wakabayashi and B. De Strooper, "Presenilins: Members of the $\gamma$-secretase quartets, but part-time soloists too," Physiology Journal, vol. 23, no. 4, pp. 194-204, 2008.

[120] S. E. Jones and C. Jomary, "Clusterin," The International Journal of Biochemistry \& Cell Biology, vol. 34, no. 5, pp. 427-431, 2002.

[121] A.-M. Lidström, N. Bogdanovic, C. Hesse, I. Volkman, P. Davidsson, and K. Blennow, "Clusterin (apolipoprotein J) protein levels are increased in hippocampus and in frontal cortex in Alzheimer's disease," Experimental Neurology, vol. 154, no. 2, pp. 511-521, 1998.

[122] M. E. Rosenberg and J. Silkensen, "Clusterin: Physiologic and pathophysiologic considerations," The International Journal of Biochemistry \& Cell Biology, vol. 27, no. 7, pp. 633-645, 1995.

[123] P. Holton, M. Ryten, M. Nalls et al., "Initial Assessment of the Pathogenic Mechanisms of the Recently Identified Alzheimer Risk Loci," Annals of Human Genetics, vol. 77, no. 2, pp. 85-105, 2013.

[124] W. S. Kim, H. Li, K. Ruberu et al., "Deletion of Abca7 increases cerebral amyloid- $\beta$ accumulation in the J20 mouse model of Alzheimer's disease," The Journal of Neuroscience, vol. 33, no. 10, pp. 4387-4394, 2013.

[125] A. Biffi, J. M. Shulman, J. M. Jagiella et al., "Genetic variation at CR1 increases risk of cerebral amyloid angiopathy," Neurology, vol. 78, no. 5, pp. 334-341, 2012.

[126] R. Khera and N. Das, "Complement Receptor 1: Disease associations and therapeutic implications," Molecular Immunology, vol. 46, no. 5, pp. 761-772, 2009.

[127] E. M. Bradshaw, L. B. Chibnik, B. T. Keenan et al., "CD33 Alzheimer's disease locus: altered monocyte function and amyloid biology," Nature Neuroscience, vol. 16, no. 7, pp. 848-850, 2013.

[128] H. Tateno, H. Li, M. J. Schur et al., "Distinct endocytic mechanisms of CD22 (Siglec-2) and Siglec-F reflect roles in cell signaling and innate immunity," Molecular and Cellular Biology, vol. 27, no. 16, pp. 5699-5710, 2007.

[129] C. M. Karch, A. T. Jeng, P. Nowotny, J. Cady, C. Cruchaga, and A. M. Goate, "Expression of Novel Alzheimer's Disease Risk Genes in Control and Alzheimer's Disease Brains," PLoS ONE, vol. 7, no. 11, Article ID e50976, 2012.

[130] J. Zuccolo, L. Deng, T. L. Unruh et al., "Expression of MS4A and TMEM176 genes in human B lymphocyte," Frontiers in Immunology, vol. 4, 2013.

[131] J. Chapuis, F. Hansmannel, M. Gistelinck et al., "Increased expression of BIN1 mediates Alzheimer genetic risk by modulating tau pathology," Molecular Psychiatry, vol. 18, no. 11, pp. 1225-1234, 2013.

[132] S. Pant, M. Sharma, K. Patel, S. Caplan, C. M. Carr, and B. D. Grant, "AMPH-1/Amphiphysin/Binl functions with RME1/Ehd1 in endocytic recycling," Nature Cell Biology, vol. 11, no. 12, pp. 1399-1410, 2009.

[133] M. S. Tan, J. T. Yu, and L. Tan, "Bridging integrator 1 (BIN1): form, function, and Alzheimer's disease," Trends in Molecular Medicine, vol. 19, no. 10, pp. 594-603, 2013.
[134] F. Liao, H. Jiang, S. Srivatsan et al., "Effects of CD2-associated protein deficiency on amyloid- $\beta$ in neuroblastoma cells and in an APP transgenic mouse model," Molecular Neurodegeneration, vol. 10, no. 1, article no. 12, 2015.

[135] P. Monzo, N. C. Gauthier, F. Keslair et al., "Clues to CD2associated protein involvement in cytokinesis," Molecular Biology of the Cell (MBoC), vol. 16, no. 6, pp. 2891-2902, 2005.

[136] D. Harold, R. Abraham, P. Hollingworth et al., "Erratum: Genome-wide association study identifies variants at CLU and PICALM associated with Alzheimer's disease," Nature Genetics, vol. 41, no. 10, p. 1156, 2009.

[137] Q. Xiao, S. Gil, P. Yan et al., "Role of Phosphatidylinositol Clathrin Assembly Lymphoid-Myeloid Leukemia (PICALM) in intracellular Amyloid Precursor Protein (APP) processing and amyloid plaque pathogenesis," The Journal of Biological Chemistry, vol. 287, no. 25, pp. 21279-21289, 2012.

[138] K.-O. Lai and N. Y. Ip, "Synapse development and plasticity: roles of ephrin/Eph receptor signaling," Current Opinion in Neurobiology, vol. 19, no. 3, pp. 275-283, 2009.

[139] A. C. Naj, G. Jun, G. W. Beecham et al., "Common variants at MS4A4/MS4A6E, CD2AP, CD33 and EPHA1 are associated with late-onset Alzheimer's disease," Nature Genetics, vol. 43, no. 5, pp. 436-441, 2011.

[140] J.-C. Lambert, C. A. Ibrahim-Verbaas, and D. Harold, "Metaanalysis of 74,046 individuals identifies 11 new susceptibility loci for Alzheimer's disease," Nature Genetics, vol. 45, no. 12, pp. 1452-1458, 2013.

[141] K. A. Alier and B. J. Morris, "Divergent regulation of Pyk2/CAK $\beta$ phosphorylation by $\mathrm{Ca} 2+$ and cAMP in the hippocampus," Biochimica et Biophysica Acta (BBA) - Molecular Cell Research, vol. 1745, no. 3, pp. 342-349, 2005.

[142] A. C. Kaufman, S. V. Salazar, L. T. Haas et al., "Fyn inhibition rescues established memory and synapse loss in Alzheimer mice," Annals of Neurology, vol. 77, no. 6, pp. 953-971, 2015.

[143] J. Han, P. Kraft, H. Nan et al., "A genome-wide association study identifies novel alleles associated with hair color and skin pigmentation," PLoS Genetics, vol. 4, no. 5, Article ID e1000074, 2008.

[144] H. Kajiho, K. Saito, K. Tsujita et al., "RIN3: A novel Rab5 GEF interacting with amphiphysin II involved in the early endocytic pathway," Journal of Cell Science, vol. 116, no. 20, pp. 4159-4168, 2003.

[145] A. T. Kraja, I. B. Borecki, M. Y. Tsai et al., "Genetic analysis of 16 NMR-lipoprotein fractions in humans, the GOLDN study," Lipids, vol. 48, no. 2, pp. 155-165, 2013.

[146] M. Larsson, D. L. Duffy, G. Zhu et al., "GWAS findings for human iris patterns: Associations with variants in genes that influence normal neuronal pattern development," American Journal of Human Genetics, vol. 89, no. 2, pp. 334-343, 2011.

[147] L. Yu, L. B. Chibnik, G. P. Srivastava et al., "Association of brain DNA Methylation in SORL1, ABCA7, HLA-DRB5, SLC24A4, and BIN1 with pathological diagnosis of Alzheimer disease," JAMA Neurology, vol. 72, no. 1, pp. 15-24, 2015.

[148] J. Suh, S. Choi, D. M. Romano et al., "ADAM10 Missense Mutations Potentiate $\beta$-Amyloid Accumulation by Impairing Prodomain Chaperone Function," Neuron, vol. 80, no. 2, pp. 385-401, 2013.

[149] C. Cruchaga, C. M. Karch, and S. C. Jin, "Rare coding variants in the phospholipase D3 gene confer risk for Alzheimer's disease," Nature, vol. 505, no. 7484, pp. 550-554, 2014. 
[150] M. Osisami, W. Ali, and M. A. Frohman, "A role for phospholipase D3 in myotube formation," PLoS ONE, vol. 7, no. 3, Article ID e33341, 2012.

[151] J.-I. Satoh, Y. Kino, Y. Yamamoto et al., "PLD3 is accumulated on neuritic plaques in Alzheimer's disease brains," Alzheimer's Research \& Therapy, vol. 6, no. 9, 2014.

[152] M. K. Wetzel-Smith, J. Hunkapiller, T. R. Bhangale et al., "A rare mutation in UNC5C predisposes to late-onset Alzheimer's disease and increases neuronal cell death," Nature Medicine, vol. 20, no. 12, pp. 1452-1457, 2014.

[153] A. Campbell, "The potential role of aluminium in Alzheimer's disease," Nephrology Dialysis Transplantation, vol. 17, supplement 2, pp. 17-20, 2002.

[154] M. Kawahara and M. Kato-Negishi, "Link between aluminum and the pathogenesis of Alzheimer's disease: the integration of the aluminum and amyloid cascade hypotheses," International Journal of Alzheimer's Disease, vol. 2011, Article ID 276393, 17 pages, 2011.

[155] M. A. Deibel, W. D. Ehmann, and W. R. Markesbery, "Copper, iron, and zinc imbalances in severely degenerated brain regions in Alzheimer's disease: possible relation to oxidative stress," Journal of the Neurological Sciences, vol. 143, no. 1-2, pp. 137-142, 1996.

[156] I. Singh, A. P. Sagare, M. Coma et al., "Low levels of copper disrupt brain amyloid- $\beta$ homeostasis by altering its production and clearance," Proceedings of the National Acadamy of Sciences of the United States of America, vol. 110, no. 36, pp. 14771-14776, 2013.

[157] D. L. Sparks and B. G. Schreurs, "Trace amounts of copper in water induce $\beta$-amyloid plaques and learning deficits in a rabbit model of Alzheimer's disease," Proceedings of the National Acadamy of Sciences of the United States of America, vol. 100, no. 19, pp. 11065-11069, 2003.

[158] R. Squitti and R. Polimanti, "Copper phenotype in Alzheimer's disease: Dissecting the pathway," American Journal of Neurodegenerative Diseases, vol. 2, no. 2, pp. 46-56, 2013.

[159] E. House, J. Collingwood, A. Khan, O. Korchazkina, G. Berthon, and C. Exley, "Aluminium, iron, zinc and copper Influence the in vitro formation of amyloid fibrils of $A \beta 42$ in a manner which may have consequences for metal chelation therapy in Alzheimer's disease," Journal of Alzheimer's Disease, vol. 6, no. 3, pp. 291-301, 2004.

[160] E. P. Raven, P. H. Lu, T. A. Tishler, P. Heydari, and G. Bartzokis, "Increased iron levels and decreased tissue integrity in hippocampus of Alzheimer's disease detected in vivo with magnetic resonance imaging," Journal of Alzheimer's Disease, vol. 37, no. 1, pp. 127-136, 2013.

[161] M. R. Basha, W. Wei, S. A. Bakheet et al., "The fetal basis of amyloidogenesis: Exposure to lead and latent overexpression of amyloid precursor protein and $\beta$-amyloid in the aging brain," The Journal of Neuroscience, vol. 25, no. 4, pp. 823-829, 2005.

[162] M. G. Weisskopf, S. P. Proctor, R. O. Wright et al., "Cumulative lead exposure and cognitive performance among elderly men," Epidemiology, vol. 18, no. 1, pp. 59-66, 2007.

[163] L.-F. Jiang, T.-M. Yao, Z.-L. Zhu, C. Wang, and L.-N. Ji, "Impacts of $\mathrm{Cd}(\mathrm{II})$ on the conformation and self-aggregation of Alzheimer's tau fragment corresponding to the third repeat of microtubule-binding domain," Biochimica et Biophysica Acta (BBA) - Proteins and Proteomics, vol. 1774, no. 11, pp. 1414-1421, 2007.

[164] J. M. Mates, J. A. Segura, F. J. Alonso, and J. Marquez, "Roles of dioxins and heavy metals in cancer and neurological diseases using ROS-mediated mechanisms," Free Radical Biology \& Medicine, vol. 49, pp. 1328-1341, 2010.

[165] C. C. W. Leong, N. I. Syed, and F. L. Lorscheider, "Retrograde degeneration of neurite membrane structural integrity of nerve growth cones following in vitro exposure to mercury," NeuroReport, vol. 12, no. 4, pp. 733-737, 2001.

[166] J. Mutter, A. Curth, J. Naumann, R. Deth, and H. Walach, "Does inorganic mercury play a role in Alzheimer's disease? A systematic review and an integrated molecular mechanism," Journal of Alzheimer's Disease, vol. 22, no. 2, pp. 357-374, 2010.

[167] G. Gong and S. E. O'Bryant, "The arsenic exposure hypothesis for Alzheimer disease," Alzheimer Disease \& Associated Disorders, vol. 24, no. 4, pp. 311-316, 2010.

[168] A. O. Estevez, C. L. Mueller, K. L. Morgan et al., "Selenium induces cholinergic motor neuron degeneration in Caenorhabditis elegans," NeuroToxicology, vol. 33, no. 5, pp. 1021-1032, 2012.

[169] N. K. Singh, N. Chhillar, B. D. Banerjee, K. Bala, M. Basu, and M. Mustafa, "Organochlorine pesticide levels and risk of Alzheimer's disease in north Indian population," Human \& Experimental Toxicology, vol. 32, no. 1, pp. 24-30, 2013.

[170] A. V. Terry Jr., "Functional consequences of repeated organophosphate exposure: potential non-cholinergic mechanisms," Pharmacology \& Therapeutics, vol. 134, no. 3, pp. 355-365, 2012.

[171] D. Mishra, S. K. Tiwari, S. Agarwal, V. P. Sharma, and R. K. Chaturvedi, "Prenatal carbofuran exposure inhibits hippocampal neurogenesis and causes learning and memory deficits in offspring," Toxicological Sciences, vol. 127, no. 1, pp. 84-100, 2012.

[172] B. Seth, A. Yadav, S. Agarwal, S. K. Tiwari, and R. K. Chaturvedi, "Inhibition of the transforming growth factor-/SMAD cascade mitigates the anti-neurogenic effects of the carbamate pesticide carbofuran," The Journal of Biological Chemistry, vol. 292, no. 47, pp. 19423-19440, 2017.

[173] C. J. G. M. Smulders, T. J. H. Bueters, R. G. D. M. Van Kleef, and H. P. M. Vijverberg, "Selective effects of carbamate pesticides on rat neuronal nicotinic acetylcholine receptors and rat brain acetylcholinesterase," Toxicology and Applied Pharmacology, vol. 193, no. 2, pp. 139-146, 2003.

[174] L. Chen, S.-E. Yoo, R. Na, Y. Liu, and Q. Ran, "Cognitive impairment and increased $\mathrm{A} \beta$ levels induced by paraquat exposure are attenuated by enhanced removal of mitochondrial $\mathrm{H}_{2} \mathrm{O}_{2}$," Neurobiology of Aging, vol. 33, no. 2, pp. 432.e15-432.e26, 2012.

[175] X. Zhu, G. Perry, P. I. Moreira et al., "Mitochondrial abnormalities and oxidative imbalance in Alzheimer disease," Journal of Alzheimer's Disease, vol. 9, no. 2, pp. 147-153, 2006.

[176] A. Limon, J. M. Reyes-Ruiz, and R. Miledi, "Loss of functional GABA A receptors in the Alzheimer diseased brain," Proceedings of the National Acadamy of Sciences of the United States of America, vol. 109, no. 25, pp. 10071-10076, 2012.

[177] N.-N. Chen, D.-J. Luo, X.-Q. Yao et al., "Pesticides induce spatial memory deficits with synaptic impairments and an imbalanced tau phosphorylation in rats," Journal of Alzheimer's Disease, vol. 30, no. 3, pp. 585-594, 2012.

[178] F. Al-Mousa and F. Michelangeli, "Some commonly used brominated flame retardants cause $\mathrm{Ca}^{2+}$-atpase inhibition, betaamyloid peptide release and apoptosis in SH-SY5Y neuronal cells," PLoS ONE, vol. 7, no. 4, Article ID e33059, 2012.

[179] H. Viberg, A. Fredriksson, and P. Eriksson, "Neonatal exposure to polybrominated diphenyl ether (PBDE 153) disrupts spontaneous behaviour, impairs learning and memory, and decreases 
hippocampal cholinergic receptors in adult mice," Toxicology and Applied Pharmacology, vol. 192, no. 2, pp. 95-106, 2003.

[180] V. L. Trudeau, S. Chiu, S. W. Kennedy, and R. J. Brooks, "Octylphenol (OP) alters the expression of members of the amyloid protein family in the hypothalamus of the snapping turtle, Chelydra serpentina serpentina," Environmental Health Perspectives, vol. 110, no. 3, pp. 269-275, 2002.

[181] D. Sul, H.-S. Kim, E.-K. Cho et al., "2,3,7,8-TCDD neurotoxicity in neuroblastoma cells is caused by increased oxidative stress, intracellular calcium levels, and tau phosphorylation," Toxicology, vol. 255, no. 1-2, pp. 65-71, 2009.

[182] S. Agarwal, S. K. Tiwari, B. Seth et al., "Activation of autophagic flux against xenoestrogen bisphenol-A-induced hippocampal neurodegeneration via AMP kinase (AMPK)/mammalian target of rapamycin (mTOR) pathways," The Journal of Biological Chemistry, vol. 290, no. 34, pp. 21163-21184, 2015.

[183] S. Agarwal, A. Yadav, S. K. Tiwari et al., "Dynamin-related protein 1 inhibition mitigates bisphenol A-mediated alterations in mitochondrial dynamics and neural stem cell proliferation and differentiation," The Journal of Biological Chemistry, vol. 291, no. 31, pp. 15923-15939, 2016.

[184] B. Borrell, “Toxicology: The big test for bisphenol A," Nature, vol. 464, no. 7292, pp. 1122-1124, 2010.

[185] T. Hajszan and C. Leranth, "Bisphenol A interferes with synaptic remodeling," Frontiers in Neuroendocrinology, vol. 31, no. 4, pp. 519-530, 2010.

[186] S. Singh and S. S.-L. Li, "Epigenetic effects of environmental chemicals bisphenol A and phthalates," International Journal of Molecular Sciences, vol. 13, no. 8, pp. 10143-10153, 2012.

[187] S. K. Tiwari, S. Agarwal, L. K. S. Chauhan, V. N. Mishra, and R. K. Chaturvedi, "Bisphenol-A Impairs Myelination Potential During Development in the Hippocampus of the Rat Brain," Molecular Neurobiology, vol. 51, no. 3, pp. 1395-1416, 2015.

[188] S. K. Tiwari, S. Agarwal, B. Seth et al., "Inhibitory Effects of Bisphenol-A on Neural Stem Cells Proliferation and Differentiation in the Rat Brain Are Dependent on Wnt/ $\beta$-Catenin Pathway," Molecular Neurobiology, vol. 52, no. 3, pp. 1735-1757, 2015.

[189] J. Chen, K. C. Ahn, and N. A. Gee, "Triclocarban enhances testosterone action: a new type of endocrine disruptor?" Endocrinology, vol. 149, no. 3, pp. 1173-1179, 2008.

[190] K. C. Ahn, B. Zhao, J. Chen et al., "In vitro biologic activities of the antimicrobials triclocarban, its analogs, and triclosan in bioassay screens: Receptor-based bioassay screens," Environmental Health Perspectives, vol. 116, no. 9, pp. 1203-1210, 2008.

[191] M. Yegambaram, B. Manivannan, T. G. Beach, and R. U. Halden, "Role of environmental contaminants in the etiology of Alzheimer's disease: a review," Current Alzheimer Research, vol. 12, no. 2, pp. 116-146, 2015.

[192] C. Glabe, "Intracellular mechanisms of amyloid accumulation and pathogenesis in Alzheimer's disease," Journal of Molecular Neuroscience, vol. 17, no. 2, pp. 137-145, 2001.

[193] S. Oddo, A. Caccamo, J. D. Shepherd et al., "Triple-transgenic model of Alzheimer's Disease with plaques and tangles: intracellular A $\beta$ and synaptic dysfunction," Neuron, vol. 39, no. 3, pp. 409-421, 2003.

[194] J. W. Lustbader, M. Cirilli, C. Lin et al., "ABAD Directly Links A $\beta$ to Mitochondrial Toxicity in Alzheimer's Disease," Science, vol. 304, no. 5669, pp. 448-452, 2004.
[195] N. Canu, L. Dus, C. Barbato et al., "Tau cleavage and dephosphorylation in cerebellar granule neurons undergoing apoptosis," The Journal of Neuroscience, vol. 18, no. 18, pp. 7061-7074, 1998.

[196] G. V. W. Johnson, R. S. Jope, and L. I. Binder, "Proteolysis of tau by calpain," Biochemical and Biophysical Research Communications, vol. 163, no. 3, pp. 1505-1511, 1989.

[197] M. Malik, M. D. Fenko, A. M. Sheikh, G. Wen, and X. Li, "A novel approach for characterization of cathepsin $\mathrm{D}$ protease and its effect on tau and $\beta$-amyloid proteins," Neurochemical Research, vol. 36, no. 5, pp. 754-760, 2011.

[198] E. Vasileiou, R. M. Montero, C. M. Turner, and G. Vergoulas, "P2X7 receptor at the heart of disease," Hippokratia, vol. 14, no. 3, pp. 155-163, 2010.

[199] X. Sun, Y. Wu, B. Chen et al., "Regulator of calcineurin 1 (RCAN1) facilitates neuronal apoptosis through caspase-3 activation," The Journal of Biological Chemistry, vol. 286, no. 11, pp. 9049-9062, 2011.

[200] C. Li, R. Zhao, K. Gao et al., "Astrocytes: implications for neuroinflammatory pathogenesis of Alzheimer's disease," Current Alzheimer Research, vol. 8, no. 1, pp. 67-80, 2011.

[201] A. Copani, D. Melchiorri, A. Caricasole et al., " $\beta$-amyloidInduced Synthesis of the Ganglioside Gd3 Is a Requisite for Cell Cycle Reactivation and Apoptosis in Neurons," The Journal of Neuroscience, vol. 22, no. 10, pp. 3963-3968, 2002.

[202] K. Nakayama, T. Ohkawara, M. Hiratochi, C.-S. Koh, and H. Nagase, "The intracellular domain of amyloid precursor protein induces neuron-specific apoptosis," Neuroscience Letters, vol. 444, no. 2, pp. 127-131, 2008.

[203] Y. Xu, H.-S. Kim, Y. Joo et al., "Intracellular domains of amyloid precursor-like protein 2 interact with $\mathrm{CP} 2$ transcription factor in the nucleus and induce glycogen synthase kinase- $3 \beta$ expression," Cell Death \& Differentiation, vol. 14, no. 1, pp. 79-91, 2007.

[204] R. V. Rao, H. M. Ellerby, and D. E. Bredesen, "Coupling endoplasmic reticulum stress to the cell death program," Cell Death \& Differentiation, vol. 11, no. 4, pp. 372-380, 2004.

[205] J. Hitomi, T. Katayama, Y. Eguchi et al., "Involvement of caspase- 4 in endoplasmic reticulum stress-induced apoptosis and A $\beta$-induced cell death," The Journal of Cell Biology, vol. 165, no. 3, pp. 347-356, 2004.

[206] D. C. Rubinsztein, M. DiFiglia, N. Heintz et al., "Autophagy and its possible roles in nervous system diseases, damage and repair.," Autophagy, vol. 1, no. 1, pp. 11-22, 2005.

[207] Y. Omata, Y.-M. Lim, Y. Akao, and L. Tsuda, "Age-induced reduction of autophagy-related gene expression is associated with onset of Alzheimer's disease," American Journal of Neurodegenerative Diseases, vol. 3, no. 3, pp. 134-142, 2014.

[208] P. Nilsson, M. Sekiguchi, and T. Akagi, "Autophagy-related protein 7 deficiency in amyloid $\beta(A \beta)$ precursor protein transgenic mice decreases $A \beta$ in the multivesicular bodies and induces $A \beta$ accumulation in the Golgi," The American Journal of Pathology, vol. 185, no. 2, pp. 305-313, 2015.

[209] S. M. Son, E. S. Jung, H. J. Shin, J. Byun, and I. Mook-Jung, "A $\beta$ induced formation of autophagosomes is mediated by RAGECaMKK $\beta$-AMPK signaling," Neurobiology of Aging, vol. 33, no. 5, pp. 1006.e11-1006.e23, 2012.

[210] F. Lim, F. Hernández, J. J. Lucas, P. Gómez-Ramos, M. A. Morán, and J. Ávila, "FTDP-17 mutations in tau transgenic mice provoke lysosomal abnormalities and tau filaments in forebrain," Molecular and Cellular Neuroscience, vol. 18, no. 6, pp. 702-714, 2001. 
[211] W.-L. Lin, J. Lewis, S.-H. Yen, M. Hutton, and D. W. Dickson, "Ultrastructural neuronal pathology in transgenic mice expressing mutant (P301L) human tau," Journal of Neurocytology, vol. 32, no. 9, pp. 1091-1105, 2003.

[212] C. Jo, S. Gundemir, S. Pritchard, Y. N. Jin, I. Rahman, and G. V. W. Johnson, "Nrf2 reduces levels of phosphorylated tau protein by inducing autophagy adaptor protein NDP52," Nature Communications, vol. 5, article 3496, 2014.

[213] P. A. Jaeger, F. Pickford, C.-H. Sun, K. M. Lucin, E. Masliah, and T. Wyss-Coray, "Regulation of amyloid precursor protein processing by the beclin 1 complex," PLoS ONE, vol. 5, no. 6, Article ID e11102, 2010.

[214] F. Pickford, E. Masliah, M. Britschgi et al., "The autophagyrelated protein beclin 1 shows reduced expression in early Alzheimer disease and regulates amyloid $\beta$ accumulation in mice," The Journal of Clinical Investigation, vol. 118, no. 6, pp. 2190-2199, 2008.

[215] A. Salminen, K. Kaarniranta, A. Kauppinen et al., "Impaired autophagy and APP processing in Alzheimer's disease: the potential role of Beclin 1 interactome," Progress in Neurobiology, vol. 106-107, pp. 33-54, 2013.

[216] Z. Cai and L. J. Yan, "Rapamycin, autophagy, and Alzheimer's disease," Journal of Biochemical and Pharmacological Research, vol. 1, no. 2, pp. 84-90, 2013.

[217] P. Spilman, N. Podlutskaya, M. J. Hart et al., "Inhibition of mTOR by rapamycin abolishes cognitive deficits and reduces amyloid-beta levels in a mouse model of Alzheimer's disease," PLoS ONE, vol. 5, no. 4, Article ID e9979, 2010.

[218] W. Gsell, R. Conrad, M. Hickethier et al., "Decreased Catalase Activity but Unchanged Superoxide Dismutase Activity in Brains of Patients with Dementia of Alzheimer Type," Journal of Neurochemistry, vol. 64, no. 3, pp. 1216-1223, 1995.

[219] L. M. Sayre, D. A. Zelasko, P. L. R. Harris, G. Perry, R. G. Salomon, and M. A. Smith, "4-Hydroxynonenal-derived advanced lipid peroxidation end products are increased in Alzheimer's disease," Journal of Neurochemistry, vol. 68, no. 5, pp. 2092-2097, 1997.

[220] S. Arlt, U. Beisiegel, and A. Kontush, "Lipid peroxidation in neurodegeneration: new insights into Alzheimer's disease," Current Opinion in Lipidology, vol. 13, no. 3, pp. 289-294, 2002.

[221] R. J. Mark, M. A. Lovell, W. R. Markesbery, K. Uchida, and M. P. Mattson, "A role for 4-hydroxynonenal, an aldehydic product of lipid peroxidation, in disruption of ion homeostasis and neuronal death induced by amyloid $\beta$-peptide," Journal of Neurochemistry, vol. 68, no. 1, pp. 255-264, 1997.

[222] W. R. Markesbery and M. A. Lovell, "Four-hydroxynonenal, a product of lipid peroxidation, is increased in the brain in Alzheimer's disease," Neurobiology of Aging, vol. 19, no. 1, pp. 3336, 1998.

[223] M. L. Selley, D. R. Close, and S. E. Stern, "The effect of increased concentrations of homocysteine on the concentration of (E)4-hydroxy-2-nonenal in the plasma and cerebrospinal fluid of patients with Alzheimer's disease," Neurobiology of Aging, vol. 23, no. 3, pp. 383-388, 2002.

[224] M. A. Lovell, S. P. Gabbita, and W. R. Markesbery, "Increased DNA oxidation and decreased levels of repair products in Alzheimer's disease ventricular CSF," Journal of Neurochemistry, vol. 72, no. 2, pp. 771-776, 1999.

[225] P. Mecocci, U. MacGarvey, and M. F. Beal, "Oxidative damage to mitochondrial DNA is increased in Alzheimer's disease," Annals of Neurology, vol. 36, no. 5, pp. 747-751, 1994.
[226] A. Nunomura, G. Perry, G. Aliev et al., "Oxidative damage is the earliest event in Alzheimer disease," Journal of Neuropathology \& Experimental Neurology, vol. 60, no. 8, pp. 759-767, 2001.

[227] A. Nunomura, G. Perry, M. A. Pappolla et al., "RNA oxidation is a prominent feature of vulnerable neurons in Alzheimer's disease," The Journal of Neuroscience, vol. 19, no. 6, pp. 1959$1964,1999$.

[228] G. Münch, A. M. Cunningham, P. Riederer, and E. Braak, "Advanced glycation endproducts are associated with Hirano bodies in Alzheimer's disease," Brain Research, vol. 796, no. 12, pp. 307-310, 1998.

[229] R. Castellani, K. Hirai, G. Aliev et al., "Role of mitochondrial dysfunction in Alzheimer's disease," Journal of Neuroscience Research, vol. 70, no. 3, pp. 357-360, 2002.

[230] R. K. Chaturvedi and M. F. Beal, "Mitochondrial approaches for neuroprotection," Annals of the New York Academy of Sciences, vol. 1147, pp. 395-412, 2008.

[231] K. Hirai, G. Aliev, A. Nunomura et al., "Mitochondrial abnormalities in Alzheimer's disease," The Journal of Neuroscience, vol. 21, no. 9, pp. 3017-3023, 2001.

[232] S. J. Baloyannis, "Dendritic pathology in Alzheimer's disease," Journal of the Neurological Sciences, vol. 283, no. 1-2, pp. 153-157, 2009.

[233] R. K. Chaturvedi and M. Flint Beal, "Mitochondrial diseases of the brain," Free Radical Biology \& Medicine, vol. 63, pp. 1-29, 2013.

[234] G. Aliev, D. Seyidova, M. L. Neal et al., "Atherosclerotic lesions and mitochondria DNA deletions in brain microvessels as a central target for the development of human $\mathrm{AD}$ and $\mathrm{AD}$-like pathology in aged transgenic mice," Annals of the New York Academy of Sciences, vol. 977, pp. 45-64, 2002.

[235] A. Aliyev, S. G. Chen, D. Seyidova et al., "Mitochondria DNA deletions in atherosclerotic hypoperfused brain microvessels as a primary target for the development of Alzheimer's disease," Journal of the Neurological Sciences, vol. 229-230, pp. 285-292, 2005.

[236] H. K. Anandatheerthavarada, G. Biswas, M. Robin, and N. G. Avadhani, "Mitochondrial targeting and a novel transmembrane arrest of Alzheimer's amyloid precursor protein impairs mitochondrial function in neuronal cells," The Journal of Cell Biology, vol. 161, no. 1, pp. 41-54, 2003.

[237] R. Resende, P. I. Moreira, T. Proença et al., "Brain oxidative stress in a triple-transgenic mouse model of Alzheimer disease," Free Radical Biology \& Medicine, vol. 44, no. 12, pp. 2051-2057, 2008.

[238] C. A. Hansson, S. Frykman, M. R. Farmery et al., "Nicastrin, presenilin, APH-1, and PEN-2 form active $\gamma$-secretase complexes in mitochondria," The Journal of Biological Chemistry, vol. 279, no. 49, pp. 51654-51660, 2004.

[239] X. Wang, B. Su, H. Fujioka, and X. Zhu, "Dynamin-like protein 1 reduction underlies mitochondrial morphology and distribution abnormalities in fibroblasts from sporadic Alzheimer's disease patients," The American Journal of Pathology, vol. 173, no. 2, pp. 470-482, 2008.

[240] X. Wang, B. Su, S. L. Siedlak et al., "Amyloid- $\beta$ overproduction causes abnormal mitochondrial dynamics via differential modulation of mitochondrial fission/fusion proteins," Proceedings of the National Acadamy of Sciences of the United States of America, vol. 105, no. 49, pp. 19318-19323, 2008.

[241] P. I. Moreira, M. S. Santos, A. Moreno, and C. Oliveira, "Amyloid $\beta$-peptide promotes permeability transition pore in 
brain mitochondria," Bioscience Reports, vol. 21, no. 6, pp. 789800, 2001.

[242] P. I. Moreira, M. S. Santos, A. Moreno, A. C. Rego, and C. Oliveira, "Effect of amyloid $\beta$-peptide on permeability transition pore: A comparative study," Journal of Neuroscience Research, vol. 69, no. 2, pp. 257-267, 2002.

[243] C. Pereira, M. S. Santos, and C. Oliveira, "Mitochondrial function impairment induced by amyloid $\beta$-peptide on PC12 cells," NeuroReport, vol. 9, no. 8, pp. 1749-1755, 1998.

[244] R. Guerreiro, A. Wojtas, J. Bras et al., "TREM2 variants in Alzheimer's disease," The New England Journal of Medicine, vol. 368, no. 2, pp. 117-127, 2013.

[245] T. Jonsson, H. Stefansson, and S. Steinberg, "Variant of TREM2 associated with the risk of Alzheimer's disease," The New England Journal of Medicine, vol. 368, pp. 107-116, 2013.

[246] J. B. El Khoury, K. J. Moore, T. K. Means et al., “CD36 mediates the innate host response to $\beta$-amyloid," The Journal of Experimental Medicine, vol. 197, no. 12, pp. 1657-1666, 2003.

[247] C. R. Stewart, L. M. Stuart, K. Wilkinson et al., "CD36 ligands promote sterile inflammation through assembly of a Toll-like receptor 4 and 6 heterodimer," Nature Immunology, vol. 11, no. 2, pp. 155-161, 2010.

[248] H. Fillit, W. Ding, L. Buee et al., "Elevated circulating tumor necrosis factor levels in Alzheimer's disease," Neuroscience Letters, vol. 129, no. 2, pp. 318-320, 1991.

[249] W. S. T. Griffin, L. C. Stanley, C. Ling et al., "Brain interleukin 1 and S-100 immunoreactivity are elevated in Down syndrome and Alzheimer disease," Proceedings of the National Acadamy of Sciences of the United States of America, vol. 86, no. 19, pp. 76117615, 1989.

[250] N. S. Patel, D. Paris, V. Mathura, A. N. Quadros, F. C. Crawford, and M. J. Mullan, "Inflammatory cytokine levels correlate with amyloid load in transgenic mouse models of Alzheimer's disease," Journal of Neuroinflammation, vol. 2, no. 1, article 9, 2005.

[251] J. Vom Berg, S. Prokop, K. R. Miller et al., "Inhibition of IL12/IL-23 signaling reduces Alzheimer's diseasea-like pathology and cognitive decline," Nature Medicine, vol. 18, no. 12, pp. 18121819, 2012.

[252] S. E. Hickman, E. K. Allison, and J. El Khoury, "Microglial dysfunction and defective $\beta$-amyloid clearance pathways in aging Alzheimer's disease mice," The Journal of Neuroscience, vol. 28, no. 33, pp. 8354-8360, 2008.

[253] J. K. Harrison, Y. Jiang, S. Chen et al., "Role for neuronally derived fractalkine in mediating interactions between neurons and CX3CR1-expressing microglia," Proceedings of the National Acadamy of Sciences of the United States of America, vol. 95, no. 18, pp. 10896-10901, 1998.

[254] S. Lee, N. H. Varvel, M. E. Konerth et al., "CX3CR1 deficiency alters microglial activation and reduces beta-amyloid deposition in two Alzheimer's disease mouse models," The American Journal of Pathology, vol. 177, no. 5, pp. 2549-2562, 2010.

[255] D. G. Walker, J. E. Dalsing-Hernandez, N. A. Campbell, and L.F. Lue, "Decreased expression of CD200 and CD200 receptor in Alzheimer's disease: A potential mechanism leading to chronic inflammation," Experimental Neurology, vol. 215, no. 1, pp. 5-19, 2009.

[256] L.-B. Yang, R. Li, S. Meri, J. Rogers, and Y. Shen, "Deficiency of complement defense protein CD59 may contribute to neurodegeneration in Alzheimer's disease," The Journal of Neuroscience, vol. 20, no. 20, pp. 7505-7509, 2000.
[257] V. Vukic, D. Callaghan, D. Walker et al., "Expression of inflammatory genes induced by beta-amyloid peptides in human brain endothelial cells and in Alzheimer's brain is mediated by the JNK-AP1 signaling pathway," Neurobiology of Disease, vol. 34, no. 1, pp. 95-106, 2009.

[258] G. C. Deluca, R. Alterman, J. L. Martin et al., "Casting light on multiple sclerosis heterogeneity: the role of HLA-DRB1 on spinal cord pathology," Brain, vol. 136, no. 4, pp. 1025-1034, 2013.

[259] D. A. Hafler, A. Compston, S. Sawcer et al., "Risk alleles for multiple sclerosis identified by a genomewide study," The New England Journal of Medicine, vol. 357, no. 9, pp. 851-862, 2007.

[260] S. E. Baranzini, J. Wang, R. A. Gibson et al., "Genome-wide association analysis of susceptibility and clinical phenotype in multiple sclerosis," Human Molecular Genetics, vol. 18, no. 4, pp. 767-778, 2009.

[261] F. B. S. Briggs, X. Shao, B. A. Goldstein, J. R. Oksenberg, L. F. Barcellos, and P. L. De Jager, "Genome-wide association study of severity in multiple sclerosis," Genes \& Immunity, vol. 12, no. 8, pp. 615-625, 2011.

[262] L. Haider, M. T. Fischer, J. M. Frischer et al., "Oxidative damage in multiple sclerosis lesions," Brain, vol. 134, no. 7, pp. 1914-1924, 2011.

[263] I. Nikić, D. Merkler, C. Sorbara et al., "A reversible form of axon damage in experimental autoimmune encephalomyelitis and multiple sclerosis," Nature Medicine, vol. 17, no. 4, pp. 495499, 2011.

[264] T. Zeis, A. Probst, A. J. Steck, C. Stadelmann, W. Brück, and N. Schaeren-Wiemers, "Molecular changes in white matter adjacent to an active demyelinating lesion in early multiple sclerosis: molecular changes in MS periplaque white matter," Brain Pathology, vol. 19, no. 3, pp. 459-466, 2009.

[265] M. T. Fischer, R. Sharma, J. L. Lim et al., "NADPH oxidase expression in active multiple sclerosis lesions in relation to oxidative tissue damage and mitochondrial injury," Brain, vol. 135, no. 3, pp. 886-899, 2012.

[266] S. Hametner, I. Wimmer, L. Haider, S. Pfeifenbring, W. Brück, and H. Lassmann, "Iron and neurodegeneration in the multiple sclerosis brain," Annals of Neurology, vol. 74, no. 6, pp. 848-861, 2013.

[267] K. I. Rathore, B. J. Kerr, A. Redensek et al., "Ceruloplasmin protects injured spinal cord from iron-mediated oxidative damage," The Journal of Neuroscience, vol. 28, no. 48, pp. 1273612747, 2008.

[268] T. W. Kensler, N. Wakabayashi, and S. Biswal, "Cell survival responses to environmental stresses via the Keap1-Nrf2-ARE pathway," Annual Review of Pharmacology and Toxicology, vol. 47, pp. 89-116, 2007.

[269] J. van Horssen, G. Schreibelt, J. Drexhage et al., "Severe oxidative damage in multiple sclerosis lesions coincides with enhanced antioxidant enzyme expression," Free Radical Biology \& Medicine, vol. 45, no. 12, pp. 1729-1737, 2008.

[270] R. A. Linker, D.-H. Lee, S. Ryan et al., "Fumaric acid esters exert neuroprotective effects in neuroinflammation via activation of the Nrf2 antioxidant pathway," Brain, vol. 134, no. 3, pp. 678692, 2011.

[271] J. Y. Kim, S. Shen, K. Dietz et al., "HDAC1 nuclear export induced by pathological conditions is essential for the onset of axonal damage," Nature Neuroscience, vol. 13, no. 2, pp. 180-189, 2010.

[272] S. J. Park, F. Ahmad, A. Philp et al., "Resveratrol ameliorates aging-related metabolic phenotypes by inhibiting cAMP phosphodiesterases," Cell, vol. 148, no. 3, pp. 421-433, 2012. 
[273] K. S. Shindler, E. Ventura, M. Dutt, P. Elliott, D. C. Fitzgerald, and A. Rostami, "Oral resveratrol reduces neuronal damage in a model of multiple sclerosis," Journal of Neuro-Ophthalmology, vol. 30, no. 4, pp. 328-339, 2010.

[274] M. Forte, B. G. Gold, G. Marracci et al., "Erratum: Cyclophilin $\mathrm{D}$ inactivation protects axons in experimental autoimmune encephalomyelitis, an animal model of multiple sclerosis (Proceedings of the National Academy of Sciences of the United States of America (2007) 104, (7558-7563) DOI: 10.1073/pnas.0702228104)," Proceedings of the National Acadamy of Sciences of the United States of America, vol. 104, no. 44, p. 17554, 2007.

[275] F. Aboul-Enein, H. Rauschka, B. Kornek et al., "Preferential loss of myelin-associated glycoprotein reflects hypoxia-like white matter damage in stroke and inflammatory brain diseases," Journal of Neuropathology \& Experimental Neurology, vol. 62, no. 1, pp. 25-33, 2003.

[276] U. Graumann, R. Reynolds, A. J. Steck, and N. SchaerenWiemers, "Molecular changes in normal appearing white matter in multiple sclerosis are characteristic of neuroprotective mechanisms against hypoxic insult," Brain Pathology, vol. 13, no. 4, pp. 554-573, 2003.

[277] B. D. Trapp and P. K. Stys, "Virtual hypoxia and chronic necrosis of demyelinated axons in multiple sclerosis," The Lancet Neurology, vol. 8, no. 3, pp. 280-291, 2009.

[278] D. Paling, B. S. Solanky, F. Riemer et al., "Sodium accumulation is associated with disability and a progressive course in multiple sclerosis," Brain, vol. 136, no. 7, pp. 2305-2317, 2013.

[279] M. J. Craner, J. Newcombe, J. A. Black, C. Hartle, M. L. Cuzner, and S. G. Waxman, "Molecular changes in neurons in multiple sclerosis: Altered axonal expression of Nav1.2 and Nav1.6 sodium channels and $\mathrm{Na}+\mathrm{Ca} 2+$ exchanger," Proceedings of the National Acadamy of Sciences of the United States of America, vol. 101, no. 21, pp. 8168-8173, 2004.

[280] J. Dunn and A. Blight, "Dalfampridine: A brief review of its mechanism of action and efficacy as a treatment to improve walking in patients with multiple sclerosis," Current Medical Research and Opinion, vol. 27, no. 7, pp. 1415-1423, 2011.

[281] G. E. Hardingham and H. Bading, "Synaptic versus extrasynaptic NMDA receptor signalling: implications for neurodegenerative disorders," Nature Reviews Neuroscience, vol. 11, no. 10, pp. 682-696, 2010.

[282] D. J. Mahad, I. Ziabreva, G. Campbell et al., "Mitochondrial changes within axons in multiple sclerosis," Brain, vol. 132, no. 5, pp. 1161-1174, 2009.

[283] G. Grasselli, S. Rossi, A. Musella et al., "Abnormal NMDA receptor function exacerbates experimental autoimmune encephalomyelitis," British Journal of Pharmacology, vol. 168, no. 2, pp. 502-517, 2013.

[284] C. Paul and C. Bolton, "Modulation of blood-brain barrier dysfunction and neurological deficits during acute experimental allergic encephalomyelitis by the N-methyl-D-aspartate receptor antagonist memantine," The Journal of Pharmacology and Experimental Therapeutics, vol. 302, no. 1, pp. 50-57, 2002.

[285] T. Smith, A. Groom, B. Zhu, and L. Tukski, "Autoimmune encephalomyelitis ameliorated by AMPA antagonists," Nature Medicine, vol. 6, no. 1, pp. 62-66, 2000.

[286] G. Worku Hassen, J. Feliberti, L. Kesner, A. Stracher, and F. Mokhtarian, "Prevention of axonal injury using calpain inhibitor in chronic progressive experimental autoimmune encephalomyelitis," Brain Research, vol. 1236, pp. 206-215, 2008.
[287] D. Offen, J. F. Kaye, O. Bernard et al., "Mice overexpressing $\mathrm{Bcl}-2$ in their neurons are resistant to myelin oligodendrocyte glycoprotein (MOG)-induced experimental autoimmune encephalomyelitis (EAE)," Journal of Molecular Neuroscience, vol. 15, no. 3, pp. 167-175, 2000.

[288] O. Aktas, A. Smorodchenko, S. Brocke et al., "Neuronal damage in autoimmune neuroinflammation mediated by the death ligand TRAIL," Neuron, vol. 46, no. 3, pp. 421-432, 2005.

[289] T. Chitnis, J. Imitola, Y. Wang et al., "Elevated neuronal expression of CD200 protects Wlds mice from inflammationmediated neurodegeneration," The American Journal of Pathology, vol. 170, no. 5, pp. 1695-1712, 2007.

[290] T. Dziedzic, I. Metz, T. Dallenga et al., "Wallerian degeneration: A major component of early axonal pathology in multiple sclerosis," Brain Pathology, vol. 20, no. 5, pp. 976-985, 2010.

[291] E. Sundqvist, M. Bäärnhielm, L. Alfredsson, J. Hillert, T. Olsson, and I. Kockum, "Confirmation of association between multiple sclerosis and CYP27B1," European Journal of Human Genetics, vol. 18, no. 12, pp. 1349-1352, 2010.

[292] S. Haahr, N. Koch-Henriksen, A. Møller-Larsen, L. S. Eriksen, and H. M. Andersen, "Increased risk of multiple sclerosis after late Epstein-Barr virus infection: a historical prospective study.", Multiple Sclerosis (Houndmills, Basingstoke, England), vol. 1, no. 2, pp. 73-77, 1995.

[293] S. Haahr, A. M. Plesner, B. F. Vestergaard, and P. Höllsberg, "A role of late Epstein-Barr virus infection in multiple sclerosis," Acta Neurologica Scandinavica, vol. 109, no. 4, pp. 270-275, 2004.

[294] P. Sundström, P. Juto, G. Wadell et al., "An altered immune response to Epstein-Barr virus in multiple sclerosis: A prospective study," Neurology, vol. 62, no. 12, pp. 2277-2282, 2004.

[295] K. C. Simon, I. A. F. Van Der Mei, K. L. Munger et al., "Combined effects of smoking, anti-EBNA antibodies, and HLA-DRB1 ${ }^{\star} 1501$ on multiple sclerosis risk," Neurology, vol. 74, no. 17, pp. 1365-1371, 2010.

[296] X. Li, Y. Zhang, Y. Yan et al., "Neural Stem Cells Engineered to Express Three Therapeutic Factors Mediate Recovery from Chronic Stage CNS Autoimmunity," Molecular Therapy, vol. 24, no. 8, pp. 1456-1469, 2016.

[297] M. Bergsland, R. Covacu, C. Perez Estrada, M. Svensson, and L. Brundin, "Nitric oxide-induced neuronal to glial lineage fatechange depends on NRSF/REST function in neural progenitor cells," Stem Cells, vol. 32, no. 9, pp. 2539-2549, 2014.

[298] S. Khezri, M. Javan, M. Goudarzvand, S. Semnanian, and H. Baharvand, "Dibutyryl cyclic AMP inhibits the progression of experimental autoimmune encephalomyelitis and potentiates recruitment of endogenous neural stem cells," Journal of Molecular Neuroscience, vol. 51, no. 2, pp. 298-306, 2013.

[299] M. Zawadzka, L. E. Rivers, S. P. J. Fancy et al., "CNS-resident glial progenitor/stem cells produce Schwann cells as well as oligodendrocytes during repair of CNS demyelination," Cell Stem Cell, vol. 6, no. 6, pp. 578-590, 2010.

[300] L. Bai, J. Hecker, A. Kerstetter, and R. H. Miller, "Myelin repair and functional recovery mediated by neural cell transplantation in a mouse model of multiple sclerosis," Neuroscience Bulletin, vol. 29, no. 2, pp. 239-250, 2013.

[301] K. S. Carbajal, C. Schaumburg, R. Strieter, J. Kane, and T. E. Lane, "Migration of engrafted neural stem cells is mediated by CXCL12 signaling through CXCR4 in a viral model of multiple sclerosis," Proceedings of the National Acadamy of Sciences of the United States of America, vol. 107, no. 24, pp. 11068-11073, 2010. 
[302] R. E. James, J. Hillis, I. Adorján et al., "Loss of galectin-3 decreases the number of immune cells in the subventricular zone and restores proliferation in a viral model of multiple sclerosis," Glia, vol. 64, no. 1, pp. 105-121, 2016.

[303] W. T. Arscott, J. Soltys, J. Knight, and Y. Mao-Draayer, "Interferon $\beta$-1b directly modulates human neural stem/progenitor cell fate," Brain Research, vol. 1413, pp. 1-8, 2011.

[304] F. Sher, S. Amor, W. Gerritsen et al., "Intraventricularly injected Olig2-NSCs attenuate established relapsing-remitting EAE in mice," Cell Transplantation, vol. 21, no. 9, pp. 1883-1897, 2012.

[305] J. Guo, H. Li, C. Yu et al., "Decreased neural stem/progenitor cell proliferation in mice with chronic/nonremitting experimental autoimmune encephalomyelitis," Neurosignals, vol. 18, no. 1, pp. $1-8,2010$.

[306] L. M. Whitman, C. A. Blanc, C. S. Schaumburg, D. H. Rowitch, and T. E. Lane, "Olig1 function is required for remyelination potential of transplanted neural progenitor cells in a model of viral-induced demyelination," Experimental Neurology, vol. 235, no. 1, pp. 380-387, 2012.

[307] S. Copray, V. Balasubramaniyan, J. Levenga, J. de Bruijn, R. Liem, and E. Boddeke, "Olig2 overexpression induces the in vitro differentiation of neural stem cells into mature oligodendrocytes," Stem Cells, vol. 24, no. 4, pp. 1001-1010, 2006.

[308] S. Rittchen, A. Boyd, A. Burns et al., "Myelin repair in vivo is increased by targeting oligodendrocyte precursor cells with nanoparticles encapsulating leukaemia inhibitory factor (LIF)," Biomaterials, vol. 56, pp. 78-85, 2015.

[309] V. A. Rafalski, P. P. Ho, J. O. Brett et al., "Expansion of oligodendrocyte progenitor cells following SIRT1 inactivation in the adult brain," Nature Cell Biology, vol. 15, no. 6, pp. 614624, 2013.

[310] P. Cruz-Martinez, A. Martinez-Ferre, J. Jaramillo-Merchán, A. Estirado, S. Martinez, and J. Jones, "FGF8 activates proliferation and migration in mouse post-natal oligodendrocyte progenitor cells," PLoS ONE, vol. 9, no. 9, Article ID e108241, 2014.

[311] Y. Wang, J. Imitola, S. Rasmussen, K. C. O'Connor, and S. J. Khoury, "Paradoxical dysregulation of the neural stem cell pathway sonic hedgehog-Glil in autoimmune encephalomyelitis and multiple sclerosis," Annals of Neurology, vol. 64, no. 4, pp. 417-427, 2008.

[312] G. Santilli, G. Lamorte, L. Carlessi et al., "Mild hypoxia enhances proliferation and multipotency of human neural stem cells," PLoS ONE, vol. 5, no. 1, Article ID e8575, 2010.

[313] O. Imamura, M. Arai, M. Dateki et al., "Nicotinic acetylcholine receptors mediate donepezil-induced oligodendrocyte differentiation," Journal of Neurochemistry, vol. 135, no. 6, pp. 1086-1098, 2015.

[314] Y. Wang, J.-H. Piao, E. C. Larsen, Y. Kondo, and I. D. Duncan, "Migration and remyelination by oligodendrocyte progenitor cells transplanted adjacent to focal areas of spinal cord inflammation," Journal of Neuroscience Research, vol. 89, no. 11, pp. 1737-1746, 2011.

[315] M. El Behi, C. Sanson, C. Bachelin et al., "Adaptive human immunity drives remyelination in a mouse model of demyelination," Brain, vol. 140, no. 4, pp. 967-980, 2017.

[316] Y. A. Syed, C. Zhao, D. Mahad et al., "Antibody-mediated neutralization of myelin-associated EphrinB3 accelerates CNS remyelination," Acta Neuropathologica, vol. 131, no. 2, pp. 281298, 2016.

[317] M. Azin, J. Mirnajafi-Zadeh, and M. Javan, "Fibroblast growth factor-2 enhanced the recruitment of progenitor cells and myelin repair in experimental demyelination of rat hippocampal formations," Cell, vol. 17, no. 3, pp. 540-546, 2015.

[318] A. Preisner, S. Albrecht, Q.-L. Cui et al., "Non-steroidal anti-inflammatory drug indometacin enhances endogenous remyelination," Acta Neuropathologica, vol. 130, no. 2, pp. 247261, 2015.

[319] S. Moyon, A. L. Dubessy, M. S. Aigrot et al., "Demyelination causes adult CNS progenitors to revert to an immature state and express immune cues that support their migration," The Journal of Neuroscience, vol. 35, no. 1, pp. 4-20, 2015.

[320] M. Preston, X. Gong, W. Su et al., "Digestion products of the PH20 hyaluronidase inhibit remyelination," Annals of Neurology, vol. 73, no. 2, pp. 266-280, 2013.

[321] H. Lyubetska, L. Zhang, J. Kong, and M. Vrontakis, "An elevated level of circulating galanin promotes developmental expression of myelin basic protein in the mouse brain," Neuroscience, vol. 284, pp. 581-589, 2015.

[322] C.-D. Chen, J. A. Sloane, H. Li et al., "The antiaging protein klotho enhances oligodendrocyte maturation and myelination of the CNS," The Journal of Neuroscience, vol. 33, no. 5, pp. 19271939, 2013.

[323] Y. Amir-Levy, K. Mausner-Fainberg, and A. Karni, "Treatment with Anti-EGF Ab Ameliorates Experimental Autoimmune Encephalomyelitis," Multiple Sclerosis International, vol. 2014, Article ID 926134, 9 pages, 2014.

[324] A. C. Vana, C. F. Lucchinetti, T. Q. Le, and R. C. Armstrong, "Myelin transcription factor 1 (Myt1) expression in demyelinated lesions of rodent and human CNS," Glia, vol. 55, no. 7, pp. 687-697, 2007.

[325] P. M. Madsen, D. Motti, S. Karmally et al., "Oligodendroglial TNFR2 mediates membrane TNF-dependent repair in experimental autoimmune encephalomyelitis by promoting oligodendrocyte differentiation and remyelination," The Journal of Neuroscience, vol. 36, no. 18, pp. 5128-5143, 2016.

[326] J. Qin, A. H. Sikkema, K. van der Bij et al., "GDla overcomes inhibition of myelination by fibronectin via activation of protein kinase A: Implications for multiple sclerosis," The Journal of Neuroscience, vol. 37, no. 41, pp. 9925-9938, 2017.

[327] M. Ghareghani, K. Zibara, H. Sadeghi et al., "Fluvoxamine stimulates oligodendrogenesis of cultured neural stem cells and attenuates inflammation and demyelination in an animal model of multiple sclerosis," Scientific Reports, vol. 7, no. 1, 2017.

[328] A. Dulamea, "Mesenchymal stem cells in multiple sclerosis translation to clinical trials," Journal of Medicine and Life, vol. 8, no. 1, pp. 24-27, 2015.

[329] T. Gharibi, M. Ahmadi, N. Seyfizadeh, F. Jadidi-Niaragh, and M. Yousefi, "Immunomodulatory characteristics of mesenchymal stem cells and their role in the treatment of multiple sclerosis," Cellular Immunology, vol. 293, no. 2, pp. 113-121, 2015.

[330] S. Llufriu, M. Sepúlveda, Y. Blanco et al., "Randomized placebocontrolled phase II trial of autologous mesenchymal stem cells in multiple sclerosis," PLoS ONE, vol. 9, no. 12, Article ID e113936, 2014.

[331] P. Connick, M. Kolappan, C. Crawley et al., "Autologous mesenchymal stem cells for the treatment of secondary progressive multiple sclerosis: an open-label phase 2 a proof-of-concept study," The Lancet Neurology, vol. 11, no. 2, pp. 150-156, 2012.

[332] J. F. Li, D. J. Zhang, T. Geng et al., "The potential of human umbilical cord-derived mesenchymal stem cells as a novel cellular therapy for multiple sclerosis,", Cell Transplantation, vol. 23, supplement 1, pp. S113-S122, 2014. 
[333] C. H. Ryu, K. Y. Park, Y. Hou, C. H. Jeong, S. M. Kim, and S.-S. Jeun, "Gene therapy of multiple sclerosis using interferon $\beta$-secreting human bone marrow mesenchymal stem cells," BioMed Research International, vol. 2013, Article ID 696738, 2013.

[334] C. Marin-Banasco, M. Suardiaz Garcia, I. Hurtado Guerrero et al., "Mesenchymal properties of SJL mice-stem cells and their efficacy as autologous therapy in a relapsing-remitting multiple sclerosis model," Stem cell research \& Therapy, vol. 5, no. 134, 2014.

[335] L. Bai, D. P. Lennon, A. I. Caplan et al., "Hepatocyte growth factor mediates mesenchymal stem cell-induced recovery in multiple sclerosis models," Nature Neuroscience, vol. 15, no. 6, pp. 862-870, 2012.

[336] M. Cobo, P. Anderson, K. Benabdellah et al., "Mesenchymal stem cells expressing vasoactive intestinal peptide ameliorate symptoms in a model of chronic multiple sclerosis," Cell Transplantation, vol. 22, no. 5, pp. 839-854, 2013.

[337] L. Salinas Tejedor, G. Berner, K. Jacobsen et al., "Mesenchymal stem cells do not exert direct beneficial effects on CNS remyelination in the absence of the peripheral immune system," Brain, Behavior, and Immunity, vol. 50, pp. 155-165, 2015.

[338] Y. Hou, C. Heon Ryu, J. A. Jun, S. M. Kim, C. H. Jeong, and S.S. Jeun, "Interferon $\beta$-secreting mesenchymal stem cells combined with minocycline attenuate experimental autoimmune encephalomyelitis," Journal of Neuroimmunology, vol. 274, no. 1-2, pp. 20-27, 2014.

[339] X. Wang, E. A. Kimbrel, K. Ijichi et al., "Human ESC-derived MSCs outperform bone marrow MSCs in the treatment of an EAE model of multiple sclerosis," Stem Cell Reports, vol. 3, no. 1, pp. 115-130, 2014.

[340] J. Zhu, J. Zhang, Q. Li, Y. Du, B. Qiao, and X. Hu, "Transplanting of Mesenchymal Stem Cells May Affect Proliferation and Function of CD4+T Cells in Experimental Autoimmune Encephalomyelitis," Experimental and Clinical Transplantation, vol. 10, no. 5, pp. 492-500, 2012.

[341] G. El-Akabawy and L. A. Rashed, "Beneficial effects of bone marrow-derived mesenchymal stem cell transplantation in a non-immune model of demyelination," Annals of Anatomy, vol. 198, pp. 11-20, 2015.

[342] V. K. Harris, Q. J. Yan, T. Vyshkina, S. Sahabi, X. Liu, and S. A. Sadiq, "Clinical and pathological effects of intrathecal injection of mesenchymal stem cell-derived neural progenitors in an experimental model of multiple sclerosis," Journal of the Neurological Sciences, vol. 313, no. 1-2, pp. 167-177, 2012.

[343] Y. Fisher-Shoval, Y. Barhum, O. Sadan et al., "Transplantation of placenta-derived mesenchymal stem cells in the EAE mouse model of MS," Journal of Molecular Neuroscience, vol. 48, no. 1 , pp. 176-184, 2012.

[344] S. M. Shalaby, N. A. Sabbah, T. Saber, and R. A. Abdel Hamid, "Adipose-derived mesenchymal stem cells modulate the immune response in chronic experimental autoimmune encephalomyelitis model," IUBMB Life, vol. 68, no. 2, pp. 106115, 2016.

[345] I. R. Kashani, A. Hedayatpour, P. Pasbakhsh et al., " $17 \beta$-estradiol enhances the efficacy of adipose-derived mesenchymal stem cells on remyelination in mouse model of multiple sclerosis," Acta Medica Iranica, vol. 50, no. 12, pp. 789-797, 2012.

[346] Y. Barhum, S. Gai-Castro, M. Bahat-Stromza, R. Barzilay, E. Melamed, and D. Offen, "Intracerebroventricular transplantation of human mesenchymal stem cells induced to secrete neurotrophic factors attenuates clinical symptoms in a mouse model of multiple sclerosis," Journal of Molecular Neuroscience, vol. 41, no. 1, pp. 129-137, 2010.

[347] J. D. Glenn, M. D. Smith, P. A. Calabresi, and K. A. Whartenby, "Mesenchymal stem cells differentially modulate effector CD8+ $\mathrm{T}$ cell subsets and exacerbate experimental autoimmune encephalomyelitis," Stem Cells, vol. 32, no. 10, pp. 2744-2755, 2014.

[348] C. Chen, K. Akiyama, T. Yamaza et al., “Telomerase governs immunomodulatory properties of mesenchymal stem cells by regulating FAS ligand expression," EMBO Molecular Medicine, vol. 6, no. 3, pp. 322-334, 2014.

[349] S. Dang, H. Xu, C. Xu et al., "Autophagy regulates the therapeutic potential of mesenchymal stem cells in experimental autoimmune encephalomyelitis," Autophagy, vol. 10, no. 7, pp. 1301-1315, 2014.

[350] S. Wakao, D. Matsuse, and M. Dezawa, "Mesenchymal stem cells as a source of schwann cells: Their anticipated use in peripheral nerve regeneration," Cells Tissues Organs, vol. 200, no. 1, pp. 3141, 2014.

[351] E. Mikaeili Agah, K. Parivar, and M. T. Joghataei, “Therapeutic effect of transplanted human Wharton's jelly stem cell-derived oligodendrocyte progenitor cells (hWJ-MSC-derived OPCs) in an animal model of multiple sclerosis," Molecular Neurobiology, vol. 49, no. 2, pp. 625-632, 2014.

[352] C. Steffenhagen, F.-X. Dechant, E. Oberbauer et al., "Mesenchymal stem cells prime proliferating adult neural progenitors toward an oligodendrocyte fate," Stem Cells and Development, vol. 21, no. 11, pp. 1838-1851, 2012.

[353] L. Bai, D. P. Lennon, V. Eaton et al., "Human bone marrowderived mesenchymal stem cells induce Th2-polarized immune response and promote endogenous repair in animal models of multiple sclerosis," Glia, vol. 57, no. 11, pp. 1192-1203, 2009.

[354] M. Mohajeri, A. Farazmand, M. Mohyeddin Bonab, B. Nikbin, and A. Minagar, "FOXP3 gene expression in multiple sclerosis patients pre- and post mesenchymal stem cell therapy," Iranian Journal of Allergy, Asthma and Immunology, vol. 10, no. 3, pp. 155-161, 2011.

[355] M. Cristofanilli, V. K. Harris, A. Zigelbaum et al., "Mesenchymal stem cells enhance the engraftment and myelinating ability of allogeneic oligodendrocyte progenitors in dysmyelinated mice," Stem Cells and Development, vol. 20, no. 12, pp. 2065-2076, 2011.

[356] N. L. Payne, G. Sun, C. McDonald et al., "Human adiposederived mesenchymal stem cells engineered to secrete IL-10 inhibit APC function and limit CNS autoimmunity," Brain, Behavior, and Immunity, vol. 30, pp. 103-114, 2013.

[357] A. Mohammadzadeh, A. A. Pourfathollah, S. Shahrokhi et al., "Evaluation of AD-MSC (adipose-derived mesenchymal stem cells) as a vehicle for IFN- $\beta$ delivery in experimental autoimmune encephalomyelitis," Clinical Immunology, vol. 169, pp. 98-106, 2016.

[358] N. L. Payne, A. Dantanarayana, G. Sun et al., "Early intervention with gene-modified mesenchymal stem cells overexpressing interleukin- 4 enhances anti-inflammatory responses and functional recovery in experimental autoimmune demyelination," Cell Adhesion \& Migration, vol. 6, no. 3, pp. 179-189, 2012.

[359] Y. Hou, C. H. Ryu, K. Y. Park, S. M. Kim, C. H. Jeong, and S.-S. Jeun, "Effective combination of human bone marrow mesenchymal stem cells and minocycline in experimental autoimmune encephalomyelitis mice," Stem Cell Research \& Therapy, vol. 4, no. 4, article no. 77, 2013. 
[360] H. Rafieemehr, M. KheIrandish, and M. Soleimani, "Neuroprotective effects of transplanted mesenchymal stromal cellsderived human umbilical cord blood neural progenitor cells in EAE," Iranian Journal of Allergy, Asthma and Immunology, vol. 14, no. 6, pp. 596-604, 2015.

[361] C. M. Rice and N. J. Scolding, "Adult human mesenchymal cells proliferate and migrate in response to chemokines expressed in demyelination," Cell Adhesion \& Migration, vol. 4, no. 2, pp. 235-240, 2010.

[362] W. Liao, V. Pham, L. Liu et al., "Mesenchymal stem cells engineered to express selectin ligands and IL-10 exert enhanced therapeutic efficacy in murine experimental autoimmune encephalomyelitis," Biomaterials, vol. 77, pp. 87-97, 2016.

[363] K. Kemp, E. Gray, E. Mallam, N. Scolding, and A. Wilkins, "Inflammatory cytokine induced regulation of superoxide dismutase 3 expression by human mesenchymal stem cells," Stem Cell Reviews and Reports, vol. 6, no. 4, pp. 548-559, 2010.

[364] C. Lanza, S. Morando, A. Voci et al., "Neuroprotective mesenchymal stem cells are endowed with a potent antioxidant effect in vivo," Journal of Neurochemistry, vol. 110, no. 5, pp. 1674-1684, 2009.

[365] C. Shimojima, H. Takeuchi, S. Jin et al., "Conditioned medium from the stem cells of human exfoliated deciduous teeth ameliorates experimental autoimmune encephalomyelitis," The Journal of Immunology, vol. 196, no. 10, pp. 4164-4171, 2016.

[366] A. P. Tafreshi, N. Payne, G. Sun, A. Sylvain, K. Schulze, and C. Bernard, "Inactive GSK3 $\beta$ is disturbed in the spinal cord during experimental autoimmune encephalomyelitis, but rescued by stem cell therapy," Neuroscience, vol. 277, pp. 498-505, 2014.

[367] M. J. Kim, J. Y. Lim, S. A. Park et al., "Effective combination of methylprednisolone and interferon $\beta$-secreting mesenchymal stem cells in a model of multiple sclerosis," Journal of Neuroimmunology, vol. 314, pp. 81-88, 2018.

[368] S. Khezri, S. M. Abtahi Froushani, and M. Shahmoradi, "Nicotine Augments the Beneficial Effects of Mesenchymal Stem Cell-based Therapy in Rat Model of Multiple Sclerosis," Immunological Investigations, pp. 1-12, 2017.

[369] M. Togha, M. Jahanshahi, L. Alizadeh et al., "Rapamycin Augments Immunomodulatory Properties of Bone MarrowDerived Mesenchymal Stem Cells in Experimental Autoimmune Encephalomyelitis," Molecular Neurobiology, vol. 54, no. 4, pp. 2445-2457, 2017.

[370] J. J. Jadasz, L. Tepe, F. Beyer et al., "Human mesenchymal factors induce rat hippocampal- and human neural stem cell dependent oligodendrogenesis," Glia, vol. 66, no. 1, pp. 145-160, 2018.

[371] A. K. Pandit, K. Prasad, and T. Seth, "Autologous hematopoietic stem cell transplantation in progressive severe multiple sclerosis," Annals of Indian Academy of Neurology, vol. 18, no. 4, pp. 459-463, 2015.

[372] N. Pfender, R. Saccardi, and R. Martin, "Autologous hematopoietic stem cell transplantation as a treatment option for aggressive multiple sclerosis," Current Treatment Options in Neurology, vol. 15, no. 3, pp. 270-280, 2013.

[373] R. K. Burt, A. E. Traynor, B. Cohen et al., “T cell-depleted autologous hematopoietic stem cell transplantation for multiple sclerosis: Report on the first three patients," Bone Marrow Transplantation, vol. 21, no. 6, pp. 537-541, 1998.

[374] S. V. Abrahamsson, D. F. Angelini, A. N. Dubinsky et al., "Nonmyeloablative autologous haematopoietic stem cell transplantation expands regulatory cells and depletes IL-17 producing mucosal-associated invariant T cells in multiple sclerosis," Brain, vol. 136, no. 9, pp. 2888-2903, 2013.

[375] S. Kyrcz-Krzemień, G. Helbig, K. Torba, A. Koclęga, and M. Krawczyk-Kuliś, "Safety and efficacy of hematopoietic stem cells mobilization in patients with multiple sclerosis," International Journal of Hematology, vol. 21, no. 1, pp. 42-45, 2016.

[376] R. K. Burt, R. Balabanov, X. Han et al., "Association of nonmyeloablative hematopoietic stem cell transplantation with neurological disability in patients with relapsing-remitting multiple sclerosis," Journal of the American Medical Association, vol. 313, no. 3, pp. 275-284, 2015.

[377] G. La Nasa, R. Littera, E. Cocco, M. G. Marrosu, L. Contu, and L. Battistina, "Allogeneic hematopoietic stem cell transplantation in a patient affected by large granular lymphocyte leukemia and multiple sclerosis," Annals of Hematology, vol. 83, no. 6, pp. 403405, 2004.

[378] L. C. M. Arruda, J. T. C. de Azevedo, G. L. V. de Oliveira et al., "Immunological correlates of favorable long-term clinical outcome in multiple sclerosis patients after autologous hematopoietic stem cell transplantation," Clinical Immunology, vol. 169, pp. 47-57, 2016.

[379] Y. Blanco, A. Saiz, E. Carreras, and F. Graus, "Changes of matrix metalloproteinase-9 and its tissue inhibitor (TIMP-1) after autologous hematopoietic stem cell transplantation in multiple sclerosis," Journal of Neuroimmunology, vol. 153, no. 12, pp. 190-194, 2004.

[380] G. L. V. de Oliveira, A. F. Ferreira, E. P. L. Gasparotto et al., "Defective expression of apoptosis-related molecules in multiple sclerosis patients is normalized early after autologous haematopoietic stem cell transplantation," Clinical \& Experimental Immunology, vol. 187, no. 3, pp. 383-398, 2017.

[381] A. Thiruvalluvan, M. Czepiel, Y. A. Kap et al., "Survival and functionality of human induced pluripotent stem cell-derived oligodendrocytes in a nonhuman primate model for multiple sclerosis," Stem Cells Translational Medicine, vol. 5, no. 11, pp. 1550-1561, 2016.

[382] M. G. Massa, B. Gisevius, S. Hirschberg et al., "Multiple sclerosis patient-specific primary neurons differentiated from urinary renal epithelial cells via induced pluripotent stem cells," PLoS ONE, vol. 11, no. 5, Article ID e0155274, 2016.

[383] C. Zhang, J. Cao, X. Li et al., "Treatment of multiple sclerosis by transplantation of neural stem cells derived from induced pluripotent stem cells," SCIENCE CHINA Life Sciences, vol. 59, no. 9, pp. 950-957, 2016.

[384] M. Czepiel, V. Balasubramaniyan, W. Schaafsma et al., "Differentiation of induced pluripotent stem cells into functional oligodendrocytes," Glia, vol. 59, no. 6, pp. 882-892, 2011.

[385] B. Song, G. Sun, D. Herszfeld et al., "Neural differentiation of patient specific iPS cells as a novel approach to study the pathophysiology of multiple sclerosis," Stem Cell Research, vol. 8, no. 2, pp. 259-273, 2012.

[386] H. Wakao, K. Yoshikiyo, U. Koshimizu et al., "Expansion of functional human mucosal-associated invariant $\mathrm{T}$ cells via reprogramming to pluripotency and redifferentiation," Cell Stem Cell, vol. 12, no. 5, pp. 546-558, 2013.

[387] P. Douvaras, T. Rusielewicz, K. H. Kim, J. D. Haines, P. Casaccia, and V. Fossati, "Epigenetic modulation of human induced pluripotent stem cell differentiation to oligodendrocytes," International Journal of Molecular Sciences, vol. 17, no. 4, article no. 614,2016

[388] C. Laterza, A. Merlini, D. De Feo et al., "Ipsc-derived neural precursors exert a neuroprotective role in immune-mediated 
demyelination via the secretion of LIF," Nature Communications, vol. 4, article no. 2597, 2013.

[389] P. Li, M. Li, X. Tang, S. Wang, Y. A. Zhang, and Z. Chen, "Accelerated generation of oligodendrocyte progenitor cells from human induced pluripotent stem cells by forced expression of Sox10 and Olig2," SCIENCE CHINA Life Sciences, vol. 59, no. 11, pp. 1131-1138, 2016.

[390] M. Su, Y. Song, Z. He, R. Hu, D. Rood, and L. Lai, “Administration of embryonic stem cell-derived thymic epithelial progenitors expressing MOG induces antigen-specific tolerance and ameliorates experimental autoimmune encephalomyelitis," Journal of Autoimmunity, vol. 58, pp. 36-47, 2015.

[391] A. S. Fazeli, D. Nasrabadi, A. Pouya et al., "Proteome analysis of post-transplantation recovery mechanisms of an EAE model of multiple sclerosis treated with embryonic stem cell-derived neural precursors," Journal of Proteomics, vol. 94, pp. 437-450, 2013.

[392] H. Kim, P. Walczak, C. Kerr et al., "Immunomodulation by transplanted human embryonic stem cell-derived oligodendroglial progenitors in experimental autoimmune encephalomyelitis," Stem Cells, vol. 30, no. 12, pp. 2820-2829, 2012.

[393] W. C. Plaisted, A. Zavala, E. Hingco et al., "Remyelination is correlated with regulatory $\mathrm{T}$ cell induction following human embryoid body-derived neural precursor cell transplantation in a viral model of multiple sclerosis," PLoS ONE, vol. 11, no. 6, Article ID e0157620, 2016.

[394] M. Sundberg, H. Skottman, R. Suuronen, and S. Narkilahti, "Production and isolation of NG2+ oligodendrocyte precursors from human embryonic stem cells in defined serum-free medium," Stem Cell Research, vol. 5, no. 2, pp. 91-103, 2010.

[395] B. S. Letzen, C. Liu, N. V. Thakor, J. D. Gearhart, A. H. All, and C. L. Kerr, "MicroRNA expression profiling of oligodendrocyte differentiation from human embryonic stem cells," PLoS ONE, vol. 5, no. 5, Article ID e10480, 2010.

[396] G. Shroff, "Evaluation of patients with multiple sclerosis using reverse nutech functional score and expanded disability status scale after human embryonic stem cell therapy," Clinical and Translational Medicine, vol. 5, no. 43, 2016.

[397] G. Muthian and J. J. Bright, "Quercetin, a Flavonoid Phytoestrogen, Ameliorates Experimental Allergic Encephalomyelitis by Blocking IL-12 Signaling Through JAK-STAT Pathway in T Lymphocyte," Journal of Clinical Immunology, vol. 24, no. 5, pp. 542-552, 2004.

[398] R. Verbeek, E. A. F. Van Tol, and J. M. Van Noort, "Oral flavonoids delay recovery from experimental autoimmune encephalomyelitis in SJL mice," Biochemical Pharmacology, vol. 70, no. 2, pp. 220-228, 2005.

[399] C. Natarajan and J. J. Bright, "Curcumin inhibits experimental allergic encephalomyelitis by blocking IL-12 signaling through Janus kinase-STAT pathway in T lymphocytes," The Journal of Immunology, vol. 168, no. 12, pp. 6506-6513, 2002.

[400] L. Xie, X.-K. Li, N. Funeshima-Fuji et al., "Amelioration of experimental autoimmune encephalomyelitis by curcumin treatment through inhibition of IL-17 production," International Immunopharmacology, vol. 9, no. 5, pp. 575-581, 2009.

[401] F. Sato, N. E. Martinez, M. Shahid, J. W. Rose, N. G. Carlson, and I. Tsunoda, "Resveratrol exacerbates both autoimmune and viral models of multiple sclerosis," The American Journal of Pathology, vol. 183, no. 5, pp. 1390-1396, 2013.

[402] G. M. Liuzzi, T. Latronico, M. T. Branà et al., "Structuredependent inhibition of gelatinases by dietary antioxidants in rat astrocytes and sera of multiple sclerosis patients," Neurochemical Research, vol. 36, no. 3, pp. 518-527, 2011.

[403] M. Mohajeri, M. Sadeghizadeh, F. Najafi, and M. Javan, "Polymerized nano-curcumin attenuates neurological symptoms in EAE model of multiple sclerosis through down regulation of inflammatory and oxidative processes and enhancing neuroprotection and myelin repair," Neuropharmacology, vol. 99, pp. 156-167, 2015.

[404] S. Giacoppo, M. Galuppo, G. E. Lombardo et al., "Neuroprotective effects of a polyphenolic white grape juice extract in a mouse model of experimental autoimmune encephalomyelitis," Fitoterapia, vol. 103, pp. 171-186, 2015.

[405] J. Warford, Q. R. D. Jones, M. Nichols, V. Sullivan, H. P. V. Rupasinghe, and G. S. Robertson, "The flavonoid-enriched fraction AF4 suppresses neuroinflammation and promotes restorative gene expression in a mouse model of experimental autoimmune encephalomyelitis," Journal of Neuroimmunology, vol. 268, no. 1-2, pp. 71-83, 2014.

[406] S. Kanakasabai, E. Casalini, C. C. Walline, C. Mo, W. Chearwae, and J. J. Bright, "Differential regulation of $\mathrm{CD}^{+}{ }^{+} \mathrm{T}$ helper cell responses by curcumin in experimental autoimmune encephalomyelitis," The Journal of Nutritional Biochemistry, vol. 23, no. 11, pp. 1498-1507, 2012.

[407] J. J. Bright, "Curcumin and autoimmune disease," Advances in Experimental Medicine and Biology, vol. 595, pp. 425-451, 2007.

[408] D. Wang, S.-P. Li, J.-S. Fu, L. Bai, and L. Guo, "Resveratrol augments therapeutic efficiency of mouse bone marrow mesenchymal stem cell-based therapy in experimental autoimmune encephalomyelitis," International Journal of Developmental Neuroscience, vol. 49, pp. 60-66, 2016.

[409] A. J. Fahey, R. Adrian Robins, and C. S. Constantinescu, "Curcumin modulation of IFN- $\beta$ and IL-12 signalling and cytokine induction in human T cells," Journal of Cellular and Molecular Medicine, vol. 11, no. 5, pp. 1129-1137, 2007.

[410] T. J. Imler Jr. and T. M. Petro, "Decreased severity of experimental autoimmune encephalomyelitis during resveratrol administration is associated with increased IL-17+IL-10+ T cells, CD4IFN- $\gamma+$ cells, and decreased macrophage IL-6 expression," International Immunopharmacology, vol. 9, no. 1, pp. 134-143, 2009.

[411] N. P. Singh, V. L. Hegde, L. J. Hofseth, M. Nagarkatti, and P. S. Nagarkatti, "Resveratrol (trans-3,5,4/-trihydroxystilbene) ameliorates experimental allergic encephalomyelitis, primarily via induction of apoptosis in $\mathrm{T}$ cells involving activation of aryl hydrocarbon receptor and estrogen receptor," Molecular Pharmacology, vol. 72, no. 6, pp. 1508-1521, 2007.

[412] H. R. Ghaiad, M. M. Nooh, M. M. El-Sawalhi, and A. A. Shaheen, "Resveratrol Promotes Remyelination in Cuprizone Model of Multiple Sclerosis: Biochemical and Histological Study," Molecular Neurobiology, vol. 54, no. 5, pp. 3219-3229, 2017.

[413] C. Santangelo, R. Vari, B. Scazzocchio et al., "Anti-inflammatory Activity of Extra Virgin Olive Oil Polyphenols: Which Role in the Prevention and Treatment of Immune-Mediated Inflammatory Diseases? Endocrine, metabolic \& immune disorders drug targets," Endocrine, Metabolic \& Immune Disorders - Drug Targets, vol. 18, pp. 36-50, 2018.

[414] M. Srinivasan and D. K. Lahiri, "Significance of NF- $\kappa$ B as a pivotal therapeutic target in the neurodegenerative pathologies of Alzheimer's disease and multiple sclerosis," Expert Opinion on Therapeutic Targets, vol. 19, no. 4, pp. 471-487, 2015. 
[415] S. Chen, "Natural products triggering biological targets- a review of the anti-inflammatory phytochemicals targeting the arachidonic acid pathway in allergy asthma and rheumatoid arthritis," Current Drug Targets, vol. 12, no. 3, pp. 288-301, 2011.

[416] A. Sierra, O. Abiega, A. Shahraz, and H. Neumann, "Janusfaced microglia: beneficial and detrimental consequences of microglial phagocytosis," Frontiers in Cellular Neuroscience, vol. 7, article 6, 2013.

[417] M. Rahimifard, F. Maqbool, S. Moeini-Nodeh et al., "Targeting the TLR4 signaling pathway by polyphenols: a novel therapeutic strategy for neuroinflammation," Ageing Research Reviews, vol. 36, pp. 11-19, 2017.

[418] J. Chen, Y. Zhou, S. Mueller-Steiner et al., "SIRT1 protects against microglia-dependent amyloid- $\beta$ toxicity through inhibiting NF- $\kappa \mathrm{B}$ signaling," The Journal of Biological Chemistry, vol. 280, no. 48, pp. 40364-40374, 2005.

[419] C. Dong, R. J. Davis, and R. A. Flavell, "MAP kinases in the immune response," Annual Review of Immunology, vol. 20, pp. 55-72, 2002.

[420] L. Zhang, C. Wu, S. Zhao et al., "Demethoxycurcumin, a natural derivative of curcumin attenuates LPS-induced proinflammatory responses through down-regulation of intracellular ROS-related MAPK/NF- $\kappa \mathrm{B}$ signaling pathways in N9 microglia induced by lipopolysaccharide," International Immunopharmacology, vol. 10, no. 3, pp. 331-338, 2010.

[421] S.-J. Kim, H.-J. Jeong, K.-M. Lee et al., "Epigallocatechin-3gallate suppresses NF- $\kappa$ B activation and phosphorylation of p38 MAPK and JNK in human astrocytoma U373MG cells," The Journal of Nutritional Biochemistry, vol. 18, no. 9, pp. 587-596, 2007.

[422] F. Moosavi, R. Hosseini, L. Saso, and O. Firuzi, "Modulation of neurotrophic signaling pathways by polyphenols," Drug Design, Development and Therapy, vol. 10, pp. 23-42, 2015.

[423] Y. Satoh, Y. Kobayashi, A. Takeuchi, G. Pagès, J. Pouysségur, and T. Kazama, "Deletion of ERK1 and ERK2 in the CNS causes cortical abnormalities and neonatal lethality: Erk1 deficiency enhances the impairment of neurogenesis in Erk2-deficient mice," The Journal of Neuroscience, vol. 31, no. 3, pp. 1149-1155, 2011.

[424] F. Zhang, Y. F. Lu, Q. Wu, J. Liu, and J. S. Shi, "Resveratrol promotes neurotrophic factor release from astroglia," Experimental Biology and Medicine, vol. 237, no. 8, pp. 943-948, 2012.

[425] K. K. Liao, M. J. Wu, P. Y. Chen et al., "Curcuminoids promote neurite outgrowth in PC12 cells through MAPK/ERK- and PKC-dependent pathways," Journal of Agricultural and Food Chemistry, vol. 60, no. 1, pp. 433-443, 2012.

[426] A. L. B. Zeni, A. D. E. Zomkowski, M. Maraschin, A. L. S. Rodrigues, and C. I. Tasca, "Involvement of PKA, CaMKII, PKC, MAPK/ERK and PI3K in the acute antidepressant-like effect of ferulic acid in the tail suspension test," Pharmacology Biochemistry \& Behavior, vol. 103, no. 2, pp. 181-186, 2012.

[427] A. Ebrahimi and H. Schluesener, "Natural polyphenols against neurodegenerative disorders: potentials and pitfalls," Ageing Research Reviews, vol. 11, no. 2, pp. 329-345, 2012.

[428] L. Saso and O. Firuzi, "Pharmacological applications of antioxidants: lights and shadows," Current Drug Targets, vol. 15, no. 13, pp. 1177-1199, 2014. 


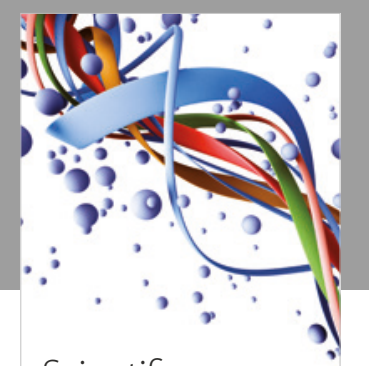

Scientifica
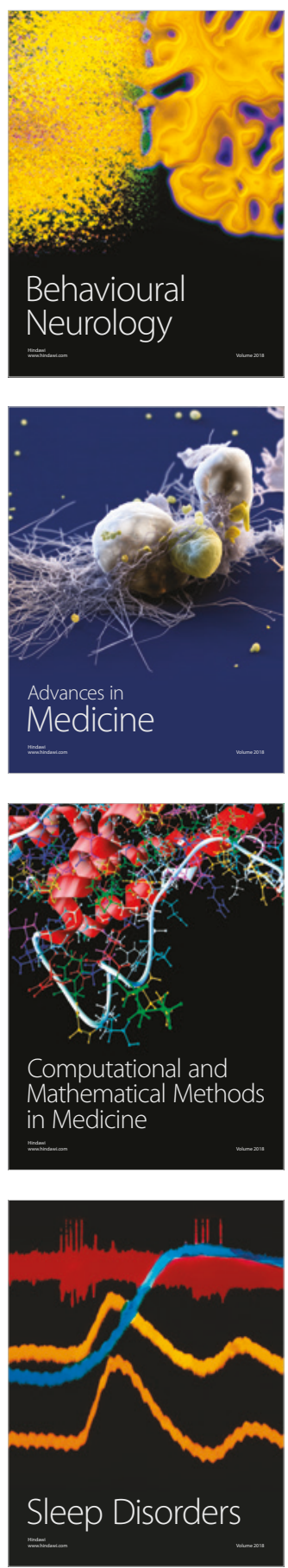

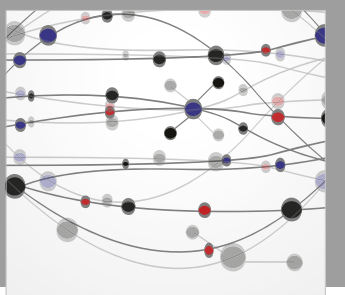

The Scientific World Journal

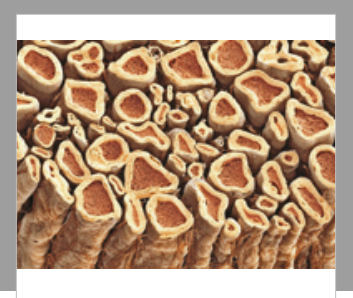

Case Reports in

Neurological Medicine

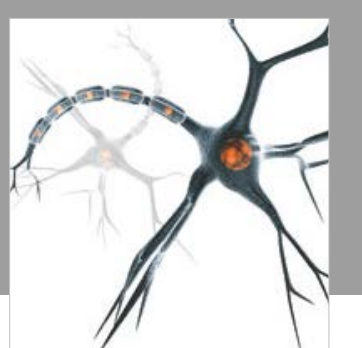

Neural Plasticity

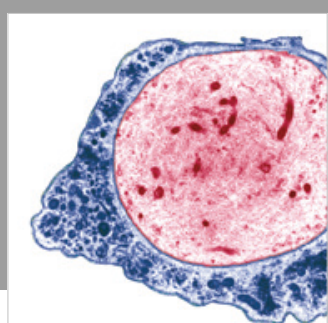

Multiple Sclerosis

International

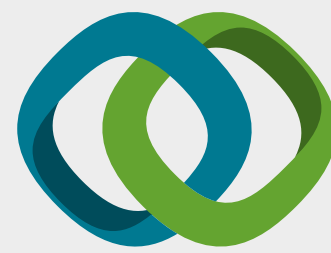

Hindawi

Submit your manuscripts at

www.hindawi.com
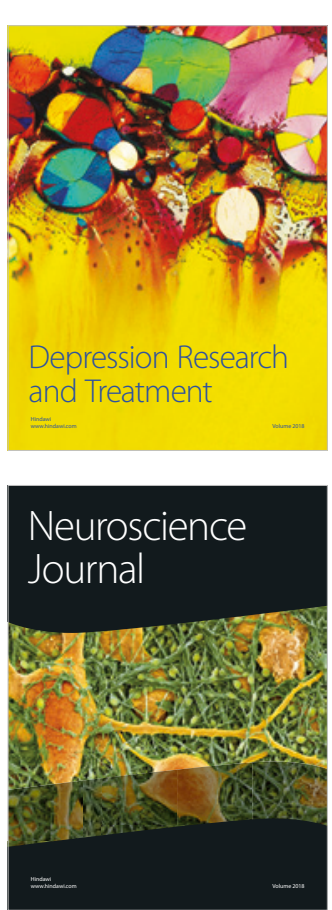

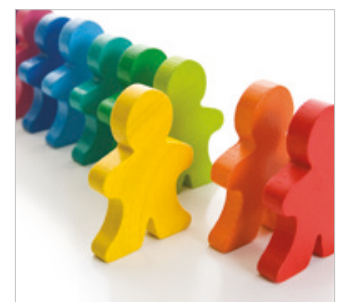

Autism

Research and Treatment
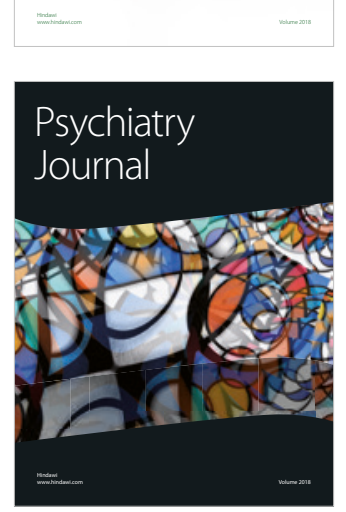
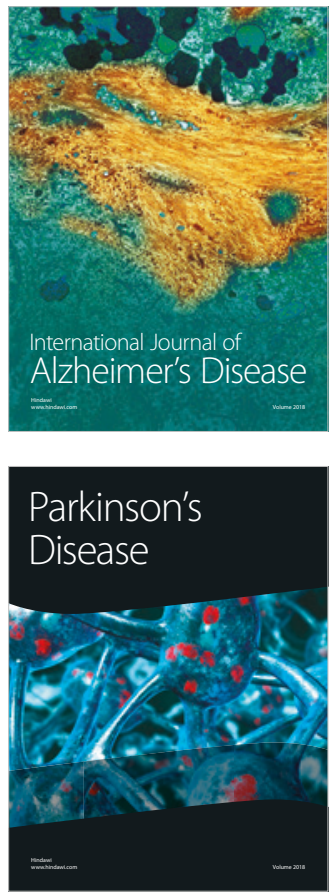
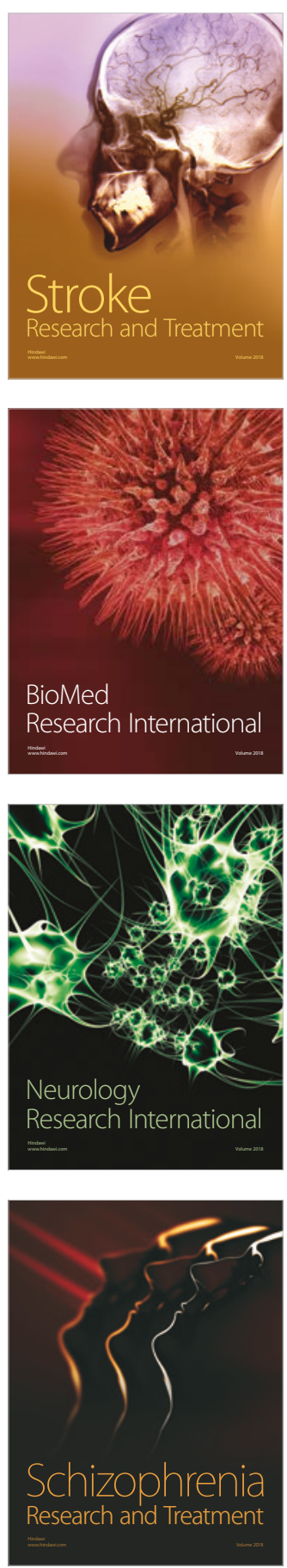